Linköping Studies in Science and Technology

Dissertation No. 2091

\title{
Construction \\ Logistics in a City \\ Development Setting
}

\section{Mats Janné}


Linköping Studies in Science and Technology.

Dissertation No. 2091

\section{Construction Logistics in a City Development Setting}

Mats Janné

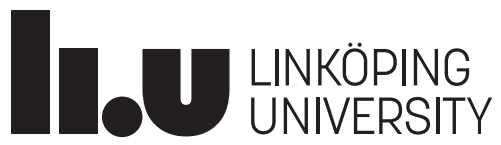




\section{Construction Logistics in a City Development Setting}

Mats Janné

Linköping Studies in Science and Technology. Dissertation No. 2091

Copyright (C), Mats Janné, 2020, unless otherwise noted.

Cover photo by Mats Janné, 2020

ISBN 978-91-7929-806-7

ISSN 0345-7524

Linköping University

Department of Science and Technology

SE-601 74 Norrköping, Sweden

Printed by LiU-Tryck, Linköping, Sweden, 2020 
For mom \& dad 


\section{Abstract}

With the current urbanization trend, there is an increased need for city development, i.e. to build apartment buildings, hospitals, schools and infrastructure in cities and urban areas to meet the rising demands. At the same time, land is increasingly seen as a finite resource. This has led to the regeneration of decommissioned industrial-use land for development purposes. This means that multiple individual construction projects are being built in the same or nearby areas during the same time-period. However, the end products of construction projects are produced at their place of consumption, which means that large quantities of materials and resources need to be delivered to, and removed from, each construction site. This leads to new transport flows being created in connection to city development. These transport flows need to be coordinated to ensure efficient construction productivity and reduce the transports' environmental and social impact on the urban transport system. At the same time, it is important to ensure that construction sites can be managed from a logistics perspective without impairing efficiency due to the challenges of building in urban environments.

One way of managing logistics to and from construction projects in city development is through so-called construction logistics setups (CLS). However, the implementation of CLS's affect many different stakeholders and the interorganizational relationships between them. The implementation of CLS's therefore faces three challenges; management of transport to and from construction sites, management of logistics at construction sites, and managing the interorganizational relationships amongst construction project stakeholders. The development of CLS's is often undertaken by mimicking previous setups as there is currently no guiding procedure for developing and implementing CLS's. To reduce the $a d$ $h o c$ approach to developing and implementing CLS's, the purpose of this dissertation is to propose a framework for developing construction logistics setups. The purpose is fulfilled with the aid of the following four research questions:

RQ1: Taking the perspectives of different stakeholders', why are CLS's implemented?

RQ2: What type of CLS services are offered?

RQ3: How can performance effects of CLS's be measured?

RQ4: How do CLS's affect the identified challenges of managing the transports to and from construction sites, managing logistics at construction sites, and managing the interorganizational relationships amongst construction project stakeholders?

To answer the research questions, three main methodologies have been used; literature reviews to inform the background of the studies and develop analytical frameworks, and case study and Delphi research for the empirical studies. 
In fulfilling the research purpose, the findings of this dissertation suggests that when developing a CLS, three activities need to be considered; 1. setting the scope of the CLS, 2. deciding on the structure of the CLS, and 3. managing the interorganizational relationships of the CLS. These activities are the foundation of the developed framework. The contents of the activities were derived through the research questions.

When answering RQ1, it was found that contractors implement CLS's to ensure construction productivity, developers implement CLS's to reduce disturbances to businesses and residents nearby, and municipalities implement CLS's to reduce disturbances to third-parties and to reduce the impact from construction logistics on the urban transport system. These stakeholder drivers for implementing CLS's will impact the scope of the CLS. Furthermore, the scope of the CLS was found to be dependent on both the contextual considerations of the CLS in terms of physical context at site and in terms of what is being built, as well as the organizational context in terms of what stakeholders are part of the project, where in the hierarchy the CLS is located, and what level of mandate the CLS has. The scope will also set the terms for how transports are managed through the CLS. If for instance there is limited space at site, this can imply that time-planned deliveries are favoured.

In answering RQ2, it was found that as a consequence of what transport management approach is chosen, the structure of the CLS will differ. This dissertation shows that assetbased setups are similar to traditional logistics outsourcing and TPL in which physical distribution services are offered. Non-asset based services on the other hand act more as supply chain orchestrators similar to fourth-party logistics service providers. In these cases, supplied services are aimed more at ensuring that the right services and capabilities can be procured for the CLS. One value-adding service that was found crucial to include in CLS's is a joint booking and planning system. Having this type of support systems will allow the CLS to coordinate the different stakeholders connected to the CLS. Related to the structure of the CLS, RQ3 suggest that performance needs to be monitored for deliveries, on-site logistics, and the coordination of logistics activities on and off site. The performance monitoring needs to be developed from a logistics point-of-view, taking into consideration the different stakeholders' perspectives.

Finally, in answering RQ4, it was found that a CLS can affect the identified challenges positively. In essence, a CLS aims at managing construction logistics and if developed and implemented from this notion, transports to and from site as well as on-site logistics management can become more efficient. Additionally, the dissertation shows that CLS's can help in managing the interorganizational relationships within the construction project(s). However, this builds on the notion of having well-developed and communicated service offerings and regulations, e.g. through business and governance models.

It was also found that the activities of the framework are interrelated and dependent on one another, suggesting that developing construction logistics setups is an iterative process. The proposed framework should thus be seen as a guideline for how to develop the setup, allowing for adaptations of the setup to the context for which it is developed. 


\section{Populärvetenskaplig sammanfattning}

Med pågående urbaniseringstrend finns det ett ökat behov av att bygga bostadshus, sjukhus, skolor och infrastruktur i stadsområden för att möta de ökande behoven. Samtidigt ses mark allt mer som en ändlig resurs. Detta har lett till att avvecklad industriell mark tas i anspråk för förtätning och storskaliga stadsutvecklingsprojekt där flera enskilda byggprojekt byggs i närliggande områden under samma tidsperiod. Byggprojekt produceras dock på konsumtionsplatsen vilket innebär att stora mängder material och resurser måste levereras till och tas bort från varje byggarbetsplats. Detta leder i sin tur till att nya transportflöden skapas i samband med stadsutveckling. Dessa måste samordnas för att säkerställa effektiv byggproduktion samtidigt som transporternas miljömässiga och sociala påverkan på det urbana transportsystemet kan minskas. Samtidigt är det viktigt att byggarbetsplatserna kan hanteras ur ett logistikperspektiv utan försämrad effektivitet på grund av det urbana läget.

Ett sätt att hantera logistiken till och från byggprojekt inom stadsutveckling är genom så kallade bygglogistiklösningar (BLL). Dock påverkar införandet av BLL många olika intressenter och de interorganisatoriska relationer dem emellan. Införandet av BLL ställs därför inför tre utmaningar; att hantera transporter till och från byggprojekt, att hantera logistiken på byggarbetsplatser och att samordna de interorganisatoriska relationerna mellan byggprojektets intressenter. Utvecklandet av BLL utgår ofta från tidigare lösningar då det i nuläget saknas riktlinjer för hur man kan utveckla och implementera lösningarna. För att minska den här ad hoc-strategin för utvecklandet av BLL är syftet med denna avhandling att föreslå ett ramverk för att utveckla bygglogistiklösningar. Syftet uppnås med hjälp av följande forskningsfrågor:

FF1: Utifrån olika intressenters perspektiv, varför implementeras bygglogistiklösningar?

FF2: Vilken typ av bygglogistiktjänster erbjuds?

FF3: Hur kan bygglogistiklösningars prestanda mätas?

FF4: Hur påverkas de tre identifierade utmaningarna av implementeringen av bygglogistiklösningar? Hur påverkar bygglogistiklösningar de identifierade utmaningarna med att hantera transporter till och från byggprojekt, att hantera arbetsplatslogistiken och att samordna de interorganisatoriska relationerna mellan byggprojektets intressenter?

För att besvara forskningsfrågorna har tre huvudmetoder använts; litteraturgranskningar för studiernas bakgrund och att utveckla analytiska ramverk, och fallstudieforskning och Delphi-forskning för de empiriska studierna. 
I uppfyllandet av syftet föreslår avhandlingen att tre aktiviteter måste övervägas när man utvecklar en BLL; 1. fastställa omfattningen av BLL, 2. besluta om BLL-strukturen och 3. hantera interorganisatoriska relationerna $i$ BLL. Dessa aktiviteter är grunden för det utvecklade ramverket. Innehållet $i$ aktiviteterna härleddes genom forskningsfrågorna.

I besvarandet av FF1 befanns att entreprenörer implementerar BLL:er för att säkerställa byggproduktivitet, byggherrar implementerar BLL:er för att minska störningar för företag och boende i närheten, och kommuner implementerar BLL:er för att minska störningar för tredje part och för att minska påverkan från bygglogistik på det urbana transportsystemet. De identifierade drivkrafterna för att implementera BLL:er kommer även att påverka BLL:ens struktur. Avhandlingen visar att BLL-strukturen är beroende av kontextuella överväganden med avseende på arbetsplatsens fysiska egenskaper samt vad som byggs, såväl som den organisatoriska kontexten med avseende på vilka intressenter som är del av projektet, var i hierarkin BLL:en placeras och vilken mandatnivå BLL:en har. BLLomfattningen sätter även villkoren för hur transporter hanteras i projektet. Om utrymmet exempelvis är begränsat kan detta innebära att tidsplanerade leveranser premieras.

I besvarandet av FF2 befanns det att en konsekvens av hur transporthanteringen läggs upp så kommer BLL-strukturen att påverkas. Den här avhandlingen visar att fysiska logistiklösningar liknar traditionell outsourcing av logistik och TPL där fysiska distributionstjänster erbjuds. Icke-fysiska logistiklösningar fungerar mer som försörjningskedjeorkestratorer och påminner om fjärdepartslogistiktleverantörer. I dessa fall syftar de erbjudna tjänsterna mer till att säkerställa att rätt tjänster och kapacitet kan erbjudas genom BLL. En värdeadderande tjänst fanns vara en grundförutsättning för BLL:er, nämligen gemensamma boknings- och planeringssystem. Ett sådant system hjälper BLL-operatören i koordinationen av de olika intressenterna som är kopplade till BLL:en. I framtagandet av BLL-strukturen föreslår FF3 även att logistikprestanda måste följas upp i processerna leveranser, arbetsplatslogistik och samordning av logistikaktiviteter på och utanför byggarbetsplatsen. Prestationsutvärderingen måste utvecklas ur ett logistikhänseende med hänsyn tagen till de olika intressenternas perspektiv.

Slutligen, i besvarandet av FF4, befanns att en BLL kan påverka de identifierade utmaningarna positivt. I grund och botten syftar en BLL till att hantera bygglogistik och om BLL:en utvecklas och implementeras utifrån detta synsätt kan transporter till och från byggarbetsplats samt logistikhantering på plats bli effektivare. Vidare visar avhandlingen att BLL:er kan hjälpa till att hantera de interorganisatoriska relationerna inom byggprojekten. Detta bygger dock på att man har väl utvecklade och kommunicerade serviceerbjudanden med tillhörande regelverk för hur service skall användas. Dessa bör kommuniceras genom affärs- och styrningsmodeller.

Det konstaterades också att ramverkets aktiviteter är inbördes relaterade och beroende av varandra, vilket tyder på att utvecklandet av bygglogistiklösningar är en iterativ process. Det föreslagna ramverket bör därför ses som riktlinjer för hur man utvecklar BLL, vilket möjliggör för anpassningar av lösningen till det sammanhang för vilken den utvecklas. 


\section{Foreword}

Wow. This is it. I have finished my PhD journey! This would not have been possible without the support of the people around me. The following few humble lines are dedicated to the people who have been there through thick and thin during these five years.

First and foremost, I want to thank my amazing supervisors, Anna Fredriksson and Martin Rudberg. Working with the two of you is a pleasure, and I have learned so much from the two of you. From the bottom of my heart, thank you!

Secondly, I want to thank my friends and colleagues in the construction logistics group, past and present; Andreas Ekeskär, Henric Jonsson, Micael Thunberg, Yashar Gholami, Petter Haglund, Farah Naz, and Ahmet Sezer. I cannot thank you enough for all the laughter, and occasional serious discussions we have had through the years. Speaking of occasionally having serious conversations; thank you Ellen Grumert and Joakim Ekström!

Thirdly, I want to thank all my colleagues at the division of Communications and Transport Systems, this place would not be the same without you. A special thank you to Viveka Nilson and Sophie Lindesvik, your help with, well, everything is invaluable. Thank you for keeping track of me and my travels when I don't seem to manage that myself.

Fourth, a massive thank you to Martin Svanberg for reading, commenting, and discussing my dissertation during the final seminar. The end result is so much better thanks to you!

Fifth, a few very special friends; Mats and Johan, thank you for worrying, celebrating, and providing a (mostly) healthy measure of banter, it helps! Mattias, thank you for always being there to share in mountainbike geekiness to distract my, at times, preoccupied mind. Calle and Ida (and Oscar of course!), it's been a weird year and I haven't seen you as much as I would have liked, but it means the world to me that you are in my life. Carl-Magnus, not only were you a great colleague and mentor, but you also became one of my dearest friends. I would not be here today had you and Rolf not taken a chance on employing me for the Øresund EcoMobility project all those years ago, thank you!

Finally, and most importantly, my thanks go out to my family. I love you all! This would not have happened without your support and belief in me. $<3$

Mats Janné

Jursla, 2020 


\section{Acknowledgement}

There are a number of people that have contributed to this research that I wish to thank. I am very grateful to Lars Gutwasser, Sandra Lasson, Fredrik Bergman, Robin Billsjö, Amanda Baumgartner, Anders Ivarsson, Abdinasir Osman, Daniel Eriksson, Per Bramfalk, Stefan Fenelius, Camilla Einarsson, Johan Danielsson, Arvid Westin, Rasmus Linge, Jihad Ghaziri, Tommie Valkeaniemi, Björn Ribbhagen, Christer Källström, Malin Lindskog, Monica Billger, Kajsa Hulthén, Victor Eriksson, Karl Bergström, Maria Oscott, Lovisa Westblom, Rodrigue Al Fahel, Eric Sens, Michael Berden, Marie Morel, Susanne Balm, Walther Ploos van Amstel, Pamela Nolz, Tom van Lier, Nicolas Brusselaers, Koen Mommens, Cathy Macharis, Cecilie Flyen, Selamawit Fufa, Christoffer Venås, Ole Stensbjerg, Rikard Dahlström, Peter Åman, Robert Larsson, and Antti Peltokorpi. Thank you all for great discussions and for providing input to my research project.

I would further like to extend my gratitude to the Development Fund of the Swedish Construction Industry SBUF, as well as Sweden's Innovation Agency VINNOVA/JPI Urban Europe, for financing this research. 


\section{Dissertation outline}

The dissertation is titled Construction logistics in a city development setting and consists of two parts. The first part of the dissertation describes the background to why this work is necessary, together with the purpose and research objectives. It will also guide the reader through the literature that forms the analytical foundation of the dissertation. Finally, the research questions are addressed, the conclusions are presented, and the contributions highlighted alongside ideas on further research. This dissertation is of a compilation character (dissertation by publication), comprising seven papers that are appended as part two of the dissertation. The seven papers are listed below alongside the authors contributions to the appended papers.

\section{Paper 1}

Janné, M. (2018). "Supply Chain Management, logistics, and third-party logistics in construction - A literature review". Previously presented as a conference paper at the $3^{\text {rd }}$ VREF Conference on Urban Freight in 2016. Janné was the sole author, responsible for research design, data collection, analysis, and authorship.

\section{Paper 2}

Janné, M. and Fredriksson, A. (2019). "Construction logistics governing guidelines in urban development projects". Published in Construction Innovation. Both authors contributed equally throughout the study.

\section{Paper 3}

Fredriksson, A., Janné, M. and Rudberg, M. (2020). "Characterizing third-party logistics setups in the context of construction". Under review in International Journal of Physical Distribution \& Logistics Management. Janné contributed in data collection, writing, and revising, but Fredriksson took the main responsibility in finalizing paper 3.

\section{Paper 4}

Janné, M. and Rudberg, M. (2020). "Effects of employing third-party logistics arrangements in construction projects". Published in Production Planning \& Control. Both authors contributed equally to the paper in all stages of the research process.

\section{Paper 5}

Janné, M. and Fredriksson, A. (2020). "Construction logistics in urban development projects - Learning from, or repeating, past mistakes of city logistics?”. Under review in International Journal of Logistics Management. Previously presented as a conference paper at the $30^{\text {th }}$ annual NOFOMA Conference in 2018. Janné was the main author, 
responsible for the analysis and the majority of the writing. Research design and data collection was shared amongst the authors.

\section{Paper 6}

Janné, M., Rudberg, M. and Sezer, A. (2020). “Construction logistics performance metrics: A Delphi study". Working paper. Janné was the main author, responsible for the research design, data collection and the majority of the writing. Analysis and revision work were shared amongst the authors.

\section{Paper 7}

Janné, M., Fredriksson, A. and Peltokorpi, A. (2019). "Designing construction logistics setups in hospital projects". Working paper previously presented as a conference paper at the $31^{\text {st }}$ annual NOFOMA Conference in 2019. Janné was the main author, responsible for the research design and the majority of the writing. Data collection, analysis and revision of the paper was shared amongst the authors. 
"Words ought to be a little wild, for they are the assault of thoughts upon the unthinking."

- John Maynard Keynes (1933) 


\section{Table of contents}

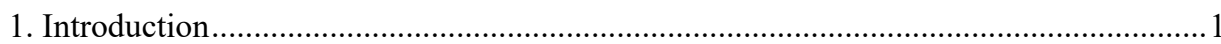

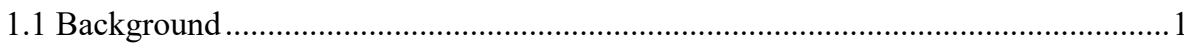

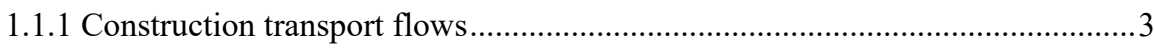

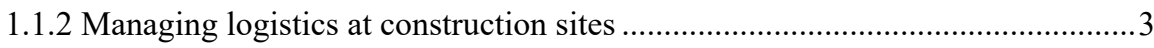

1.1.3 Interorganizational relationships amongst construction stakeholders ................4

1.2 Managing construction logistics in a city development setting .............................. 4

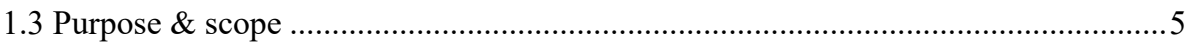

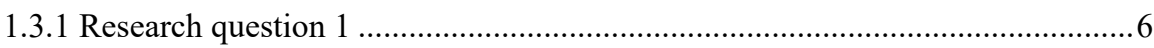

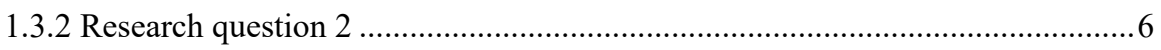

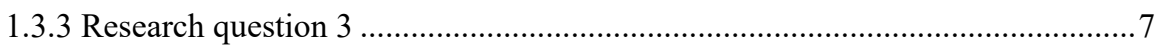

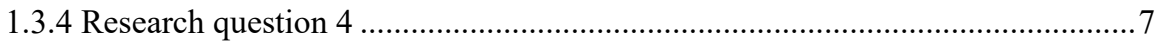

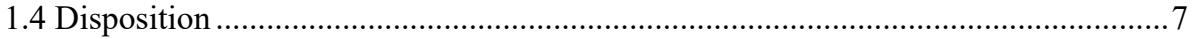

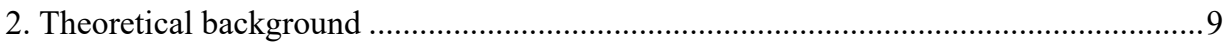

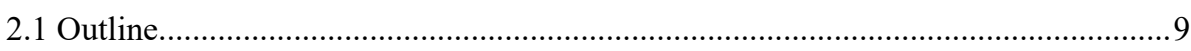

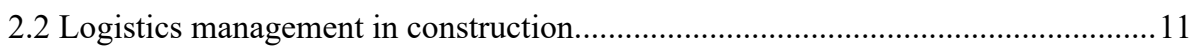

2.2.1 Construction logistics management to and from site.................................... 12

2.2.2 Construction logistics management on-site .................................................. 13

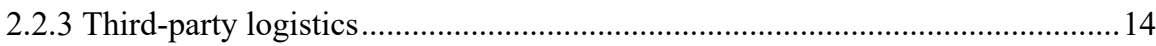

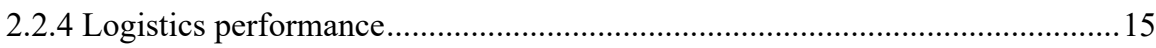

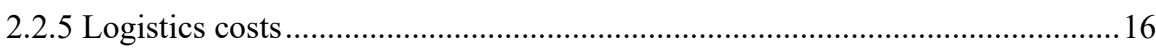

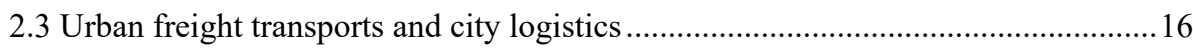

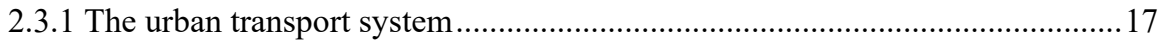

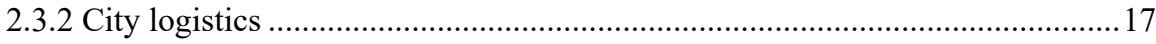

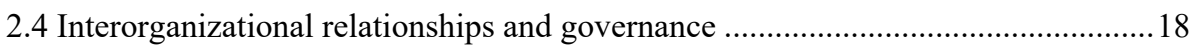

2.4.1 Interorganizational relationships in construction........................................... 19

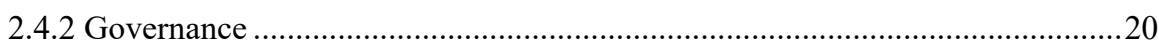

2.4.3 Control mechanisms and governance enablers ........................................... 21

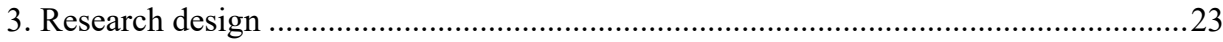

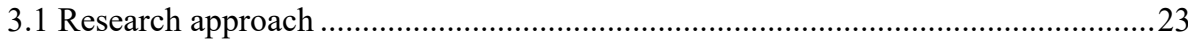


3.2 Choice of research methods .24

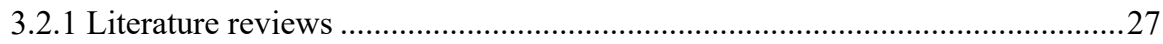

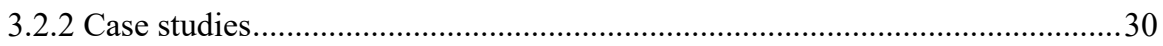

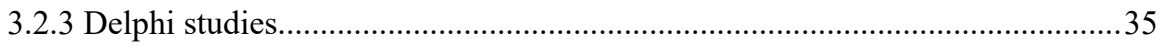

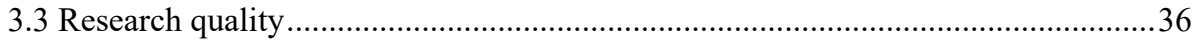

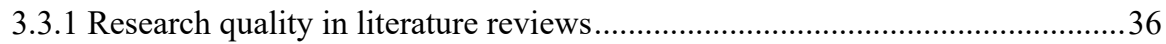

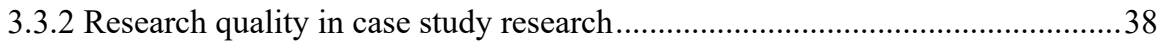

3.3.3 Research quality in Delphi study research.................................................. 40

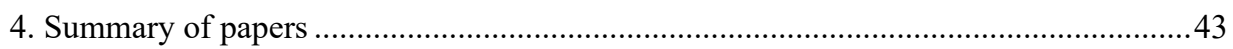

4.1 Paper 1: Supply chain management, logistics, and third-party logistics in construction

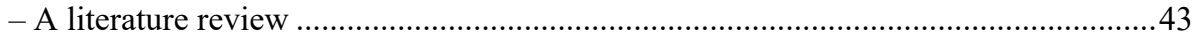

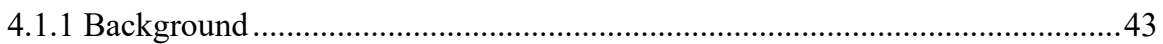

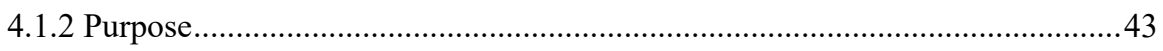

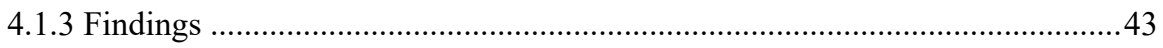

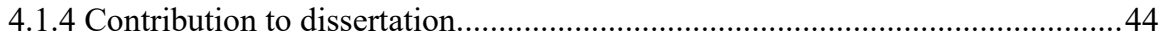

4.2 Paper 2: Construction logistics governing guidelines in urban development projects

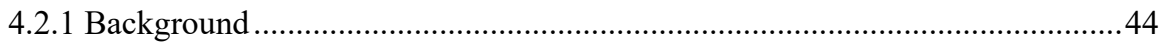

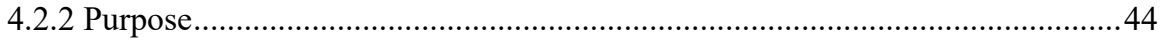

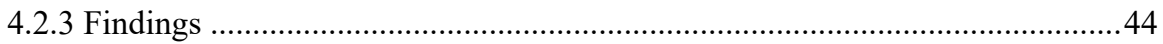

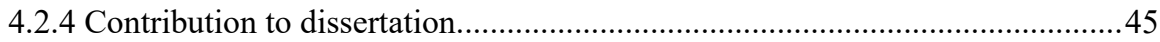

4.3 Paper 3: Characterizing third-party logistics setups in the context of construction45

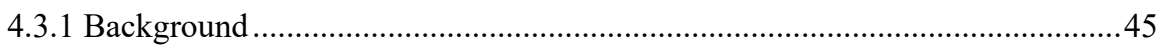

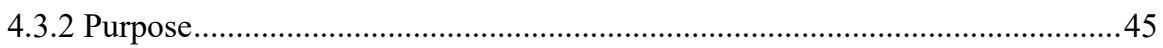

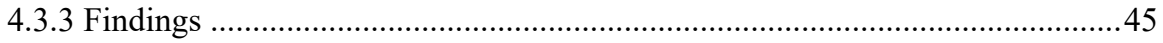

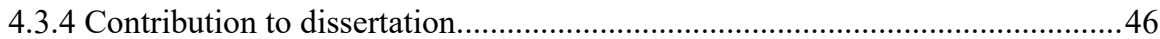

4.4 Paper 4: Effects of employing third-party logistics arrangements in construction

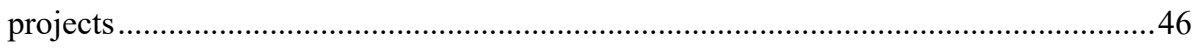

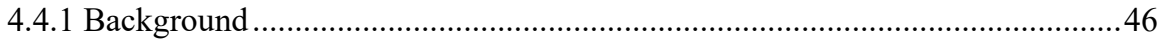

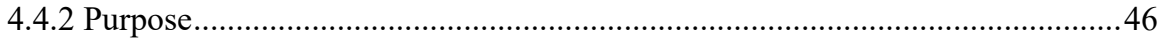

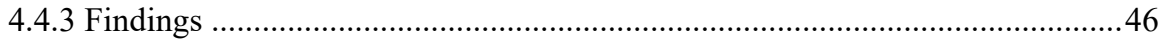

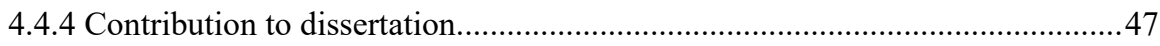

4.5 Paper 5: Construction logistics in urban development projects - Learning from, or repeating, past mistakes of city logistics?. 


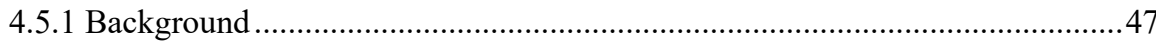

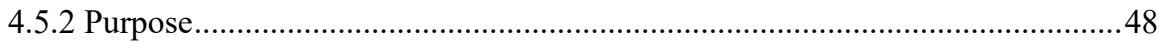

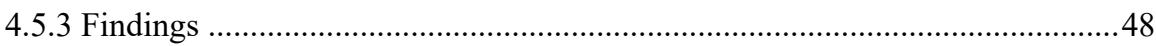

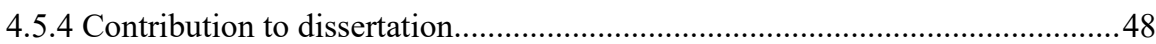

4.6 Paper 6: Construction logistics performance metrics: A Delphi study ....................49

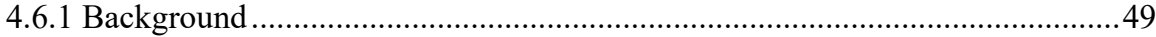

4.6.2 Purpose

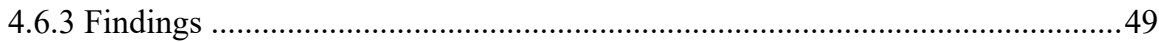

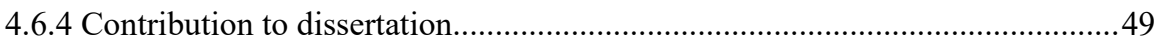

4.7 Paper 7: Designing construction logistics setups in hospital projects ....................50

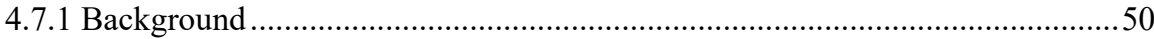

4.7.2 Purpose

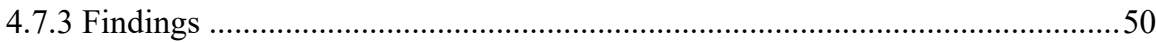

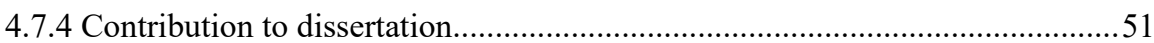

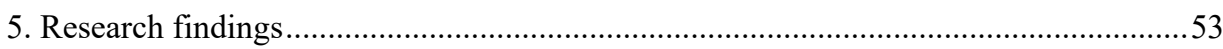

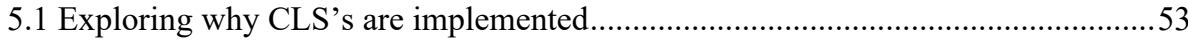

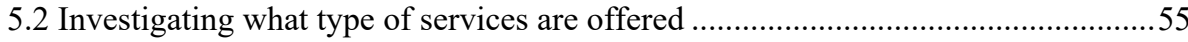

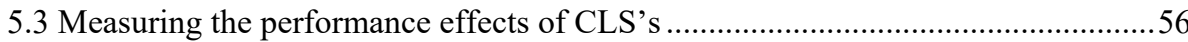

5.4 Exploring how CLS's affect the identified challenges ..........................................58

5.4.1 Managing transports to and from construction projects ....................................58

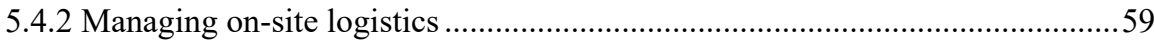

5.4.3 Managing interorganizational relationships amongst construction project

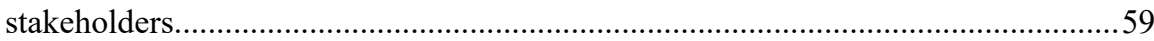

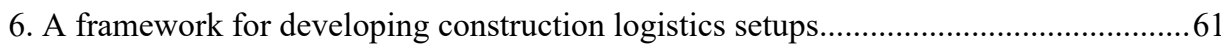

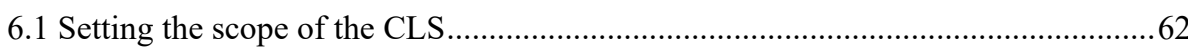

6.1.1 Identifying contextual considerations of the project.......................................62

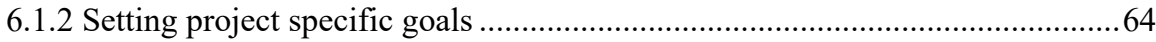

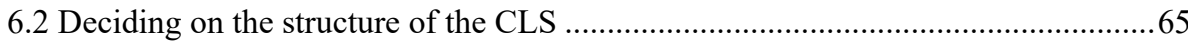

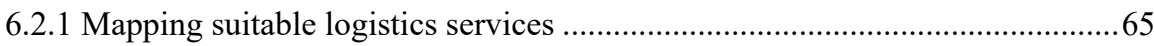

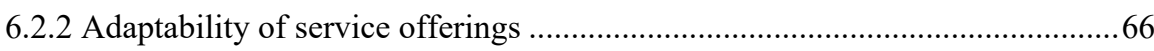

6.2.3 Establishing construction logistics performance monitoring............................67

6.3 Managing the interorganizational relationships of the CLS .................................68

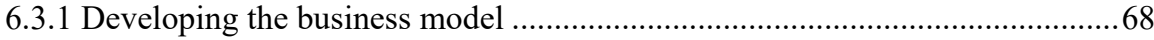

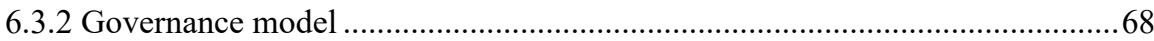


6.4 The framework, its applicability, and generalizability .... .69

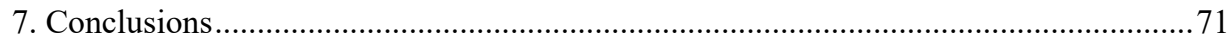

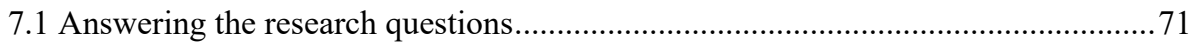

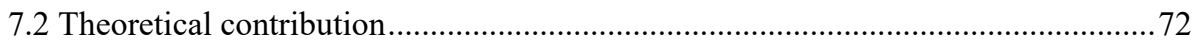

7.3 Managerial implications of using the framework ................................................. 74

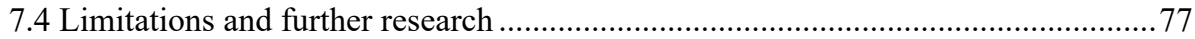

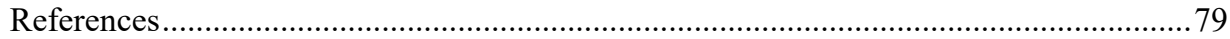

Paper 1 - Supply Chain Management, logistics, and third-party logistics in construction - A literature review

Paper 2 - Construction logistics governing guidelines in urban development projects

Paper 3 - Characterizing third-party logistics setups in the context of construction

Paper 4 - Effects of employing third-party logistics arrangements in construction projects

Paper 5 - Construction logistics in urban development projects - Learning from, or repeating, past mistakes of city logistics?

Paper 6 - Construction logistics performance metrics: A Delphi study

Paper 7 - Designing construction logistics setups in hospital projects 


\section{List of figures and tables}

Figure 1 - Material flows in construction affect three zones in the urban environment; the construction site, areas in vicinity of the site, and the surrounding city ....................2

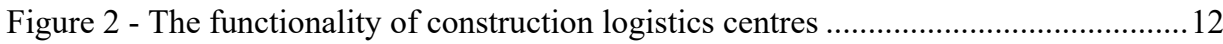

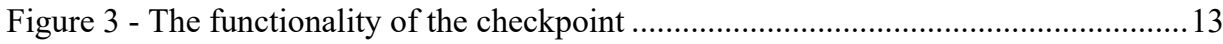

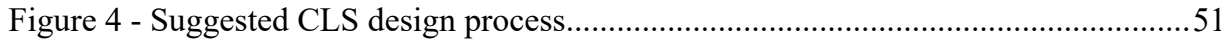

Figure 5 - The connection between papers and research questions .................................53

Figure 6 - The framework for developing construction logistics setups .........................61

Figure 7 - Setting the scope of the CLS's is dependent on identifying the contextual considerations and setting project specific CLS goal

Figure 8 - Deciding on the structure the CLS means mapping suitable services based on the scope of the CLS, as well as investigating how to offer adaptability of CLS services, and how to monitor the provided services

Figure 9 - Managing the interorganizational relationships of the CLS is intimately connected to the business model, as well as the governance model, of the CLS ......68

Figure 10 - The three steps in the framework are iteratively connected..... .69

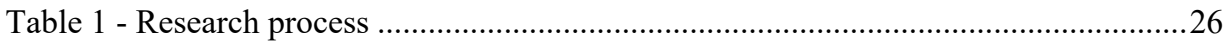

Table 2 - Research design of the papers' literature reviews ............................................29

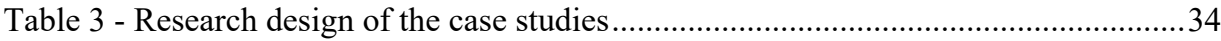

Table 4 - Content analysis milestones (based on Seuring and Gold, 2012) ......................37

Table 5 - Means to ensure research quality in case studies (based on Yin, 2014).............39

Table 6 - Means to address and control biases in Delphi studies (based on Hallowell and

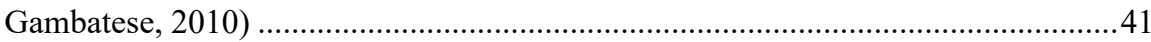

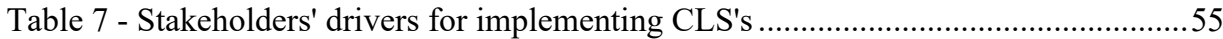

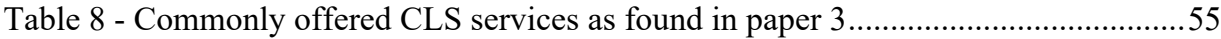

Table 9 - Construction logistics performance metrics as ranked in paper 6 .......................57 


\section{List of abbreviations and definitions}

CD: City development. An overarching strategy for cities to grow through construction and densification projects to meet the needs for housing, workplaces, schools, hospitals, and infrastructure.

CLC: Construction Logistics Centre. A terminal-based construction logistics setup in which construction materials can be consolidated from smaller shipments to reduce the amount of deliveries to construction projects.

CLS: Construction Logistics Setup, Construction Logistics Solution. In cases where construction logistics solution is used, it is interchangeable with construction logistics setup (cf. paper 2).

FQP: Freight Quality Partnerships. A structured agglomeration of city logistics stakeholders, aiming to include stakeholders in the discussion of how to solve urban freight problems.

ICT: Information and Communication Technology. Systems for managing and exchanging information. In this dissertation primarily delivery booking and planning systems.

JIT: Just-In-Time. The philosophy behind the checkpoint CLS in which a time-slot is booked for a delivery.

LSP: Logistics Service Provider. An external party offering to perform logistics activities for a focal company.

RBV: Resource-Based View of the firm. The theoretical base for resource governance. $\mathrm{RBV}$ focuses on the acquisition, deployment and maintenance of resources.

SCM: Supply Chain Management. The systemic and strategic coordination of traditional business functions within and across businesses in a supply chain, aiming at longterm performance for all supply chain partners.

SCO: Supply Chain Orientation. A prerequisite for SCM is that supply chain partners are supply chain oriented, striving towards achieving overall long-term performance for the entire supply chain.

TCE: Transaction Cost Economics. The theoretical base for governance as a function of cost and opportunism maintenance. TCE states that a relationship between parties will be based on a will to reduce the costs of transactions.

TPL: Third-Party Logistics. The outsourcing of a company's logistics function to an LSP with the aim of increasing value-adding time in the focal company. 
UCC: Urban Consolidation Centre. A terminal-based city logistics initiative in which goods for an urban distribution area is consolidated from smaller shipments to reduce the overall number of deliveries in the distribution area.

UDP: Urban Development Project. Large-scale development projects that satisfy immediate housing needs for a city or quartier as a part of City development strategies.

UFT: Urban Freight Transport. All goods movements in to, out from, through, or within an urban area, utilizing the urban transport system.

UTS: Urban Transport System. The transport system of a city or urban area. The UTS includes infrastructure, stakeholders, and transport modes.

VMI: Vendor-Managed Inventory. An inventory on site, managed by a supplier who restocks the inventory when needed and invoices contractors only for goods used. 


\section{Introduction}

This dissertation is the final part of a doctoral research project focusing on construction logistics setups and their role in governing and coordinating material and resource flows and stakeholders in a city development setting. In this chapter, the underlying problems that motivate this dissertation are described and the purpose of the dissertation is presented alongside the research questions and the scope of the dissertation. Finally, the dissertation's disposition is presented.

\subsection{Background}

Currently there is a strong, global, urbanization trend. United Nations $(2015$, p. 7) reports that, in 2007, the urban population exceeded the rural population globally for the first time, and in Europe, approximately 75 per cent of the population was living in urban areas in 2014 (United Nations, 2015, p. 209). In Sweden, the corresponding figure was approx. 86 per cent, and by 2050, the Swedish urban population is predicted to surpass 90 per cent (United Nations, 2015, p. 209). This means that there is a need for city development, i.e. to build houses, apartment buildings, hospitals, schools, office buildings, and infrastructure in cities and urban areas. At the same time, land is increasingly seen as a finite resource (Yin et al., 2016). This has led to the regeneration of decommissioned industrial-use land for development purposes (European Environment Agency, 2015). According to Yin et al. (2016), densifying a city through the "land-recycling" of industrial areas and ports allows a city to grow within its boundaries without taking valuable e.g. agricultural areas into development. Instead, city development is commonly achieved through densification projects and large-scale urban development projects (UDP) that can satisfy immediate needs and redefine the city (Bornstein, 2010, Swyngedouw et al., 2002). However, these large-scale projects are often spanning long time-horizons and encompassing joint overall budgets reaching levels of approx. $€ 1$ billion or more (Flyvbjerg, 2014, Majoor, 2018). Additionally, in city development, many different stakeholders are affected, e.g. construction companies (contractors, subcontractors, installers, etc.), developers, suppliers, transporters, municipalities, residents, hospital staff, etc. Often these stakeholders have an opinion of the construction projects and how it is carried out, adding to the organizational complexity of projects as different stakeholders enter and exit projects (Lehtinen et al., 2019, Bakhshi et al., 2016).

What further complicates city development is that, in construction, the end products (buildings or infrastructure) are produced at the place of consumption (Ekeskär and Rudberg, 2016). This means that resources (i.e. materials, machinery, and personnel) needs to be delivered to, and removed from, each construction site during the construction process 
(Lindén and Josephson, 2013). As cities and urban areas are predominantly developed through densification of urban areas, the existing urban transport system (UTS) is utilized for the projects' deliveries and unloading zones (Löfgren, 2010). This means that, not only do the construction projects and their transports affect the environment negatively, but there is also and increased infrastructure demand through the additional transports that come from the construction logistics activities. Simultaneously, there is also a reduction in the available infrastructure capacity as parts of the infrastructure is utilized as delivery zones.

In order to reduce the negative impact that construction transport activities have on the urban transport system, construction logistics management needs to be considered by the projects. According to Ying et al. (2018) however, construction logistics management has traditionally been approached in an ad hoc manner by the individual construction projects, focusing on construction logistics as a daily operations issue and solving the current logistics needs from day-to-day (Jang et al., 2003). Construction logistics management has thus not been considered as a long-term challenge or opportunity (Ying et al., 2018). With the increase in urbanization however, the problem of construction logistics management becomes more tangible as more and more projects are built and supplied within dense urban areas. This adds additional strain on the UTS (Browne, 2015), as well as disturbances to surrounding areas (Dubois et al., 2019). This has in turn led to more cities, developers, and contractors seeing the need for better construction logistics management (Dubois et al., 2019), both on site and during transports (Ghanem et al., 2018). According to Fredriksson et al. (2020), construction related transports pass through three different zones in the UTS; the construction site (zone 1), the vicinity of the construction site (zone 2), and the surrounding city (zone 3 ). Figure 1 highlights the three zones in which construction logistics operates within urban areas.

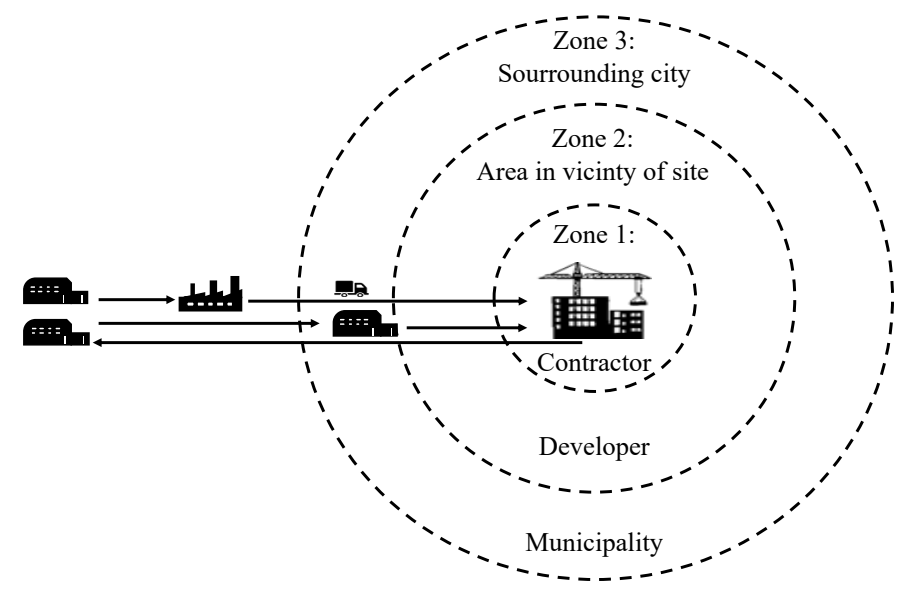

Figure 1 - Material flows in construction affect three zones in the urban environment; the construction site, areas in vicinity of the site, and the surrounding city

According to Spillane et al. (2013), the increased urbanization activities has made the three zones of Figure 1 more interrelated than previous, making construction logistics management a joint problem area to solve for the stakeholders. However, different 
stakeholders of the CLS have different goals and focuses, and as Lavikka et al. (2019) notes, these different goals makes it difficult to unite the views on how to carry out construction logistics. In these three zones, different stakeholders and their considerations need to be met, forming three different contexts that affect the development of construction logistics setups (CLS). In zone 1, efficient construction projects and on-site operations are of concern to contractors (Spillane et al., 2013). In zone 2, developers are concerned with reducing disturbances to tenants and businesses close by the construction sites, and in the third zone, municipalities are concerned with reducing disturbances to third parties and citizens (Browne, 2015). Thus, introducing CLS's face three challenges; managing transports to and from construction projects (related to zones 2 and 3), managing logistics at construction sites (zone 1), and managing the interorganizational relationships amongst construction project stakeholders (cross-sectional over all zones).

\subsubsection{Construction transport flows}

Managing transports to and from construction projects is the first challenge that this dissertation is concerned with. Different European studies ( $c f$. Department for Transport, 2017, Löfgren, 2010, Strale et al., 2015) have shown that construction-related transport amounts to between 17 and 22 per cent of the urban freight transports. These transports are carried out in a transport system populated by both goods and passenger transports (Carlsson and Janné, 2012, Dablanc, 2007). Construction transports thus put additional strain on the UTS by the infrastructure demand that deliveries and retrievals from construction sites incurs (Dablanc, 2007). Additionally, demands from municipalities, citizens, and businesses to reduce disturbances from deliveries and traffic (Dablanc, 2007) means that the transport side of construction logistics has to be managed in an efficient way (Dubois et al., 2019). Deliveries to construction sites and retrievals thus need to be coordinated and managed in a way that reduces their impact on the UTS (Guerlain et al., 2019), while ensuring that construction can proceed without reduced efficiency on site due to missed or delayed material deliveries (Dubois et al., 2019).

\subsubsection{Managing logistics at construction sites}

Managing logistics at construction sites is the second challenge that this dissertation is concerned with. The individual projects are managed by their own construction project organizations, focusing on completing the individual projects on time and within budget (Flyvbjerg, 2014, Gualini and Majoor, 2007). Additionally, with the denser, more confined construction sites common in city development, Spillane et al. (2013) highlights that the sites themselves need to be managed from a logistics point-of-view to ensure efficient construction projects and on-site operations. By better management of on-site logistics activities such as planning, storage, materials tracking, and waste management (Ying et al., 2018), space can be freed up on site (Spillane and Oyedele, 2017) and risks of material related accidents and wastage can be reduced (Spillane et al., 2013, Jang et al., 2003). Importantly, managing on-site logistics activities also helps construction projects' operations efficiency, ensuring the delivery of the project itself as materials are available at location when needed (Ying et al., 2018, Agapiou et al., 1998a). 


\subsubsection{Interorganizational relationships amongst construction stakeholders}

Managing the interorganizational relationships amongst construction project stakeholders is the third challenge that this dissertation is concerned with. The construction industry is characterized by high levels of resource dependency (Penrose, 1959, Yuchtman and Seashore, 1967) and, as described by Dubois and Gadde (2000), temporary network structures are utilized to ensure that this resource dependency can be met. However, the temporary nature of construction projects also means that different contractors, subcontractors, consultants and builders' merchants need to be procured every time a new construction project is launched (Dubois and Gadde, 2000, Kristiansen et al., 2005). Ultimately, this means that to a large extent, the construction projects act as autonomous entities with their own suppliers and subcontractors, disconnected from the company level (Dubois and Gadde, 2002a, Karrbom Gustavsson and Hallin, 2015). This temporary nature also means that the industry has struggled to find good forms of long-term collaborative relationships, instead favouring adversarial contracts and arm's length relationships as highlighted by amongst others Fernie and Thorpe (2007) and Green et al. (2005). In densification projects and UDP's, multiple individual projects are carried out within the same confined space (Gualini and Majoor, 2007, Axelsson and Granath, 2018) and different projects need to collaborate to achieve the UDP goal (Spillane et al., 2013). Thus, in these types of projects, there is a need to move away from adversarial contracts and arm's length relationships and instead focus on collaboration and understanding amongst stakeholders to work towards the common goal of finalizing the projects (Ekeskär, 2019, Ekeskär et al., 2019).

\subsection{Managing construction logistics in a city development setting}

As described above, construction logistics in city development face three major challenges, i.e. managing the transport flows to and from the construction projects, managing logistics at construction sites, and managing the interorganizational relationships amongst construction project stakeholders. The three challenges can be managed under the realm of construction logistics management. One way to approach construction logistics management is through the use of CLS's (Dubois et al., 2019). A CLS can, for the purpose of this dissertation, be defined as;

An agreed upon governance structure that controls, manages, and monitors the flow of materials, waste, machinery, and personnel to, from, and on the construction site. As such, the CLS includes one or several logistics services depending on the scope and purpose of the flows considered in the setup.

CLS's can range from small-scale initiatives such as a change in working practices to ensure efficient logistics operations to and on site (Perttula et al., 2006, Tanskanen et al., 2015), to utilizing planning systems (Hadaya and Pellerin, 2010), or introducing large-scale terminal setups (e.g. construction logistics centres) (Lundesjö, 2015) or just-in-time (JIT) solutions (e.g. checkpoints) (Akintoye, 1995, Sundquist et al., 2018). In the construction industry however, these setups are still a rather rare phenomenon (Langley, 2015, Ekeskär, 
2016), especially when proposed as joint setups for multiple construction projects, e.g., for UDP's.

Previous research has primarily focused on the effects of CLS's in construction from either a supply chain management (SCM) perspective ( $c f$. Ekeskär, 2016, Ekeskär et al., 2019), a construction site perspective ( $c f$. Lindén and Josephson, 2013, Spillane and Oyedele, 2017), or from a city logistics perspective ( $c f$. Transport for London, 2013, Browne, 2015). The SCM perspective have seen that CLS's are faced with challenges in reaching acceptance from different stakeholders, especially early in iterations of CLS's (Ekeskär and Rudberg, 2016). Hedborg Bengtsson et al. (2018) as well as Ekeskär et al. (2019) have, however, also shown that in time, the acceptance has increased and the CLS's are seen as good platforms for cooperation and innovative working practices within UDP's.

From the construction site perspective, studies have focused on how CLS's affect the working practices on-site, and how new CLS services can be utilized to increase construction site efficiency (Lindén and Josephson, 2013, Spillane and Oyedele, 2017). Primarily the focus has been on finding ways to reduce waiting time on site and shift some of the material handling from craftsmen to logistics specialists (Lindén and Josephson, 2013), but also on how CLS's can reduce materials on-site, thus reducing material related risks of having too much materials on site as well as reducing the handling of the materials (Spillane and Oyedele, 2017). The city logistics perspective has focused on reducing disturbances to the UTS as well as residents and businesses in the vicinity of construction projects (Browne, 2015, Dubois et al., 2019). All these studies and research directions have shown that even though there are barriers to CLS's to overcome, they can affect construction projects positively.

CLS's are, however, often procured on a project-by-project basis (Browne, 2015). This makes it difficult to achieve longevity in CLS concepts and operations, as well as bringing both positive and negative lessons learned from one setup to another (Khalfan et al., 2010). One issue is that there is no guiding procedure for developing and implementing the CLS and the services offered by the setup. Instead, the development and implementation procedure of the CLS is often based on mimicking previous solutions without taking current contextual factors into consideration, i.e. thinking that one solution fits all (Janné and Fredriksson, 2019). The risk with this approach is that the implemented CLS does not meet the stakeholders' needs.

\subsection{Purpose \& scope}

With the increased introduction and utilization of CLS's described previously, and the ad hoc development and implementation of the same, there is a need for a clear development process of CLS's. A systemized development process can ensure that the challenges of ensuring construction project efficiency, site efficiency, and managing transports to and from site are considered in the development of CLS's. The purpose of this dissertation is thus to propose a framework for developing construction logistics setups. 
The scope of this dissertation is construction projects forming part of city development. In this dissertation, city development means that a city has a strategy for how the city should meet the needs from urbanization in terms of evolving the city in a sustainable and attractive way. The concept of city development encompasses construction projects building individual houses, apartment buildings, hospitals, urban development projects, schools, offices, and infrastructure.

The unit of observation in this dissertation is the relationship between the CLS, the construction projects connected to the CLS, the UTS, and the affected stakeholders. The unit of analysis is the CLS itself.

The effect the CLS has on construction projects and the UTS depends on the initiating stakeholder and what is important to control from their perspective. Thus, the perspectives studied in this research are the municipal perspective, the contractor perspective, the developer perspective, and the third-party logistics service provider (TPL provider) perspective. These are the stakeholders who are directly affected by a CLS or the ones introducing the CLS.

Depending on the stakeholder perspective, different aspects of the zone model in Figure 1 are of importance; contractors are concerned primarily with what is going on in zone 1 (the construction site), developers are concerned with disturbances in zone 2 (the vicinity of the site), and municipalities are concerned with disturbances in zone 3 (the UTS). Additionally, the TPL provider is concerned with delivering value to customers of the CLS. These focal areas and perspectives make up the context of this dissertation.

\subsubsection{Research question 1}

Different stakeholders have different goals with the CLS, and this will lead to different outcomes of the CLS (Dubois et al., 2019). However, there is no clear definition of what a CLS can cover in terms of goals and goal fulfilment. Partly, this is due to the varying goals of initiators and CLS's (Dubois et al., 2019, Ekeskär and Rudberg, 2016). A CLS focused on reduced transports through consolidation can have a positive effect on third-party disturbances for instance (Lundesjö, 2015), whereas a CLS focused on evening out transport work over time can have a positive effect on the efficiency of the construction site (Dubois et al., 2019). Thus, there is a need to further the understanding of the different goals of CLS implementors and how these impact the choice of CLS. The first research question is thus dedicated to the why of a CLS and is formulated as:

RQ1: Taking the perspectives of different stakeholders', why are CLS's implemented?

\subsubsection{Research question 2}

As discussed previously, CLS's can range from small-scale initiatives such as changes in working practices on- or off-site (Perttula et al., 2006, Tanskanen et al., 2015), to largescale setups with terminals and/or checkpoints with just-in-time (JIT) control of deliveries. (Sundquist et al., 2018, Akintoye, 1995). However, exactly what constitutes a CLS in terms of offered services is still largely unknown. There is thus a need to further the understanding 
of how to determine and categorize CLS services. The second research question explores the what of a CLS, i.e. what services make up the CLS and is formulated as:

RQ2: What type of CLS services are offered?

\subsubsection{Research question 3}

As noted by Dubois et al. (2019), construction logistics and CLS's are gaining momentum. However, the monitoring of construction logistics performance is still lagging behind the level of performance monitoring of other industries (Wegelius-Lehtonen, 2001, Ying et al., 2018). Ying et al. (2018) found that few studies have focused on construction logistics performance, and those that have focus on costs or a specific construction logistics activity, e.g. transport performance. Yet, in order to improve CLS's and construction logistics operations, it is crucial to measure construction logistics performance (Wegelius-Lehtonen, 2001, Thunberg and Persson, 2014). The third research question thus focuses on how CLS performance effects can be measured and is formulated as:

RQ3: How can performance effects of CLS's be measured?

\subsubsection{Research question 4}

As discussed previously, introducing CLS's face three challenges of managing the transport flows to and from the construction projects (cf. Browne, 2015), managing logistics at construction sites (cf. Spillane et al., 2013), and managing the interorganizational relationships amongst construction project stakeholders (cf. Ekeskär et al., 2019). However, due to CLS's still being novel occurrences (Langley, 2015, Ekeskär and Rudberg, 2016), research on CLS's is also still at an early stage. There are thus only a few studies that investigate the effect CLS's have on these challenges, and as noted by amongst others Ying et al. (2018), the main focus has often been on the cost of construction logistics. To get a more comprehensive view of how CLS's affect the previously identified challenges, the fourth research question explores this phenomenon further and is formulated as:

RQ4: How do CLS's affect the identified challenges of managing transports to and from construction projects, managing logistics at construction sites, and managing the interorganizational relationships amongst construction project stakeholders?

\subsection{Disposition}

The disposition of the dissertation is as follows: Chapter 1 gives a brief introduction to the problems that have been studied in this research project and introduces the purpose and research questions. To address the purpose and fulfil the research questions, chapter 2 presents the theoretical background that the dissertation rests upon. The research design is presented in chapter 3, detailing the research approach and methodology of the dissertation. Chapter 4 presents research findings by summarizing the seven papers that this dissertation is built upon and chapter 5 synthesizes the findings to meet the research questions. These findings are discussed in chapter 6 , and chapter 7 concludes the dissertation and highlights contributions and future research directions. 


\section{Theoretical background}

This chapter describes the theoretical background on which this dissertation rests. The chapter starts with an outline of the important aspects to consider when developing CLS's, thus motivating the choice of theoretical concepts used throughout the dissertation. Thereafter, the theoretical concepts themselves are presented.

\subsection{Outline}

Building on the identified challenges; managing transports to and from construction projects, managing logistics at construction sites, and managing the interorganizational relationships amongst construction project stakeholders, three theoretical concepts are used for the analysis. The three theoretical concepts are logistics management in construction, urban freight transports and city logistics, and interorganizational relationships and governance. Logistics management in construction relates to the first two challenges, as these challenges are at the core of logistics; transport flows and on-site logistics. Furthermore, as the scope of this research is city development, urban freight transports and city logistics adds to the contextual understanding of how to manage the transport flows to and from site, as this in essence means managing freight logistics in urban areas. Finally, to understand how to manage interorganizational relationships amongst construction project stakeholders, there is a need to first understand the mechanisms underpinning interorganizational relationships and governance. Deeper motivations for these theoretical concepts follow below.

The foundation of any CLS lies in the $C L$ part, i.e. construction logistics. The first theoretical concept presented in chapter 2.2 is thus Logistics management in construction. What CLS's aim to manage is primarily ensuring that materials and resources are delivered to, retrieved from, and managed on construction sites (Ekeskär and Rudberg, 2016, Dubois et al., 2019). Chapter 2.2 takes its departure point from a definition of logistics management, moving towards the definition of construction logistics management that this dissertation is built upon. Construction logistics in its essence means supplying construction projects with materials and resources. Ghanem et al. (2018) further categorizes construction logistics into two primary functions; the transport of resources and materials to and from the construction site and the management of logistics activities on the construction site. Chapter 2.2 thus continues with a discussion on construction logistics from these two focus areas. CLS's are often operated by third-party logistics (TPL) providers. To understand how TPL can facilitate better logistics management and give guidance on future developments, as well as barriers for CLS's chapter 2.2 continues with an account of TPL research. To be able to assess the construction logistics operations, and 
subsequently, be able to improve both construction logistics and construction project performance, there is also a need to measure logistics performance and logistics costs imposed by the CLS (Wegelius-Lehtonen, 2001, Thunberg and Persson, 2014). Chapter 2.2 thus addresses these areas as well to add to the overall understanding of construction logistics and CLS's.

The second theoretical concept presented in chapter 2.3 is Urban freight transports and city logistics. This dissertation is concerned with city development, and as such, the urban transport system (UTS) sets limitations for how construction logistics can be carried out. When construction occurs in urban areas, construction logistics becomes part of urban freight transports (UFT). As highlighted by Anderson et al. (2005), UFT's play an important role in the prosperity of cities by delivering goods to consumers and businesses. However, the transports also affect the urban environment negatively through emissions, congestion, noise, and accidents (Dablanc, 2007). Reducing the impact from urban freight transports is sought to be achieved by introducing and applying different city logistics measures (Anderson et al., 2005, Aastrup et al., 2012). City logistics is a more established research area than construction logistics and at the same time, measures introduced in city logistics will affect construction logistics. Additionally, as highlighted by amongst others Strale et al. (2015), Department for Transport (2017), and Löfgren (2010), construction related transports make up a significant part of UFT's. Thus, understanding the challenges of UFT's and the solutions proposed by city logistics is vital for understanding what context construction logistics in city development is subject to as well as what measures have been introduced and how they impact UFT's. Therefore, chapter 2.3 sets out to describe the UTS and the city logistics measures introduced to reduce the impact from UFT's.

The third and final theoretical concept presented in chapter 2.4 is Interorganizational relationships and governance. As discussed by Dubois and Gadde (2000), the construction industry is characterized by temporary relationships with developers, contractors, subcontractors, consultants, builders' merchants, and logistics operators being tendered and procured with every new construction project. This means that new supply chains and interorganizational relationships are formed with each new project. To further the understanding of the structure of the construction industry, chapter 2.4 starts with an account of interorganizational relationships in construction, and how different stakeholders relate towards one-another. This section also presents how the industry has evolved towards more specialized companies as discussed by amongst others Kristiansen et al. (2005). In all types of interorganizational exchanges, the way that stakeholders relate to each other will set conditions for how well balanced the relationship will be (Selviaridis and Norrman, 2014, Hedborg Bengtsson et al., 2018), in this dissertation e.g. how well-received the CLS will be. To further understand how the relationships amongst the stakeholders affect the introduction of a CLS, chapter 2.3 continues by presenting governance theory, highlighting how different interests can be aligned (Boissinot and Paché, 2011). Agapiou et al. (1998a) highlights that the focus of CLS's must be to improve coordination and communication between project stakeholders, setting realistic expectations for what can be achieved. Unrealistic expectations of the CLS can occur on both the initiating side, as well as the 
utilizing side of the CLS, depending on how the CLS is regulated and communicated (Hedborg Bengtsson et al., 2018). To facilitate the relationships within the CLS, there is a need to employ different governance enablers. Chapter 2.3 is thus concluded with an account of different types of governance enablers common in business relationships, i.e. governance as cost and opportunism maintenance ( $c f$. Williamson, 1979), resource governance ( $c f$. Benson, 1975), and relational governance ( $c f$. Dyer and Singh, 1998).

\subsection{Logistics management in construction}

During the 1990's and early 2000's, the construction industry's need to increase efficiencies and decrease build-times were highlighted in numerous reports and research articles (cf. Egan, 1998, Josephson and Saukkoriipi, 2007, Latham, 1994, Strategic Forum, 2002). Part of the criticism against the construction industry was based on issues related to material flows, cost performance, and build-time overruns (Fulford and Standing, 2014, Josephson and Saukkoriipi, 2007). Vrijhoef and Koskela (2000) for instance, found that construction costs were increasing while productivity was decreasing. This sparked an increased interest in raising the productivity of the industry, and one solution proposed to combat the inefficiencies was to focus on construction logistics and supply chain management (SCM) (Egan, 1998, Strategic Forum, 2002). This in turn meant that there were increased research and development efforts in the two fields (Egan, 1998, Strategic Forum, 2002). However, as evidenced by amongst others Vrijhoef and Koskela (2000) and Bygballe et al. (2013), the construction industry has been slow to adopt SCM and construction logistics. Lately however, with more focus on city development and densification, more construction companies are embracing construction logistics and SCM to manage logistics activities (Dubois et al., 2019) and relationships with suppliers (Gosling et al., 2015).

The goal for any construction project is to deliver the project on time and on cost to the stipulated quality. However, as the construction industry is producing its end products (the house or infrastructure) at the place of consumption (Ekeskär and Rudberg, 2016), the construction industry is greatly dependent on materials arriving to site when needed (Josephson and Saukkoriipi, 2007, Lindén and Josephson, 2013). The process of managing these material flows is called logistics management and can be defined as:

Logistics management is the process of strategically managing the procurement, movement and storage of materials, parts and finished inventory (and the related information flows) through the organization and its marketing channels in such a way that current and future profitability are maximized through the cost-effective fulfilment of orders (Christopher, 2011).

In a construction setting, this is referred to as construction logistics management which in essence focuses on two areas; the management of logistics activities on the construction site to ensure efficient construction projects, and the transport of resources and materials to and from the construction site (Agapiou et al., 1998a, Ghanem et al., 2018). In this dissertation construction logistics management is defined as: 
Supplying and retrieving the right resources and materials to and from the correct customer and construction project to ensure efficient construction projects and construction sites.

\subsubsection{Construction logistics management to and from site}

One of the major functions of construction logistics is material and resource deliveries to and from site. Different studies has shown that approximately 20 per cent of all UFT's are construction-related ( $c f$. Department for Transport, 2017, Löfgren, 2010, Strale et al., 2015). There is thus a need to reduce the emissions and negative impact on the urban environment (Guerlain et al., 2019) while ensuring efficient construction projects and sites (Dubois et al., 2019). One way to manage these deliveries is through CLS's where construction logistics centres (CLC) is one of the more common setups for building in dense urban areas (Lundesjö, 2015). The aim of the CLC is according to Lundesjö (2015) the coordination of deliveries to multiple construction sites within an urban area through consolidation of goods. Instead of the traditional situation where many deliveries come to construction sites without any coordination (Ying et al., 2018), the use of a CLC can reduce the number of delivery occasions to site, thus reducing the number of times on-site personnel has to receive and handle materials (Lundesjö, 2015). Additionally, a reduction in the number of deliveries within an area also reduces the negative impact on the environment (Dablanc, 2008) as well as on third parties living or working in close proximity to the construction site (Dubois et al., 2019). Figure 2 shows a schematic overview of the functionality of a CLC.

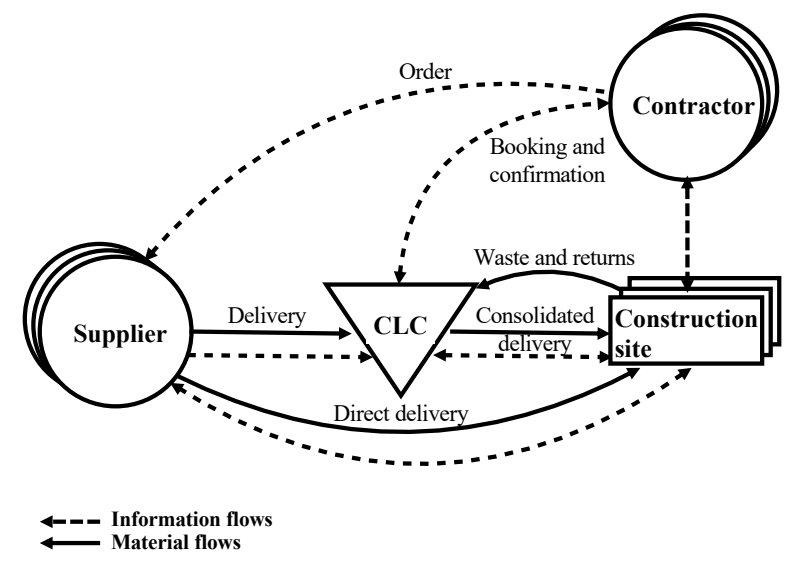

Figure 2 - The functionality of construction logistics centres

Another wide-spread CLS is the just-in-time based checkpoint (Sundquist et al., 2018, Ekeskär and Rudberg, 2016). In checkpoint setups, time-slots for deliveries are booked and specified with information on type of materials, type of vehicle, goods volumes and if any specific handling equipment is needed (Sundquist et al., 2018). The aim of the checkpoint differs from that of the CLC. By controlling at what time deliveries are made (Akintoye, 1995), the aim is to even out deliveries over the working day, thus reducing congestion on site and subsequently reducing risks of accidents (Dubois et al., 2019). According to 
Sundquist et al. (2018), this setup allows construction projects better control of when deliveries are made and the construction operations of the project can be planned accordingly. Figure 3 gives a schematic overview of a checkpoint's functionality.

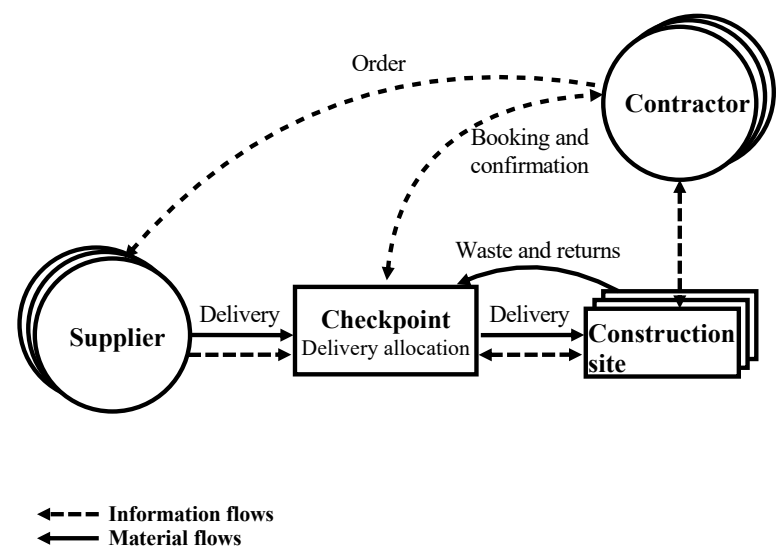

Figure 3 - The functionality of the checkpoint

Regardless the CLS used, one crucial part of construction logistics setups is the use of ICT systems for planning, coordinating, executing, and controlling logistics flows and on-site operations (Jang et al., 2003, Thunberg and Fredriksson, 2018). Thunberg and Fredriksson (2018) found that by coordinating construction project stakeholders and tracking materials and resource needs through ICT systems, construction logistics can lead to more efficient construction projects.

\subsubsection{Construction logistics management on-site}

The other important function of construction logistics management is according to amongst others Ghanem et al. (2018) and Ying et al. (2018) to ensure the efficiency of construction projects' on-site operations by managing logistics activities such as planning, storage, materials tracking, waste management, and managing on-site processes related to physical flows. This is supported by Jang et al. (2003) and Thunberg et al. (2017) who found that construction logistics can be a catalyst to manage on-site issues and enhance communication and collaboration amongst construction supply chain partners.

Managing the site and physical materials flows is essential to reduce unnecessary material movements (Thunberg and Persson, 2014), material related accidents (Spillane and Oyedele, 2013, Jang et al., 2003), and to free up space on site (Spillane and Oyedele, 2017). This can be achieved by having dedicated logistics coordination within the site organization (Sundquist et al., 2018) and utilizing logistics-based site-layout plans that specifies unloading zones and storage places on site (Josephson and Saukkoriipi, 2007, Transport for London, 2013). These measures allow for a less cluttered construction site, subsequently enhancing material traceability in the projects (Spillane and Oyedele, 2017). Additionally, Ekeskär and Rudberg (2016) found that dedicated material handlers can be utilized for the on-site materials handling. This helps the construction project to increase the control of 
materials handling, but more importantly, it allows craftsmen to focus on their trades, thus increasing their value-adding time (Ekeskär and Rudberg, 2016). Furthermore, Spillane and Oyedele (2017) highlights that warehousing on- or off-site can alleviate material related issues by increasing the overall materials control on-site. In the long run, this increased materials control can lead to higher productivity and lowered costs as materials are accounted for and present when needed (Dubois et al., 2019).

\subsubsection{Third-party logistics}

According to Marasco (2008) and Hertz and Alfredsson (2003), third-party logistics (TPL) is the outsourcing of a company's logistics function to an external logistics service provider that acts as an intermediary between two supply chain companies. As part of its services, the TPL provider can offer multiple bundled services such as transport, warehousing, inventory management, value-adding activities such as kitting and assembly work, information activities such as tracking and tracing materials, as well as supplying ICT tools for planning, and return logistics (Hertz and Alfredsson, 2003, van Laarhoven et al., 2000, Shaharudin et al., 2014). What differs the TPL arrangement from traditional spot-market purchases of logistics functions is, according to amongst others Selviaridis and Spring (2007) and Skjøtt-Larsen et al. (2006) that the relationship between service client and TPL provider must be contractually stipulated over a longer time period for the arrangement to be considered a TPL arrangement. Ultimately, the underlying reasons for employing a TPL provider will affect the terms and longevity of the relationship between the service client and the TPL provider. Cost reasoning have a tendency to lead to more arm's length relationships whereas knowledge-seeking normally leads to closer, longer, relationships (Bolumole, 2001). Through these closer, longer, relationships, the service client and the TPL provider can reach a level of trust that differs from the short-term, more adversarial arm's length agreements of sourcing transportation and warehousing on the spot-market (Berglund et al., 1999).

Another important aspect of TPL is the adaptability of the TPL provider and the level of customization that can be offered to the customer (Stefansson, 2006, Hertz and Alfredsson, 2003). Halldórsson and Vural (2019) highlight that TPL is composed of simple or complex service bundles, and that these service bundles either require tangible assets or knowledge resources to satisfy the customers service needs. In essence, this means that service offerings can be distinguished between logistics operations where the TPL provider has tangible assets, and logistics capabilities where the TPL provider offers knowledge-based services (Liu and Lyons, 2011, Stefansson, 2006). Developing niche offerings (e.g. industry segments or products managed) through service differentiation is, according to Scarsi and Spinelli (2017) and Hertz and Alfredsson (2003) a way for TPL providers to increase customer adaptations. Additionally, through service differentiation, the TPL provider can gain the specific knowledge needed for a certain customer or niche, i.e. to add to their logistics capabilities (Halldórsson and Vural, 2019, Hertz and Alfredsson, 2003). The challenge for the TPL service provider becomes one of balance; how should service offerings be adapted to provide a high level of customization to individual customers while 
retaining flexibility enough to provide services to multiple customer segments (Stefansson, 2006, Hertz and Alfredsson, 2003)?

One of the TPL markets niches that has gained popularity lately is construction logistics. CLS's are often run by TPL providers (Lindén and Josephson, 2013, Sundquist et al., 2018). Partly this is due to a lack of logistics knowledge from contractors (Ekeskär and Rudberg, 2016), and partly due to TPL providers being able to take a more neutral stance when it comes to planning, coordinating, executing and controlling the fragmented operations in construction, acting as a systems integrator within the UDP (Segerstedt and Olofsson, 2010).

\subsubsection{Logistics performance}

In order to assess whether or not logistics operations are efficient and adding value to the construction site, construction logistics performance needs to be measured (WegeliusLehtonen, 2001, Ying et al., 2018). According to Fawcett and Cooper (1998), logistics performance can be said to deal with measuring what moves and what stays put. However, what measurements are connected to the moving/unmoving elements is where performance measurements come in. Traditionally, logistics performance measurements have had an internal view as it is easier to measure within the own operations, rather than involving external stakeholders such as customers and suppliers (Ellinger et al., 1997). With the advent of supply chain management (SCM) and the view that supply chains compete against supply chains, the view of how to carry out performance measuring has shifted towards an external view, taking into consideration how the focal company performs within the supply chain and how this performance affects customers and suppliers (Ellinger et al., 1997), as well as how the logistics capabilities of the own company can be enhanced (Lu and Yang, 2010).

Fawcett and Cooper (1998) highlights that logistics performance measuring has traditionally been based on five performance areas; asset management, cost, customer service, productivity, and logistics quality. However, the measurements have all been primarily financial, i.e. focused on reducing cost of operations for the company (Fawcett and Cooper, 1998, Kurien and Qureshi, 2011). This has, according to Kurien and Qureshi (2011), changed over time, and other, less tangible values have received more attention. Non-cost issues such as quality, delivery, flexibility, and innovation (Fawcett and Cooper, 1998) have become increasingly important to measure and keep track off, alongside measures such as e.g. (perceived) customer value, information technology, and safety (Toor and Ogunlana, 2010, Domingues et al., 2015).

When it comes to setting up logistics performance measures, Gríful-Miquela (2001) and Lin et al. (2001) suggests that a good starting-point is to look at the logistics operations carried out. For each logistics operation included in the logistics setup, multiple performance measures can be included. If the logistics operations for instance include warehousing, transportation, and value-adding services, the performance measures need to encompass measurements in those categories. To get a comprehensive view of logistics 
performance, both the financial performance, the operational performance, and the service capabilities need to be measured (Liu and Lyons, 2011, Stefansson, 2006).

\subsubsection{Logistics costs}

In traditional supply chains, logistics costs are seen as indirect costs incurred through joint usage for different outputs (Harrison and van Hoek, 2011, LaLonde and Pohlen, 1996). This makes the costs difficult to allocate to a specific cost centre. Harrison and van Hoek (2011) further suggests that logistics costs traditionally have been allocated to products based on the utilization of logistics functions. These logistics functions gave way for function-based logistics cost centres such as transport, warehousing, inventory carrying, and administration costs (Heskett et al., 1973). With time, these function-based cost centers have evolved to also include order processing, information and ICT systems, and transport packaging (Stock and Lambert, 2001, Engblom et al., 2012). Other cost components can also be important when evaluating logistics costs, depending on the context of the logistics systems studied. Some examples are for instance risk and damage costs, customs, and material handling systems (Zeng and Rossetti, 2003, Shakantu et al., 2003).

More generally, logistics costs can be classified into one or more of the following cost centres; transport, warehousing, inventory carrying costs, administration, indirect costs, and procurement (Engblom et al., 2012, Stock and Lambert, 2001). However, as Harrison and van Hoek (2011) highlights, logistics costs are dependent on the logistics system being studied and the relevant cost components must be identified within that context.

All logistics cost elements are made up of fixed and variable costs. This means that there is a fixed cost for the physical assets used, as well as a variable cost for e.g. time and salary costs. In construction, site storage can for instance be comprised of receiving and unloading materials, moving them to on-site storage, registering the location of the materials, the cost of storage, etc. (Everaert et al., 2008, Fang and Ng, 2011). It is thus important to keep track of the actual logistics setup used and to map the cost centres and activities in order to find and analyse the most important logistics costs (Vasiliauskas and Jakubauskas, 2007, Lin et al., 2001).

\subsection{Urban freight transports and city logistics}

The two terms "urban freight transports" and "city logistics", alongside terms such as "urban distribution", "urban freight movement", and "urban goods movement" are often used interchangeably in literature (MDS Transmodal, 2012). In this dissertation, UFT's concerns all movements of goods by light or heavy vehicles in to, out from, through, or within the urban area (Lindholm, 2012a). This includes service transports, construction and demolition traffic, private household shopping trips, and waste management and reverse logistics (Lindholm, 2012a). City logistics refers to both the research field studying UFT's, but also to the policies, measures and initiatives imposed by municipalities and private actors on the UTS to reduce negative impact from UFT's. 


\subsubsection{The urban transport system}

The urban transport system is fairly static in its transport supply due to the existing infrastructure capacity and difficulty in changing the land use to include more infrastructure (Rodrigue and Notteboom, 2017). With increased urbanization (United Nations, 2015), the transport demand can thus at times surpass the transport supply as more construction transports are introduced into the transport system (Rodrigue and Notteboom, 2017, Ying et al., 2018). This leads to the UTS not being as efficient as it could be (Lindholm, 2012b). Yet, an efficient freight transport system is a necessity for the urban economy (Anderson et al., 2005, Lindholm, 2012b) and should be a priority for cities, inhabitants and companies alike (Lindholm, 2012b).

UTS's are subjected to a vast amount of policies and regulations (Ballantyne et al., 2013, van Wee et al., 2013). These policies and regulations aim to ensure the effective utilization of the available infrastructure (Slack et al., 2017). Yet, there are difficulties for the public and private urban transport stakeholders to consolidate their views on how to manage and regulate the system. Previous studies have noted that cities and authorities traditionally have not focused on strategies for UFT's or coordinating efforts among stakeholders (Ballantyne et al., 2013, Fossheim and Andersen, 2017), even though they are the ones holding jurisdiction over the UTS (Slack et al., 2017). Ballantyne et al. (2013) argues that freight transports and logistics thus has been treated as a problem for the logistics industry to solve. This lack of clarity and focus on freight transports adds to the complex nature of the UTS.

\subsubsection{City logistics}

Reducing the disturbances to the UTS while ensuring efficient deliveries falls under the concept of city logistics (Anderson et al., 2005, Benjelloun et al., 2010). In this dissertation, city logistics is defined as:

The delivery of consumer goods in city and suburban areas, including the reverse flow of used goods in terms of clean waste (OECD, 2003).

City logistics initiatives are often initiated by municipal and city authorities who regulate what happens in the UTS through different measures, often access conditions based on weight and/or length of vehicles, as well as time restrictions for when it is allowed to enter the distribution area (Dablanc, 2008, Aditjandra and Zunder, 2018). At the same time, technological advancements and increased awareness of what causes disturbances has changed the way that city logistics operations are carried out (Fossheim and Andersen, 2017).

Many types of initiatives have been proposed and tested in city logistics. Notable amongst these are off-hour deliveries and consolidation schemes. Off-hour deliveries means deliveries outside of normal business hours (Dablanc et al., 2013). Holguín-Veras et al. (2011) notes that the driving force behind this type of initiative is to reduce the amount of traffic in the UTS during rush-hours. By having dedicated, locked, delivery areas in shops, 
suppliers can deliver goods without shop personnel being present (Holguín-Veras et al., 2011).

Primarily however, city logistics promotes consolidation schemes such as urban consolidation centres (UCC's) (Strale, 2019, van Heeswijk et al., 2019). The goal of consolidation is according to Allen et al. (2014) to achieve higher vehicle fill rates to reduce traffic volumes while maintaining the same goods volumes. Three levels of consolidation schemes exists (Crainic et al., 2009); no dedicated physical UCC, single-tier UCC's with one terminal, two-tier UCC's where consolidation takes place in the UCC outside of the city with a satellite hub closer to the delivery area. To increase acceptance and demand of UCC's, value-adding services were introduced in many initiatives (Aastrup et al., 2012). Gammelgaard et al. (2016) found that if additional services are used, they are seen as valueadding but they are more likely to be utilized when co-created by the service provider and customer. Balm et al. (2016) and Österle et al. (2015) highlight that because of its focus on urban areas, many stakeholders are affected by city logistics measures, either directly or indirectly. City logistics has thus had to deal with how to organize initiatives in order to manage relationships and create awareness and value for the stakeholders (Fossheim and Andersen, 2017, Dablanc et al., 2013). However, when introducing UCC's focus has primarily been on technical aspects such as vehicle types and reducing transports and emissions (Gammelgaard, 2015, Malhene et al., 2012).

In order for city logistics initiatives to be accepted by end-users, there is a need to include stakeholder needs early on when developing the initiatives' business models (Magretta, 2002, Sandberg et al., 2011). Sandberg et al. (2011) describes business models as the operationalization of a business strategy, e.g. a way to clarify the logic and function of a firm. Teece (2018) expresses this as a business model essentially being a road-map for how to create and deliver value for customers. A business model thus details a set of business elements to optimize a firms flows of costs, revenues, and profits (Teece, 2018). To decide on the business model, Magretta (2002) puts forth three important questions that needs addressing; "Who is the customer?", "How do we make money in this business?", and "What does the customer value?". One initiative to reach this sought-after understanding of stakeholder needs has been to introduce Freight Quality Partnerships (FQP) which aim to include stakeholders in the discussion of how to solve urban freight problems (Lindholm, 2014, Kin et al., 2017).

\subsection{Interorganizational relationships and governance}

The construction industry has been described as suffering from inefficiencies in project delivery processes, materials management issues, cost performance, build-time overruns, and poor logistics ( $c f$. Fulford and Standing, 2014, Josephson and Saukkoriipi, 2007). One contributing factor to this description is that the construction industry is to a large extent built around temporary organizations and relationships, making long-term relationships difficult to achieve. The construction industry is further characterized by high levels of resource dependency (Donato et al., 2015, Penrose, 1959) and utilizes temporary network structures to ensure that this resource dependence can be met (Dubois and Gadde, 2000). 
As discussed by Dubois and Gadde (2002a) and Karrbom Gustavsson and Hallin (2015) this has led to construction project organizations often becoming disconnected from the company level and from the company perspective, difficult to manage throughout the construction process. In the following sections, interorganizational relationships in construction is further presented, followed by theories of governance, and control mechanisms and governance enablers.

\subsubsection{Interorganizational relationships in construction}

Dubois and Gadde (2002a) characterizes the network structure of the construction industry as two-fold; the industry has tight relationship networks within the projects, and a much looser network structure between parent companies and projects and between construction stakeholders. This means that within a project each stakeholder and activity is dependent on one another. Activities often have to be performed in sequence and if one activity is delayed, all the following activities will also be delayed (Dubois and Gadde, 2002a). Similarly, craftsmen need to have materials in place to perform their task and if deliveries are delayed the whole project can be delayed, leading to increased risks of cost overruns (Liu et al., 2015, Dubois and Gadde, 2002a). Thus, there is a need within the project environment for tight couplings between stakeholders in order to move the project forward. The couplings between the project and company levels are, however, loose in the sense that the construction projects are managed from the project organization and the parent company has little control over the everyday operations of the project (Dubois and Gadde, 2002a).

One of the main criticisms towards the construction industry is an unwillingness to change. Yet, as discussed by Kristiansen et al. (2005), the industry has experienced substantial changes through mergers and acquisitions. Large main contractors have grown and subcontractors, suppliers and builders' merchants have had to adopt their business models in order to ensure a continued workload (Kristiansen et al., 2005, Agapiou et al., 1998b). Subcontractors are specializing in certain business segments whereas builders' merchants and suppliers are entering international markets in order to enter new market segments and/or increase their market shares (Kristiansen et al., 2005, Agapiou et al., 1998b). The specialists provide asset specificity to those who do not possess the assets themselves (Williamson, 1979), and in doing so, they hold bargaining power against large contractors (Klein et al., 1978). At the same time, the specialized subcontractors and builders' merchants are also dependent on the large contractors for work, thus giving the larger stakeholders bargaining power due to size and position (Benson, 1975, p. 233). Overall, these tendencies have led to a fragmented industry where highly specialized companies are focused primarily on their own survival, making long-term cooperation amongst companies rare (cf. Agapiou et al., 1998b, Bankvall et al., 2010, Fernie and Tennant, 2013). This leads to a situation where adversarial contracts and arm's length contractual relations outweighs management of processes and relationships (Dubois and Gadde, 2002a, Fernie and Tennant, 2013). All in all these tendencies with near autonomous projects with multiple, specialized stakeholders and loose couplings to parent companies adds to the organizational 
complexity of construction projects as discussed by Kyrö et al. (2019) and Lavikka et al. (2019).

The fragmentation of the industry is, however, not only disadvantageous. Fernie et al. (2006) argues that the fragmented nature of the construction industry also allows for great flexibility at the project level, allowing for local adaptations and problem solving, but also as a means to handle the complex structure of the industry. At the same time, there is a call for the industry to move away from adversarial relationships towards more collaborative working practices and long-term commitment (Egan, 1998, Josephson and Saukkoriipi, 2007). However, the sought-after coordination and collaboration with channel partners do not necessarily occur in this environment if not all partners are striving towards the same supply chain goals (Fernie and Tennant, 2013, Saad et al., 2002).

\subsubsection{Governance}

The construction industry is dependent on multiple relationships in order to produce buildings and infrastructure. Social norms and exchanges can allow for these relationships to form a sort of self-governing system (Homans, 1958, Emerson, 1962), but reality often differs, making regulatory agreements needed. The process of setting up these regulations depends on the ruling governance strategy. Governance can be defined as:

The processes of interaction and decision-making among the actors involved in a collective problem that lead to creation, reinforcement or reproduction of social norms and institutions (Hufty, 2011, p. 405).

Governance can be used as a means to monitor, select, incentivize, or socialize a relationship amongst stakeholders with a general purpose of aligning interests and reduce information asymmetry (Boissinot and Paché, 2011). Governance strategy can thus be seen as the strategy for how social and economic coordination should take place within a specific area (Williamson, 1999, Jereb, 2017). Klakegg (2009, p. 4) point out that governance includes "developing visions and strategy, establishing frameworks for business, making decision and giving priority, empowering and maintaining follow-up of management, and confirming compliance with requirements". Boissinot and Paché (2011) translates this into three levels of governance; strategic, tactical and operational governance. The strategic level sets the long-term goals and guidelines of the governance solution, the tactical level deals with how the long-term goals can be achieved through regulations and incentives, and the operational governance sets the rules for the daily activities (Schmidt and Wilhelm, 2000, Boissinot and Paché, 2011). Additionally, stakeholders can have different drivers and needs from a governance strategy; private actors are driven by financial consideration whereas public authorities and companies are driven by providing public values (Caldwell et al., 2009, Teisman and Klijn, 2004). Friction and challenges between the public and the private will occur (Norrman and Henkow, 2014) so the different perspectives need to be consolidated into a common vision for the governance strategy to be successful (Klakegg, 2009). Finding the right governance enablers is thus important in facilitating decision making and operations when setting up a governance strategy (Jereb, 2017, Norrman and Henkow, 2014). 


\subsubsection{Control mechanisms and governance enablers}

Regardless of the governance strategy used, some control mechanisms must be in place to ensure that stakeholders adhere to the regulations and do not act opportunistically (Caldwell et al., 2009). Depending on the relationship between the stakeholders, both formal and informal control mechanisms can be suitable (Boissinot and Paché, 2011, Caldwell et al., 2009). Formal control is often applied as contractually stipulated regulations (Caldwell et al., 2009, Williamson, 2008) which often leads to an adversarial relationship between the governing, and the governed, entities in the relationship with a lower level of trust between them (Boissinot and Paché, 2011, Vivek et al., 2009). Vivek et al. (2009) found that contracts are often used as a control mechanism early on in a relationship but is not always the best alternative.

Choosing suitable control mechanisms is important, and the urge to "hedge one's bets" on multiple control mechanisms can often occur. It must however be recognized that applying multiple control mechanisms does not necessarily give added value in terms of more control and saved costs (Boissinot and Paché, 2011). To be able to set the "correct" control mechanisms, one must consider what type of relationship needs to governed, and what the relationship aims at in terms of business transactions (Caldwell et al., 2009, Williamson, 2008). According to Norrman and Henkow (2014, p. 755), traditional contracts and regulations may not cater to a more innovative relationship where responsibilities are divided in new ways. In these cases, it may be that control mechanisms needs to be more informal and based on "soft" values such as trust, commitment, and information exchange (Caldwell et al., 2009, Williamson, 2008). These are, however, not to be seen as an "easy way out" (Williamson, 2008). To get these control mechanisms to work properly is often time-consuming and resource demanding (Caldwell et al., 2009). The following three governance enablers describe commonly occurring business relationships and how to govern the relationships; governance as cost and opportunism maintenance, resource governance, and relational governance.

\section{Governance as cost and opportunism maintenance}

Governance as a function of cost and opportunism maintenance has its foundation in Transaction cost economics (TCE), stating that a relationship between parties will be based on a will to reduce the costs of transactions, and that if opportunities for an improved situation for one of the parties arise, that party will act on it without necessarily sharing that information with their counterparts (Wilkins and Ouchi, 1983, Williamson, 1979, Klein et al., 1978, Zajac and Olsen, 1993). Such opportunistic behaviour is considered to increase the cost of transactions, making trust amongst partners difficult to uphold (Boissinot and Paché, 2011). The goal of TCE and governance as cost and opportunism maintenance is to reduce the cost of transactions (Vivek et al., 2009, Williamson, 1979) which can often be achieved through vertical integration (Klein et al., 1978) (i.e. through joint ventures or through the acquisition of suppliers, clients, or competitors) or through the promotion of asset specificity (Williamson, 1985, Riordan and Williamson, 1985) (i.e. investments made to support a particular transaction). This latter strategy may however prove risky, as a partner in the relationship may discard the other if the asset specificity is of such a nature 
that the knowledge or technology can be acquired elsewhere or internalised (Williamson, 1991). To counteract opportunism the use of contracts and regulations are often preferred as governance enablers.

\section{Resource governance}

Resource governance is based on the Resource-based view of the firm (RBV) (Penrose, 1959) and focus on the acquisition, deployment and maintenance of resources (Vivek et al., 2009). Two basic principles in resource governance are authority and financial strength in interorganizational networks (Benson, 1975, p. 232). This implies that there is an element of competition to be found in the interorganizational relationships studied (Yuchtman and Seashore, 1967). According to Yuchtman and Seashore (1967), the availability of resources as well as the bargaining position of an organisation for those resources will affect interorganizational relationships within business relationships. Benson (1975, p. 233) elaborates on the structure of networks and that they can exist on two levels; internal networks and external links between networks, and within these two levels different approaches to gaining power, or bargaining position, can exist. This power can either be due to the function of the organisation, or the financial strength and centrality of the organisation (Benson, 1975, p. 233). At the same time, organisations can be found to seek stable and predictable interaction patterns with other organisations working in the same context (Pfeffer and Nowak, 1976, Pfeffer and Salancik, 1978). As such, RBV and the resource-based governance adds another dimension to TCE based governance by highlighting that firms can be governed by a joint need of developing resources and capabilities which can be accomplished through joint investments or ventures (Vivek et al., 2009, Winch, 2001).

\section{Relational governance}

As described by Vivek et al. (2009), relational governance is based on Exchange theory, building on trust amongst stakeholders in joint efforts of value creation. Trust, commitment, reliability, and interaction are seen as more important drivers for governance than transactions and opportunism (Morgan and Hunt, 1994, Dyer and Singh, 1998). Cook and Emerson (1978) highlights that mutual commitment can work as a constraint on opportunism, at least on an interpersonal level, due to social norms and natural affection. In all social networks there are a set of tacit norms that regulate behaviour, thus meaning that all interactions are based on an element of trust (Granovetter, 1985). An essential part of relationship governance is the mutual learning between partners and the development of dynamic capabilities, i.e. to establish a win-win situation from the relationship (Vivek et al., 2009, Teece, 2007, Winch, 2001). 


\section{Research design}

This chapter describes the research process and motivates the choice of research methods used as transparently as possible to allow the reader to judge the quality of the research. The individual research studies that make up the foundation of this dissertation is introduced and the research design of each is presented. The chapter is concluded with a discussion on the validity and reliability of the research.

\subsection{Research approach}

Arbnor and Bjerke (2009) and Gammelgaard (2004) argue that there are three methodological approaches to be used in logistics research i.e., the analytical approach, the systems approach, and the actors' approach. Gammelgaard (2004) describes how the analytical approach tries to decouple the studied phenomenon from time and value considerations to achieve general explanations, whereas the systems approach tries to provide models and maps of concrete logistics systems as logistics is considered too complex to derive causal-effect relations. Finally, the actors' approach builds on a contingency theory paradigm, saying that the contextual considerations of a firm affects how logistics is perceived in an organisation (Gammelgaard, 2004).

The methodological approach of this dissertation is a systems approach. According to Gammelgaard (2004, p. 481), the foundation of the systems approach is that the researcher creates "an understanding of a given part of the world" by identifying the systems' parts, links, goals and mechanisms, all with the aim of improving that system. The purpose of this dissertation is to propose a framework for developing construction logistics setups. As such, the systems approach is suitable as it allows for studying the interaction between different mechanisms (Arbnor and Bjerke, 2009) of CLS's. The system studied in this dissertation is the city development system encompassing the construction projects (i.e. the construction perspective) and the urban transport system (i.e. the city perspective).

Furthermore, one must distinguish between inductive, deductive, and abductive approaches. Bryman et al. (2019) states that the inductive approach starts from observing a phenomenon to inform theory whereas the deductive approach starts with theoretical hypothesis that are either confirmed or refuted by empirical data. This research has followed an abductive approach in which both inductive and deductive methods are combined in an iterative process to increase the understanding of a phenomenon and build knowledge (Kovács et al., 2005, Åsvoll, 2013). What this means is that in order to be able to explain the phenomenon, the researcher goes back and forth between empirical data and theory to enhance knowledge building (Dubois and Gadde, 2002b, Åsvoll, 2013). Dubois 
and Gadde (2002b) explains that this approach also allows the researcher to develop a framework by applying different theoretical fields to explain the studied phenomenon.

In this research, the author started the data collection processes of the empirical studies by first reviewing literature to inform the data collection. This review process was used to determine themes for observations, interviews, and Delphi surveys. Secondly, once data was collected, it was pre-analysed by searching for explanations for the mechanisms observed in the theoretical frameworks of the studies. If mechanisms could not be explained with the aid of the frameworks, additional literature was reviewed. If it was found that the data was not sufficient to give a full picture of the mechanisms, additional data was collected. This iterative approach can according to Dubois and Gadde (2002b) allow for a deeper understanding of both theory and the studied phenomenon.

The data was analysed by applying different theoretical explanations to the studied problems, i.e. by applying for instance, supply chain management, logistics management, city logistics, governance, and interorganizational relationship theories to fulfil the purposes of the studies that this dissertation builds on. The approach of "borrowing" other theories has become an important tool to advance the theorizing of logistics and supply chain management (Halldórsson et al., 2015, Halldórsson et al., 2007). In this dissertation, insights from the fields third-party logistics and city logistics have been used to analyse and create understanding for the mechanisms of construction logistics and CLS's. This helps in adding to existing theory (Meredith, 1993), and in this dissertation, to advance construction logistics research.

\subsection{Choice of research methods}

Research can be descriptive, exploratory, and/or explanatory (Karlsson, 2009, Yin, 2014). Descriptive research aims at describing a phenomenon (Bertrand and Fransoo, 2002, Karlsson, 2009). Explorative research on the other hand aims at finding research gaps and pose new research questions (Voss et al., 2002) and explanatory research aims at explaining causal relationships to increase understanding of why a phenomenon acts the way it does (Yin, 2014). Bertrand and Fransoo (2002), adds to this by discussing normative research, consisting of either exploratory or explanatory research. The goal of normative research is, according to Bertrand and Fransoo (2002), to develop policies, strategies, and/or actions that can be implemented or tested to improve current situations found in literature.

This research project is exploratory and normative, investigating how CLS's are, and can be, used in city development to provide directions for future research. As such, it is also seeking to advance knowledge on CLS's, i.e. it is theory building (Voss et al., 2002, Meredith, 2001). According to Wacker (1998) and Meredith (2001), theory building research is important in that it can add new insights as to how real world problems can be tackled. Theory building research can be divided into two categories, i.e. analytical conceptual research and empirical research (Wacker, 1998, Meredith, 1993). Wacker (1998) states that the purpose of analytical conceptual research is to add new insights into traditional problems by reviewing literature. From this, interpretations can be derived to 
add insights and develop theories through the logical development of relationships between different concepts into a comprehensive theory (Wacker, 1998, Meredith, 1993). However, to cement the theory building effort, both Wacker (1998) and Meredith (2001) highlight that the novel theories must be tested and validated in a real world context from where the insights were derived, or in a similar context to test the new theory. Meredith (1998), argue that to achieve this and to truly understand a phenomenon, it has to be studied through empirical research, preferably case and field research. This is further supported by Eisenhardt (1989) and Voss et al. (2002) who argue for the use of case study approaches to investigate novel phenomena as part of the theory building process.

This dissertation consists of both analytical conceptual research and empirical research conducted in six studies. The analytical conceptual research consists of a systematic literature review and the empirical part of the research consists of four case studies and one Delphi study. The research process of this dissertation is summarised in Table 1. More on how the studies were carried out is presented in the following chapter. 
Table 1 - Research process

\begin{tabular}{|c|c|c|c|c|c|c|}
\hline & $\begin{array}{l}\text { Study 1: } \\
\text { The } \\
\text { literature } \\
\text { review }\end{array}$ & $\begin{array}{l}\text { Study 2: } \\
\text { The Urban } \\
\text { development } \\
\text { project }\end{array}$ & $\begin{array}{l}\text { Study 3: } \\
\text { The office } \\
\text { project }\end{array}$ & $\begin{array}{l}\text { Study 4: } \\
\text { Multiple } \\
\text { CLS's }\end{array}$ & $\begin{array}{l}\text { Study 5: } \\
\text { Performance } \\
\text { metrics }\end{array}$ & $\begin{array}{l}\text { Study 6: } \\
\text { Hospitals }\end{array}$ \\
\hline Time frame & $2015-2018$ & $2015-2020$ & $2016-2020$ & $2017-2020$ & $2019-2020$ & $2018-2020$ \\
\hline Focus & $\begin{array}{l}\text { SCM, } \\
\text { logistics and } \\
\text { third-party } \\
\text { logistics in } \\
\text { construction }\end{array}$ & $\begin{array}{l}\text { The } \\
\text { implementation } \\
\text { and utilization } \\
\text { of a CLC in } \\
\text { Stockholm }\end{array}$ & $\begin{array}{l}\text { Effects of } \\
\text { implementing } \\
\text { a CLC in a } \\
\text { large-scale } \\
\text { office project }\end{array}$ & $\begin{array}{l}\text { Categorization } \\
\text { of CLS's and } \\
\text { their services }\end{array}$ & $\begin{array}{l}\text { Performance } \\
\text { metrics for } \\
\text { evaluating } \\
\text { construction } \\
\text { logistics }\end{array}$ & $\begin{array}{l}\text { Categorization } \\
\text { and design of } \\
\text { CLS's }\end{array}$ \\
\hline $\begin{array}{l}\text { Unit of } \\
\text { analysis }\end{array}$ & $\begin{array}{l}\text { The } \\
\text { individual } \\
\text { articles }\end{array}$ & The CLS & The CLS & The CLS's & $\begin{array}{l}\text { The } \\
\text { performance } \\
\text { metrics }\end{array}$ & The CLS's \\
\hline $\begin{array}{l}\text { Research } \\
\text { approach }\end{array}$ & Descriptive & Exploratory & Exploratory & Exploratory & Descriptive & Exploratory \\
\hline $\begin{array}{l}\text { Methods: } \\
\text { Research } \\
\text { design }\end{array}$ & $\begin{array}{l}\text { Systematic } \\
\text { literature } \\
\text { review }\end{array}$ & $\begin{array}{l}\text { One in-depth } \\
\text { single case } \\
\text { study, one } \\
\text { embedded } \\
\text { single case } \\
\text { study, } \\
\text { conceptual } \\
\text { modelling }\end{array}$ & $\begin{array}{l}\text { Single case } \\
\text { study }\end{array}$ & $\begin{array}{l}\text { Multiple case } \\
\text { study }\end{array}$ & $\begin{array}{l}\text { Four iteration } \\
\text { Delphi design }\end{array}$ & $\begin{array}{l}\text { Multiple case } \\
\text { study }\end{array}$ \\
\hline $\begin{array}{l}\text { Data } \\
\text { collection }\end{array}$ & $\begin{array}{l}\text { Peer- } \\
\text { reviewed } \\
\text { articles from } \\
\text { Scopus and } \\
\text { Emerald } \\
\text { Insight }\end{array}$ & $\begin{array}{l}\text { Semi- } \\
\text { structured } \\
\text { interviews, } \\
\text { observations, } \\
\text { project } \\
\text { documentation }\end{array}$ & $\begin{array}{l}\text { Semi- } \\
\text { structured } \\
\text { interviews, } \\
\text { observations, } \\
\text { project } \\
\text { documentation }\end{array}$ & $\begin{array}{l}\text { Semi- } \\
\text { structured } \\
\text { interviews, } \\
\text { observations, } \\
\text { project } \\
\text { documentation }\end{array}$ & Surveys & $\begin{array}{l}\text { Semi- } \\
\text { structured } \\
\text { interviews, } \\
\text { observations, } \\
\text { project } \\
\text { documentation }\end{array}$ \\
\hline Analysis & $\begin{array}{l}\text { Thematic } \\
\text { analysis, } \\
\text { content } \\
\text { analysis, } \\
\text { descriptive } \\
\text { analysis }\end{array}$ & $\begin{array}{l}\text { Systematic } \\
\text { combining, } \\
\text { within and } \\
\text { cross-case } \\
\text { analysis }\end{array}$ & $\begin{array}{l}\text { Systematic } \\
\text { combining }\end{array}$ & $\begin{array}{l}\text { Systematic } \\
\text { combining, } \\
\text { within and } \\
\text { cross-case } \\
\text { analysis }\end{array}$ & $\begin{array}{l}\text { Systematic } \\
\text { combining, } \\
\text { mean rank of } \\
\text { PM's and } \\
\text { clustering of } \\
\text { stakeholder } \\
\text { perspectives } \\
\text { through } \\
\text { statistical } \\
\text { analysis }\end{array}$ & $\begin{array}{l}\text { Systematic } \\
\text { combining, } \\
\text { within and } \\
\text { cross-case } \\
\text { analysis }\end{array}$ \\
\hline Contribution & $\begin{array}{l}\text { Background } \\
\text { understanding } \\
\text { of the } \\
\text { construction } \\
\text { industry and } \\
\text { construction } \\
\text { logistics }\end{array}$ & $\begin{array}{l}\text { The } \\
\text { implementation } \\
\text { process of a } \\
\text { CLC, the } \\
\text { utilization of a } \\
\text { CLC, effects of } \\
\text { implementing a } \\
\text { CLC }\end{array}$ & $\begin{array}{l}\text { The effects of } \\
\text { implementing } \\
\text { a CLC }\end{array}$ & $\begin{array}{l}\text { Logistics } \\
\text { services of } \\
\text { CLS's and } \\
\text { classification } \\
\text { of CLS } \\
\text { services }\end{array}$ & $\begin{array}{l}\text { Understanding } \\
\text { of what to } \\
\text { measure in } \\
\text { construction } \\
\text { logistics }\end{array}$ & $\begin{array}{l}\text { The design and } \\
\text { implementation } \\
\text { process of } \\
\text { CLS's, } \\
\text { classification } \\
\text { of CLS } \\
\text { services }\end{array}$ \\
\hline Paper(s) & 1 & $\begin{array}{l}2,5 \\
\text { (contr. to 3) }\end{array}$ & $\begin{array}{l}4 \\
\text { (contr. to 3) }\end{array}$ & 3 & 6 & $\begin{array}{l}7 \\
\text { (contr. to 3) }\end{array}$ \\
\hline
\end{tabular}




\subsubsection{Literature reviews}

A literature review is conducted in order to obtain knowledge about research gaps, analyse current state of knowledge in a particular field, and to synthesize the findings to produce new knowledge (Jesson et al., 2011, Meredith, 1993). Depending on the goal of the literature reviews, different review approaches can be adopted. According to Jesson et al. (2011), a traditional review can be said to be a gap analysis whereas a conceptual review aims to synthesize areas of conceptual knowledge to further the understanding of a certain issue. The systematic review on the other hand, applies more rigorous methodology to the review process, and can thus give greater insight into a problem area (Jesson et al., 2011).

All literature reviews should be undertaken with a critical approach, meaning that regardless of whether it is a traditional or systematic review, it should be rigorous and transparent enough so that the arguments made can be backed by evidence (Jesson et al., 2011). To provide this rigour, the following approach based on Seuring and Müller (2008) and Durach et al. (2017) can be followed:

1. Define the purpose of the literature review; is it an aid in developing research questions, an analytical framework, or is the main aim to produce conceptual insights from the literature?

2. Set the search strategy and criteria; what databases are to be used, what types of material is included and excluded from the review, what search phrases are of interest, what time period should be included in the material searches?

3. Set the analysis model; is the goal to perform a thematic analysis, a content analysis, or a structural analysis?

This research project contains a systematic literature review (paper 1), five conceptual literature reviews (papers 2, 3, 4, 5, and 7), and one traditional literature review (paper 6). The research designs of the literature reviews are presented below.

\section{Purpose of literature reviews}

The systematic literature review (paper 1) aimed at synthesising current knowledge of the state of SCM, logistics and TPL in construction and give new understanding to why the full potential of the concepts are difficult to reach in construction.

The conceptual literature reviews and the traditional review (papers 2 - 7) had the purpose of informing the research and to develop analytical frameworks and/or theoretic lenses to analyse the empirical findings through.

\section{Search strategies and criteria}

All the literature reviews had broad search scopes with minimum exclusion criteria set. The exception to this was paper 1, where only peer-reviewed articles from academic journals were included in the searches. No exclusions were made based on age of the sources for either of the reviews.

The databases used for the searches were SCOPUS (www.scopus.com), Emerald Insight (www.emeraldinsight.com) and Google Scholar (www.scholar.google.com). 
Depending on the focus of the study, different search phrases and keywords were used to match the purpose of the study.

\section{Analysis}

All the reviews were analysed with thematic analysis as well as content analysis. The first step in this is the thematic analysis in which the articles collected were carefully read to get an overview of the material and assign initial themes to classify the articles. Seuring and Gold (2012) highlights the necessity of defining the themes based on theory, as this helps in ensuring the validity of the review. As the reviews progressed, the themes were revised to better suit the material studied. This approach allowed for flexibility while still being a theory-based classification. According to Seuring and Gold (2012), this iterative process can enhance the validity of the study as the analysis is based on existing theory adjusted to the specific sample.

The next step is the content analysis in which the collected material was analysed more indepth. In this step, the material was analysed in an inductive manner within the themes identified in the previous step (Evangelista and Durst, 2015, Seuring and Müller, 2008). Articles are read thoroughly with the purpose of extracting the important findings from each of the articles in the sample. As the results of the reviews were assembled, the findings from the themes were grouped together to form descriptive representations of the areas under scrutiny. This type of synthesis can be likened to synthesis by interpretation described by Rousseau et al. (2008, p. 496), with the goal to translate key interpretations from one study to another. 


\section{Summary of literature review research design}

Table 2 summarises the literature reviews performed as part of this research project.

Table 2 - Research design of the papers' literature reviews

\begin{tabular}{|c|c|c|c|c|c|c|}
\hline $\begin{array}{l}\bar{\Xi} \\
\stackrel{\Xi}{\Xi}\end{array}$ & 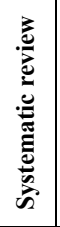 & 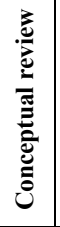 & 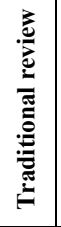 & Search strategy & Search strings & Analysis \\
\hline 1 & $\mathrm{Y}$ & & & $\begin{array}{l}\text { Published, peer-reviewed } \\
\text { scientific journal articles were } \\
\text { searched for in Emerald Insight } \\
\text { (www.emeraldinsight.com) and } \\
\text { SCOPUS. Combinations of the } \\
\text { keywords were searched for in } \\
\text { titles, abstracts and keywords. } \\
\text { No exclusion criteria regarding } \\
\text { timeframe of publication. }\end{array}$ & $\begin{array}{l}\text { Keyword searches for } \\
\text { construction, supply chain } \\
\text { management, logistics, and } \\
\text { third-party logistics. }\end{array}$ & $\begin{array}{l}\text { Thematic analysis, content } \\
\text { analysis, and descriptive } \\
\text { analysis. }\end{array}$ \\
\hline 2 & & $\mathrm{Y}$ & & $\begin{array}{l}\text { Broad search using SCOPUS } \\
\text { and Google Scholar. } \\
\text { No exclusion criteria set. }\end{array}$ & $\begin{array}{l}\text { Keyword searches for } \\
\text { construction logistics, third- } \\
\text { party logistics, construction } \\
\text { logistics centres, governance, } \\
\text { governance mechanisms, and } \\
\text { combinations of the } \\
\text { keywords. }\end{array}$ & $\begin{array}{l}\text { Thematic analysis and } \\
\text { content analysis. } \\
\text { Conceptualizing findings } \\
\text { into an analytical } \\
\text { framework. }\end{array}$ \\
\hline 3 & & $\mathrm{Y}$ & & $\begin{array}{l}\text { Broad search using SCOPUS } \\
\text { and Google Scholar. } \\
\text { No exclusion criteria set. }\end{array}$ & $\begin{array}{l}\text { Keyword searches for } \\
\text { construction logistics, third- } \\
\text { party logistics, construction } \\
\text { logistics centres, governance, } \\
\text { governance mechanisms. }\end{array}$ & $\begin{array}{l}\text { Thematic analysis and } \\
\text { content analysis. } \\
\text { Conceptualizing findings } \\
\text { into an analytical } \\
\text { framework. }\end{array}$ \\
\hline 4 & & $\mathrm{Y}$ & & $\begin{array}{l}\text { Broad search using SCOPUS } \\
\text { and Google Scholar. } \\
\text { No exclusion criteria set. }\end{array}$ & $\begin{array}{l}\text { Keyword searches for } \\
\text { construction logistics, third- } \\
\text { party logistics, construction, } \\
\text { servitization. }\end{array}$ & $\begin{array}{l}\text { Thematic analysis and } \\
\text { content analysis. } \\
\text { Conceptualizing findings } \\
\text { into an analytical } \\
\text { framework. }\end{array}$ \\
\hline 5 & & $\mathrm{Y}$ & & $\begin{array}{l}\text { Broad search using SCOPUS } \\
\text { and Google Scholar. } \\
\text { No exclusion criteria set. }\end{array}$ & $\begin{array}{l}\text { Keyword searches for } \\
\text { construction logistics, city } \\
\text { logistics, activity-based cost } \\
\text { modelling, utilization, and } \\
\text { combinations of the } \\
\text { keywords. }\end{array}$ & $\begin{array}{l}\text { Thematic analysis and } \\
\text { content analysis. } \\
\text { Conceptualizing findings } \\
\text { into an analysis model. }\end{array}$ \\
\hline 6 & & & $\mathrm{Y}$ & $\begin{array}{l}\text { Broad search using SCOPUS } \\
\text { and Google Scholar. } \\
\text { No exclusion criteria set. }\end{array}$ & $\begin{array}{l}\text { Keyword searches for } \\
\text { construction logistics, third- } \\
\text { party logistics, logistics } \\
\text { management, performance, } \\
\text { performance metrics, } \\
\text { performance measurements } \\
\text { and combinations of the } \\
\text { keywords. }\end{array}$ & $\begin{array}{l}\text { Thematic analysis and } \\
\text { content analysis to inform } \\
\text { the Delphi study's second } \\
\text { round. }\end{array}$ \\
\hline 7 & & $\mathrm{Y}$ & & $\begin{array}{l}\text { Broad search using SCOPUS } \\
\text { and Google Scholar. } \\
\text { No exclusion criteria set. }\end{array}$ & $\begin{array}{l}\text { Keyword searches for } \\
\text { construction logistics, third- } \\
\text { party logistics, and city } \\
\text { logistics. }\end{array}$ & $\begin{array}{l}\text { Thematic analysis and } \\
\text { content analysis. } \\
\text { Conceptualizing findings } \\
\text { into an analytical } \\
\text { framework. }\end{array}$ \\
\hline
\end{tabular}




\subsubsection{Case studies}

In order to develop relevant, valid, and testable new theories, Eisenhardt (1989) argues that previous literature needs to be combined with new empirical evidence. To get a deeper understanding of a phenomenon, it thus needs to be thoroughly observed in its own context (Eisenhardt, 1989, Yin, 2014). Going out into the field and investigating a phenomenon in its context is called case study research and it has become a well-established research methodology for obtaining empirical results within qualitative research (Yin, 2014). In part this can be explained by case study research being able to build deep, context-dependent knowledge in a way that "heavy" theories and quantitative knowledge cannot (Flyvbjerg, 2006), answering research questions such as how and why (Yin, 2014). Such research questions can help the research both to develop and test theory (Voss et al., 2002).

Yin (2014) proposes that there are four main types of case study designs; single case, embedded single case, multiple case and embedded multiple case designs. Single case research designs are suitable to choose when the case studied is either critical, unusual, revelatory, common or longitudinal, i.e. it is novel due to the scarcity of similar cases, it is common enough to represent similar cases in a good way, or the researcher has the opportunity to follow the case over a long time-period (Voss et al., 2002, Yin, 2014). Having an embedded single case research design builds on a similar rationale but allows the researcher to investigate multiple units of analysis in the same main case (Yin, 2014). Multiple case study designs on the other hand allows the researcher the opportunity to widen the analysis to cross-case analysis, searching for patterns across multiple examples of a phenomenon (Voss et al., 2002, Eisenhardt, 1989). The main difference between single case and multiple research designs lies in the depth a researcher can achieve in each case where single case study designs allow for deeper understanding, and multiple case study designs allows for breadth (Voss et al., 2002).

To conduct a rigorous case study, the following steps needs to be undertaken according to Eisenhardt (1989), Voss et al. (2002) and Yin (2014):

1. Case selection; is the research questions such that a single case study or a multiple case study is best? What type of access is there to the case study company/organisation? What type of data is required? What type of data collection methods will be used?

2. Preparation; review literature to learn about the phenomenon, prepare case study protocols and interview guides.

3. Data collection; collect data through the chosen data collection methods. Document the data collection and store in case study database.

4. Analysis; depending on the case selection, can cross-case analysis and in-depth incase analysis be performed?

The empirical part of this dissertation is primarily grounded in five case studies;

1. Single case study at an urban development project (paper 2)

2. Single case study at an office project (paper 4) 
3. Embedded single case study at an urban development project (paper 5)

4. Multiple case study covering multiple types of projects and CLS's (paper 3)

5. Multiple case study focused on CLS's in hospital construction projects (paper 7)

The single case studies allowed for depth in the in-case analysis whereas the multiple case studies also gave the opportunity to analyse different units and find patterns through crosscase analysis. Utilizing both single, embedded, and multiple case studies gives breadth as well as depth in the findings of this dissertation. In the following sections, the research design for these case studies are presented following the above presented structure.

\section{Case selection}

By taking an information-oriented stance in case selection, a researcher may be able to increase the possibility of obtaining as much valuable information as possible (Flyvbjerg, 2006). Voss et al. (2002) highlights that it is important to consider the variables that define the population and to hold these constant across the sample when selecting cases.

In the beginning of this doctoral project, CLS's were not that common. As such, it was reasonable to choose single case research designs to gather as much insight as possible into this phenomenon (Yin, 2014). The first two case studies (reported in papers 2 and 4) where thus chosen to be single case studies. Both cases were offered as suitable studies through collaboration with the municipality of Stockholm and a construction management company whom both were outspokenly open to research collaborations. Furthermore, both studies fulfilled the following three criteria; (1) the projects were large-scale projects in dense urban areas (urban development project and large-scale office project respectively), (2) the projects had an up-and-running CLS, and (3) the researchers could be given access to respondents for interviews, project documentation, as well as opportunities to make observations as part of the data collection.

The embedded single case study (reported in paper 5) was a continuation of the single case study reported in paper 2 . Through the on-going collaboration with the municipality of Stockholm, there was an opportunity to evaluate the utilization of a CLS through invoice data. Nine construction projects were selected as embedded units of analysis in the case study, based on information obtained on the construction projects duration and completion. This was matched against the invoice data to analyse the utilization of the CLS.

In the first of the two multiple case studies (reported in paper 3), the cases were selected through ongoing research projects and through a snowballing technique (Biernacki and Waldorf, 1981) where respondents were asked during interviews if they had information on other CLS's as well. Thirteen cases were selected that all fulfilled the criteria of being (1) CLS's involving at least two actors, (2) being dedicated to construction only, and 3) being implemented in Sweden.

The selection of the cases for the second multiple case study (paper 7) followed a similar pattern of case selection where ongoing research projects and collaborations gave insights into possible cases. Six cases that fulfilled the criteria of (1) being hospital construction projects, (2) utilizing a CLS, and (3) being operational in a Nordic context were selected. 


\section{Preparation}

All five case studies followed similar preparation phases; literature was reviewed to inform the data collection and form the basis for analysis. Findings from the literature reviews were conceptualized into research guides that were used during interviews and complemented with documentation. Ahead of interviews and/or observations, the researchers discussed the aim of the visits.

\section{Data collection}

To gather data, three primary data collection methods were used. Firstly, semi-structured interviews with key respondents were conducted in all case studies. Interviews allow a broadening, as well as a deepening, of knowledge regarding the topic under scrutiny as the respondents can give a wider insight into the problem as well as going deeper into explaining why something is the way it is (Bryman et al., 2019). The choice of conducting semi-structured interviews was to reduce the dependency on the interview guide and let the conversation flow freely (Yin, 2014).

Secondly, to get an understanding of the cases and the setups used, on-site observations were carried out in all case studies. Yin (2014) argue that observations give the researcher a good insight into the context of the case. The observations were often carried out in conjunction with the interviews, allowing the conversation to carry on on-site as well, away from meeting rooms. This can according to Bryman et al. (2019) strengthen the evidence from the interviews in that the researcher is in the respondents' turf, allowing them to feel more comfortable.

The final data collection method used was reviewing documentation and archival records. According to Yin (2014), documentation and archival records have strengths in that they are stable and can be reviewed repeatedly, while at the same time being unobtrusive, i.e. not created for the case study itself. They can, however, be difficult to obtain (Yin, 2014). In all the conducted case studies however, the researchers were granted access to documentation as well as archival records. In the office project case study for instance, the researchers had access to project planning and business intelligent systems, and in the embedded case study, three years' worth of invoice data was accessed by the researchers to evaluate the utilization of the CLC. In the embedded single case study, the archival records were the primary source of information to be analysed. In the other case studies, documentation has primarily been a source for enhancing the understanding of the cases and their inherent mechanisms.

The use of multiple data collection methods and sources in the case studies has helped to strengthen the validity and reliability of the studies through data triangulation (Voss, 2009, Yin, 2014).

\section{Analysis}

The two single case studies were analysed using analytical and conceptual reasoning based on the results from the literature reviews and the case studies (Wacker, 1998). Meredith (1993) and Wacker (1998) argue that in conceptual research approaches, analytical and 
empirical methodologies are typically combined to provide new insights into a new phenomenon through logical reasoning. The case study findings are thus contrasted against the findings of the literature reviews. By doing so, the analysis' adds new insights into how construction projects are affected by CLS's and how these solutions can affect costs and construction performance (Wacker, 1998, Meredith, 1993).

The same approach was used in the embedded single case study where the gathered data was analysed by linking the case study findings to current practices in construction logistics and city logistics (Wacker, 1998), searching for logical explanations for why the utilization of the CLC differed between projects (Eisenhardt, 1989). The case analysis was contrasted against city logistics research to find similarities and differences in the implementation of CLC's and UCC's to draw conclusions on how to increase the utilization rate of CLC's.

The multiple case studies were analysed using both within case analysis and cross-case analysis, following the grouping process suggested by Kluge (2000). The within case analysis sought to find logical explanations for how, why, and when CLS's were used within the cases (Eisenhardt, 1989, Stank et al., 2017). The cross-case analysis sought to identify similarities and differences amongst them (Eisenhardt, 1989) to identify the mechanisms of the specific CLS's that lead to a certain performance outcome. In the multiple case study presented in paper 7 , the within and cross-case analyses were also contrasted against the current state of city logistics knowledge in order to suggest how to categorize construction logistics solutions (Wacker, 1998). That categorization of CLS's was then used to propose a design process for CLS's. 


\section{Summary of case study research design}

Table 3 summarises the case studies performed as part of this research project.

Table 3 - Research design of the case studies

\begin{tabular}{|c|c|c|c|c|c|c|c|c|c|}
\hline ఏँّ & 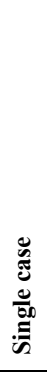 & 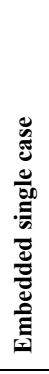 & 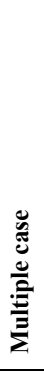 & 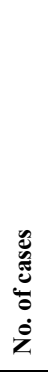 & Case selection & Data collected & 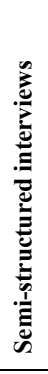 & 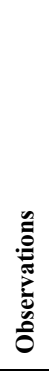 & 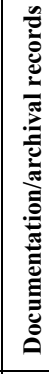 \\
\hline 2 & $\mathrm{Y}$ & & & 1 & $\begin{array}{l}\text { Case: Implementation of a CLC } \\
\text { in a large urban development } \\
\text { project in Stockholm, Sweden. } \\
\text { The case is one of the largest } \\
\text { and longest running } \\
\text { development projects in } \\
\text { Sweden utilizing a CLC and is } \\
\text { thus a good example for } \\
\text { evaluating CLC } \\
\text { implementation }\end{array}$ & $\begin{array}{l}\text { Process descriptions of the CLC } \\
\text { delivery process. } \\
\text { Stakeholders experiences of the } \\
\text { implementation of the CLC. } \\
\text { Governance mechanisms of the } \\
\text { CLC. } \\
\text { Goal of the CLC. } \\
\text { Organisational belonging of the } \\
\text { CLC. }\end{array}$ & 11 & 7 & $\mathrm{Y}$ \\
\hline 3 & & & $\mathrm{Y}$ & 13 & $\begin{array}{l}\text { Case: Different CLS's and the } \\
\text { services that the setups contain. } \\
\text { Cases with varying contexts in } \\
\text { terms of construction project, } \\
\text { CLS design, and regulatory } \\
\text { measures. All cases located in } \\
\text { Sweden. }\end{array}$ & $\begin{array}{l}\text { Process description of the CLS's. } \\
\text { Building blocks of the CLS's. } \\
\text { Goal for CLS's. } \\
\text { Organisational belonging of the } \\
\text { CLS's. }\end{array}$ & 55 & 21 & $\mathrm{Y}$ \\
\hline 4 & $\mathrm{Y}$ & & & 1 & $\begin{array}{l}\text { Case: Effects of utilizing a } \\
\text { CLC in a large-scale office } \\
\text { project in Solna, Sweden. } \\
\text { Case is located in a dense urban } \\
\text { area, thus in need of CLS. } \\
\text { Construction company } \\
\text { developed and implemented } \\
\text { CLC as part of own business, } \\
\text { thus making the case interesting } \\
\text { to evaluate from an } \\
\text { organisational point-of-view. }\end{array}$ & $\begin{array}{l}\text { Process description of the CLC } \\
\text { delivery process. } \\
\text { Delivery statistics. }\end{array}$ & 8 & 3 & $\mathrm{Y}$ \\
\hline 5 & & $\mathrm{Y}$ & & 9 & $\begin{array}{l}\text { Case: Utilization of a CLC in a } \\
\text { large urban development } \\
\text { project in Stockholm, Sweden. } \\
\text { The main case is the same as in } \\
\text { paper } 1 . \text { The nine embedded } \\
\text { cases are construction projects } \\
\text { that differ in size and scope, } \\
\text { allowing for reflections on the } \\
\text { utilization of the CLC. }\end{array}$ & $\begin{array}{l}\text { Process description of the CLC } \\
\text { delivery process. } \\
\text { Delivery statistics. } \\
\text { CLC utilization data. }\end{array}$ & 17 & 7 & $\mathrm{Y}$ \\
\hline 7 & & & $\mathrm{Y}$ & 6 & $\begin{array}{l}\text { Case: The design and } \\
\text { implementation process of } \\
\text { CLS's. } \\
\text { Cases with varying contexts in } \\
\text { terms of CLS design and } \\
\text { regulatory measures. All cases } \\
\text { are hospital construction } \\
\text { projects and located in the } \\
\text { Nordic countries. }\end{array}$ & $\begin{array}{l}\text { Process description of the CLS's. } \\
\text { Building blocks of the CLS's. } \\
\text { Regulatory measures of the } \\
\text { CLS's. } \\
\text { Goal of the CLS's. } \\
\text { Organisational belonging of the } \\
\text { CLS's. }\end{array}$ & 11 & 6 & $\mathrm{Y}$ \\
\hline
\end{tabular}




\subsubsection{Delphi studies}

The Delphi method is a technique in which multiple stakeholders contribute with their expertise to solve a problem or provide their judgement on a particular topic (Murry and Hammons, 1995). The goal of Delphi studies is according to Hallowell and Gambatese (2010) to reach consensus on the topic under scrutiny through an iterative survey process. Three common features of Delphi studies are (1) anonymous group interactions and responses, (2) multiple iterations of data collection with researcher-controlled statistical group responses and feedback, and (3) presentation of statistical group responses (Murry and Hammons, 1995). To design a Delphi study, the following four steps have to be addressed according to Hallowell and Gambatese (2010) and Sourani and Sohail (2015):

1. Respondent selection; it is important to select knowledgeable respondents against a set of predefined criteria that qualifies them as experts within the field.

2. Set the consensus criteria; this is one of the more difficult aspects of the Delphi process as consensus criteria are set based on the purpose and scope of the individual study.

3. Design the data collection; how will the surveys be distributed, how many iterations should there be, should the survey factors be randomized between the iterations to reduce the risk of respondents remembering previous patterns of response?

4. Define the analysis model; what is interesting to analyse, should the analysis be solely statistical or include content analysis, what patterns may be interesting to search for?

\section{Respondent selection}

This Delphi study reached out to main contractors, suppliers, TPL providers, consultants, municipalities, waste management companies, and academics. The respondent criteria set (Hallowell and Gambatese, 2010, Yin, 2014) for this study were that the respondents (1) should have experience from the housebuilding sector, (2) should have experience from construction logistics and/or TPL, and (3) they should together represent the different stakeholder perspectives. In total 87 potential respondents fulfilling the criteria were shortlisted and 34 respondents from Sweden, Finland, Norway, Netherlands, Great Britain, and Australia were engaged to participate in the study.

\section{Consensus criteria}

The process should continue until consensus has been reached according to a predetermined consensus target (Hallowell and Gambatese, 2010, Sourani and Sohail, 2015). Possible consensus criteria are:

- Mean values (Sourani and Sohail, 2015)

- Absolute deviation (Hallowell and Gambatese, 2010)

- Percentages of respondents agreeing on certain answers (Sourani and Sohail, 2015)

For the ranking purpose of the Delphi study, mean ranks were used as consensus criteria. The mean ranks were calculated based on Kruskal-Wallis non-parametric one-way ANOVA in which two or more independent samples of equal or different sample sizes are 
compared (Gauthier and Hawley, 2015). If the values are tied, they are assigned the average of the ranks they would have received if they had not been tied (Gauthier and Hawley, 2015).

\section{Data collection}

The Delphi surveys were distributed electronically with individual links for each of the respondents, using an online survey software. Data was compiled and analysed using a spreadsheet software. The respondents' answers were managed anonymously and only the research project group knew whom the participants in the study were in order to minimize the risk of peer pressure within the stakeholder groups.

The study consisted of four iterations. The first iteration was an open-ended survey asking respondents to submit 5-10 performance metrics (PMs) for each of the construction logistics subprocesses; delivery process, on-site logistics, and coordination between the two. The submitted PMs were contrasted against PMs found in logistics literature by the researchers to see if there were overlaps or missing PMs.

The second iteration supplied the respondents with a list of construction logistics PMs consisting of the PMs submitted previously, complemented with PMs found in literature. This iteration asked the respondents to select the top ten most relevant PMs per subprocess from the supplied list.

The third and fourth iterations asked the respondents to select and rank the top five PMs per subprocess based on the PMs selected in the second iteration.

\section{Analysis}

The main part of the analysis was based on the ranked lists of construction logistics PMs from the Delphi process and how they changed over the iterations. The ranked lists were contrasted against literature to see if there was a gap between what the construction industry and theory consider as valid logistics PMs. The study also analysed if different stakeholder groups perceive and value PMs differently.

\subsection{Research quality}

Regardless of the type of research conducted, producing results that can be trusted to be valid and reliable is of great importance (Karlsson, 2009, Eisenhardt, 1989). This means that the researcher must be transparent regarding how the research has been conducted and how the researcher has addressed the issues of validity and reliability (Karlsson, 2009, Yin, 2014). The following sections discuss how to ensure research quality for the chosen research methods, and how this has been tackled in the studies of this dissertation.

\subsubsection{Research quality in literature reviews}

All papers in this research have literature reviews as part of their research designs. This chapter discusses how research quality has been ensured. 
Paper 1 is a content analysis-based literature review with a systematic approach, and in systematic reviews, Seuring and Gold (2012) and Rousseau et al. (2008) highlight the importance of showing the methodology used and how it has been followed to enhance validity and reliability of the review. Seuring and Gold (2012, p. 552) proposes four milestones for conducting content analysis-based literature reviews; material collection, descriptive analysis, pattern of analytic categories, and material evaluation and research quality (see Table 4). Following Table 4, the milestone model is used to discuss how and if research quality has been ensured.

Table 4 - Content analysis milestones (based on Seuring and Gold, 2012)

\begin{tabular}{|c|c|}
\hline Milestones & Critical considerations \\
\hline Material collection & $\begin{array}{l}\text { Defining and delimiting material } \\
\text { Specifying the topic: suitable keywords for database search } \\
\text { Scope of journals: selective or general } \\
\text { Defining unit of analysis } \\
\text { Consistent throughout the analysis } \\
\text { Mind bias from similar papers by same group of authors }\end{array}$ \\
\hline Descriptive analysis & $\begin{array}{l}\text { Distribution over time period } \\
\text { Distribution over publication outlets (particularly journals) }\end{array}$ \\
\hline Pattern of analytic categories & $\begin{array}{l}\text { Deductive versus inductive category building (corresponds to theoretically } \\
\text { grounded versus exploratory research approaches) } \\
\text { Default two-step approach: } 1 \text {. Deductive category building, } 2 \text {. Iterative cycles } \\
\text { of inductive category refinement while coding }\end{array}$ \\
\hline $\begin{array}{l}\text { Material evaluation and research } \\
\text { quality }\end{array}$ & $\begin{array}{l}\text { Need of iterative coding cycles in case of inductive category refinements or } \\
\text { deficient inter-rater reliability } \\
\text { Transparency and objectivity (clear coding rules from outset) } \\
\text { Reliability (particularly inter-rater reliability): at least two coders, cross- } \\
\text { coding for testing agreement or aligning mental schemes } \\
\text { Validity (theoretical foundation, specific inductive refinements) }\end{array}$ \\
\hline
\end{tabular}

In the material collection phase, the following steps were undertaken to provide rigour in the literature review process:

- A search strategy was designed based on the keywords; construction, supply chain management, logistics, and third-party logistics. These keywords were discussed with the author's supervisors and deemed to be sufficiently precise, while still allowing for a wide collection of articles.

- Delimitations were set to include only peer reviewed journal articles from two databases (SCOPUS and Emerald Insight).

- Searches within these databases were general and non-discriminatory to allow for articles published in non-traditional construction management journals to be part of the sample. Searches were made in titles, abstracts and keywords to retrieve the most suitable articles.

- No delimitations were set regarding time-period of publication, allowing for a wide selection of articles that would represent the development of the research area in the descriptive analysis.

- The unit of analysis was defined as the individual article. 
- Abstracts were read carefully from a content point-of-view to find the articles suitable for the review, and for further classification.

- All searches and articles were recorded in an electronic database for transparency.

To allow for a deeper analysis of the selected articles, thematic classification of the material is vital. Seuring and Gold (2012) recommends theory-based classifications as this helps in ensuring the validity of the review while also allowing for having a baseline structure for the themes within the review. The following steps were undertaken to ensure rigour:

- The initial category classifications were theory-based. As the author is the sole author of paper 1, these classifications were discussed with the author's supervisors. This reduced some of the interpretation bias.

In the material evaluation and research quality phase, the following steps were taken.

- As the review progressed, the categories described above were revised to better suit the studied material. This deductive-inductive approach allowed for some flexibility while still being based on a theory-based classification. This iterative process can, according to Seuring and Gold (2012), enhance the validity of the study further as the analysis is based on existing theory while still being adjusted to the specific sample.

- The coding and evaluation were discussed with the authors supervisors and other colleagues in order to reduce interpretation bias. The paper was also presented as a conference paper and was revised after comments from conference participants. This can, to some extent, be likened to "discursive alignment of interpretation" as discussed by Seuring and Gold (2012), as it allowed the author to align his interpretations to those of more senior researchers.

Finally, to reduce any question marks regarding the research quality of paper 1, the author has provided a detailed methodology section in the final paper in order to ensure transparency in the overall research process.

\subsubsection{Research quality in case study research}

Due to the context specificity of case studies, showing the research quality through validity and reliability of the research is especially important (Yin, 2014, Voss, 2009). This can be achieved through the case study tactics for enhanced construct validity, internal validity, external validity, and reliability proposed by Yin $(2014$, p. 45$)$ and shown in Table 5. The measures taken to meet the case study tactics are discussed below Table 5 . 
Table 5 - Means to ensure research quality in case studies (based on Yin, 2014)

\begin{tabular}{|l|l|l|}
\hline Tests & Case study tactic & Phase of research in which tactic occurs \\
\hline Construct validity & $\begin{array}{l}\text { Use multiple sources of evidence } \\
\text { Establish chain of evidence } \\
\text { Have key informants review draft case study } \\
\text { report }\end{array}$ & $\begin{array}{l}\text { Data collection } \\
\text { Data collection } \\
\text { Composition }\end{array}$ \\
\hline Internal validity & $\begin{array}{l}\text { Do pattern matching } \\
\text { Do explanation building } \\
\text { Address rival explanations } \\
\text { Use logic models }\end{array}$ & $\begin{array}{l}\text { Data analysis } \\
\text { Data analysis } \\
\text { Data analysis } \\
\text { Data analysis }\end{array}$ \\
\hline External validity & $\begin{array}{l}\text { Use theory in single case studies } \\
\text { Use replication logic in multiple case studies }\end{array}$ & $\begin{array}{l}\text { Research design } \\
\text { Research design }\end{array}$ \\
\hline Reliability & $\begin{array}{l}\text { Use case study protocol } \\
\text { Develop case study database }\end{array}$ & $\begin{array}{l}\text { Data collection } \\
\text { Data collection }\end{array}$ \\
\hline
\end{tabular}

The concept of construct validity can be defined as identifying the correct operational measures for the studied objects (Yin, 2014, Gibbert et al., 2008). The following measures have been taken to ensure construct validity in this research:

- For all the case studies (papers 2, 3, 4, 5, and 7), multiple sources have been used for data collection. Interviews, observations, project documentation, audit reports, project management tools, statistics and company websites have been used as data sources.

- All case studies have followed an iterative process where literature has been reviewed prior to empirical data collection and revisited afterwards, to ensure that enough and correct data was collected as well as to help in the analysis. This iterative process should strengthen the construct validity. The literature has also helped in validating findings from the empirical data. The empirical data on the other hand has also revealed the need to deepen the literature review in all the papers.

- Interview protocols and notes from documentation reviews have been discussed with respondents and project officials in order to validate the understanding of documents and interview responses.

- Draft case study reports have been sent to key informants for review.

- The case studies have continuously been presented to and discussed with project and reference groups with international participants from academia and industry.

Internal validity refers to whether the relationship between cause and effect can be ensured (Voss, 2009, Gibbert et al., 2008). According to Yin (2014), internal validity is more of a concern when it comes to explanatory case studies. The case studies reported in this research project are exploratory case studies, hence the internal validity is of lesser concern. However, to strengthen the internal validity of the research the following measures has been taken:

- All case studies in this thesis were written by two or three authors. Throughout all the phases of the studies, the authors have collaborated closely and discussed any unclear aspects of data collection, data collected, statements in literature, or findings.

- Multiple data sources and data collection methods have been used, allowing for triangulation of results. 
- Pattern matching has been used as an analysis model in the two multiple case studies.

External validity is defined as how generalizability of the case study results is ensured (Karlsson, 2009, Gibbert et al., 2008). The case studies in this thesis are conducted at a large urban development project in Stockholm, Sweden, a large construction project in the Swedish municipality Solna, multiple large-scale projects in Sweden, and hospital projects in Nordic countries. All the companies and municipal representatives participating in these case studies operate in the Nordic countries, thus working in similar cultures and contexts. This has implications on the generalizability of the results. The following measures have been taken to ensure external validity:

- Literature reviews have been undertaken in all the case studies and some of the findings from the case studies have also been seen in examples in literature. This increases the generalizability of the results.

- As research findings are analysed with the aid of an international literature base, the case studies offer directions for companies and municipalities in contexts similar to the Nordic one.

- By embedding and analysing nine individual cases within the main case in paper 5, the authors add to the generalizability through replication logic.

- The multiple case studies have used replication logic within the analysis to add to the generalizability.

- Data has been collected through multiple methods and from different sources, thus allowing for triangulation to be undertaken.

Reliability is the extent to which a study can be repeated by another researcher and still come to the same conclusion (Voss, 2009, Karlsson, 2009). Reliability is a difficult measure as data collection and analysis is carried out by individuals, and some involuntary bias may be present (Yin, 2014, Voss, 2009). However, Yin (2014) and Gibbert et al. (2008) both highlight that applying a structured and transparent methodology increases the reliability of the case study. In this research, reliability has been ensured through the following measures:

- Well-structured interview guides and research protocols have been used in the data collection phases of the case studies.

- Drafts and notes from interviews and observations have been stored electronically and as hardcopies. This allows for case study material to be reviewed if necessary.

\subsubsection{Research quality in Delphi study research}

As the Delphi method builds on the judgement of individual respondents, Loo (2002) and Woudenberg (1991) argue that there is a risk of bias in replies. The same question can for instance, posed to different panels receive different replies, making replication difficult and thus affecting the reliability of the study (Woudenberg, 1991). One way to increase reliability is through the extensive and rigorous reporting on the methodology used and the assumptions made, i.e. by increasing transparency of the process (Woudenberg, 1991, Loo, 2002). 
Three important biases to address are according to Hallowell and Gambatese (2010, p. 106) the collective unconscious, the contrast effect, and the primacy effect. The collective unconscious means that current trends can affect a respondent to rank a certain factor higher than had it not been trending (Hallowell and Gambatese, 2010). The contrast effect means that a subject is enhanced or diminished by a preceding subject and the primacy effect means that a respondent unconsciously assigns a higher value to the earlier factors of a survey than the later (Hallowell and Gambatese, 2010). To address and control for these three biases, the following controls can be implemented (Table 6):

Table 6 - Means to address and control biases in Delphi studies (based on Hallowell and Gambatese, 2010)

\begin{tabular}{|l|l|}
\hline Bias & Control \\
\hline Collective unconscious & $\begin{array}{l}\text { Include reasons for factors' scores in the controlled feedback to the Delphi panel for } \\
\text { each round }\end{array}$ \\
\hline Contrast effect & $\begin{array}{l}\text { Randomize the order of questions for each panel member and for each round, and } \\
\text { report final results as a median }\end{array}$ \\
\hline Primacy effect & Randomize the order of questions for each panel member \\
\hline
\end{tabular}

To ensure content validity, the Delphi method relies firstly on its group consensus meaning that more than one respondent has a say in the ranking of factors, and secondly that the respondents are experts with domain experience (Hasson and Keeney, 2011). Hasson and Keeney (2011) argues that how the expert respondents are chosen and qualified will affect content validity. The respondents should thus be qualified against a set of predetermined requirement to increase the content validity of the study (Rowe et al., 1991, Hasson and Keeney, 2011).

Construct validity on the other hand is dependent on the researchers interpretation of the factors suggested by respondents (Hasson and Keeney, 2011, Okoli and Pawlowski, 2004). Through the controlled feedback process of the Delphi, the researcher can have uncertain statements clarified by respondents (Okoli and Pawlowski, 2004). The responses in a Delphi are not anonymous to the researcher which Hasson and Keeney (2011) argues allows this approach in ensuring validation of factors. Furthermore, tying the results of the study to theory can further validate the findings of the Delphi study (Hasson and Keeney, 2011).

The following measures have been taken to ensure research quality in the Delphi study contributing to this research:

- Prospective respondents were qualified against a set of predefined criteria and approached beforehand to confirm their interest in participating in the study.

- The results of the open-ended initial survey were clustered and compared to theory by two of the researchers independently and discussed within the research team.

- A thorough literature review was conducted for the theoretical base.

- The following iterations building on the initial survey were randomized and sent electronically to the respondents, with individual survey links for all respondents. 
- With each new iteration of the Delphi, feedback was sent to the respondents, highlighting the results of the previous study.

- Mean ranks based on Kruskal-Wallis non-parametric one-way ANOVA were used instead of mean values to derive the results of the Delphi surveys for iterations three and four in which the respondents ranked factors.

- A cluster analysis was performed to evaluate whether different stakeholder groups were ranking factors similarly and whether there was a difference between the stakeholder groups in the study.

- The Delphi study design and methodology used has been reported in a rigorous way to ensure transparency. 


\section{Summary of papers}

This chapter summarizes the seven papers that are part of this dissertation. The summary is organised by first describing the background and purpose of each paper, followed by a description of the findings of the paper and how it contributes to the dissertation.

\subsection{Paper 1: Supply chain management, logistics, and third-party logistics in construction - A literature review}

\subsubsection{Background}

During the 1990's and early 2000's, the construction industry faced a lot of criticism based on issues related to material flows, cost performance. and build-time overruns. One solution proposed to combat the inefficiencies of the construction industry was supply chain management (SCM).

SCM has not had the impact on the construction industry as was hoped. Instead, focus has often shifted towards increasing project efficiency by reducing costs, primarily logistics and purchasing costs. Other studies focused on performance measures and performance improvement of existing logistics setups. Lately, the interest for third-party logistics (TPL) to manage construction material flows has increased. However, there is a need for more research on TPL in a construction context.

\subsubsection{Purpose}

The purpose of paper 1 is to investigate the state of SCM, logistics, and TPL in construction to investigate why the full potential of the concepts are not reached. This is achieved through a systematic literature review.

\subsubsection{Findings}

Paper 1 has provided insight into how the interest in SCM and logistics in construction has increased. However, the paper also shows that there is confusion as to what SCM and logistics entail and how the concepts differ. Practitioners use supply chain vocabulary but are often talking about operational logistics in doing so. This implies that there is some supply chain awareness, but that supply chain maturity is still not widespread in construction, making SCM difficult to adopt. The key to achieving higher supply chain maturity is to ensure knowledge and information sharing amongst stakeholders. This is where TPL can play a part. TPL providers are specialists in logistics and the construction industry can benefit from their logistics knowledge while at the same time sharing their construction knowledge. 


\subsubsection{Contribution to dissertation}

The contribution from paper 1 to the dissertation lies in the identification of the interorganizational issues of the construction industry with its temporary supply chains and that this leads to difficulties in adopting the long-term aims of SCM and logistics. The paper also shows that there is a non-conformity regarding what the concepts SCM and logistics entail, adding to the difficulty in how these concepts can be adapted to the construction industry context. Furthermore, paper 1 contributes by acknowledging that a full adoption of SCM is difficult to achieve as a radical change, but rather that incremental implementation or CLS's and TPL can be a way for the industry to move towards SCM.

\subsection{Paper 2: Construction logistics governing guidelines in urban development projects}

\subsubsection{Background}

The phenomenon of logistics setups is relatively new in the construction industry. One type of CLS used is the construction logistics centre (CLC), often run by a third-party logistics (TPL) provider. One benefit of this is that the CLC and TPL provider can act as systems integrators, coordinating materials and resource deliveries to sites within the development area, reducing the number of transports and improving site efficiency.

The introduction of CLCs in the construction supply chain will impose new demands regarding governance mechanisms, dealing with how social and economic coordination should take place within a specific UDP. The few existing studies are descriptive in nature, taking one or two stakeholder perspectives of CLC's, and lack suggestions on how to organize construction logistics in UDP's. What these studies reveal is that the initiation of CLCs has not been without resistance from stakeholders in the construction supply chain but offer little guidance on how to set up and govern the CLC.

\subsubsection{Purpose}

The purpose of this paper is to analyse the initiation and utilisation of a CLC from different stakeholders' perspectives in order to suggest governance mechanisms for strategic, tactical, and operational levels and to develop guidelines for implementing these governance mechanisms.

\subsubsection{Findings}

Construction logistics setups are necessary for managing challenges such as limited space, reduced environmental impact, improved accessibility and noise restrictions in many large urban development projects. However, there must be an alignment between actions taken at the strategic, tactical and operational levels as well as between the design of the CLS and its governance mechanisms. A CLS is more likely to be perceived as a good solution if the perspectives of the users are considered early on in the governance strategy design process.

Furthermore, paper 2 shows that in order for a CLS to work properly, the responsibility of all stakeholders needs to be clearly stipulated and communicated to the right stakeholders. 
Regulations developed on the strategic level early on in the project, need to be flexible to handle the operational reality later in the project.

\subsubsection{Contribution to dissertation}

The contribution from paper 2 to the dissertation lies in the identification of CLS's as necessary for managing challenges such as limited space, reduced environmental impact, improved accessibility and noise restrictions in many large urban development projects. Furthermore, paper 2 contributes to the dissertation by highlighting conflicting perspectives between stakeholders and how these perspectives affect the development and implementation of the CLS. Paper 2 also contributes to the dissertation by highlighting the need to develop the CLS and its regulations on strategic, tactical, and operational levels and providing guidelines for how to do so.

\subsection{Paper 3: Characterizing third-party logistics setups in the context of construction}

\subsubsection{Background}

Third-party logistics (TPL) providers are establishing themselves in the construction supply chains as a direct effect of the introduction of SCM and logistics in the construction industry (as discussed in paper 1). However, these TPL companies have to adapt their service offerings due to the contextual challenges of the construction industry.

The TPL industry, as well as the logistics service research area needs to acknowledge the dynamic and multifaceted nature of logistics services and increase the understanding of the evolution of TPL service offerings in new logistics contexts. This means that the TPL industry and the logistics service research area need to identify how to design and develop construction TPL setups.

\subsubsection{Purpose}

The purpose of paper 3 is to explore the use of TPL setups in construction through a crosscase analysis of 13 construction TPL setups in Sweden in order to characterize construction TPL setups and aid the design of future CLS's.

\subsubsection{Findings}

There are three typical initiators of construction TPL setups: municipalities, developers, and contractors. This multitude of possible initiators means that there is a need to clarify who the customer of the setup is. Paper 3 also found that CLS's can be used to coordinate logistics between the construction project and the society in the vicinity of the site. In this context, the TPL provider acts as a systems integrator simultaneously coordinating and fulfilling several customers' sometimes conflicting needs. In construction, the traditional TPL scope from one-to-one business-to-business relationships thus needs to be widened.

Furthermore, paper 3 shows that construction TPL is a driver for service differentiation as the construction industry context can call for more multifaceted solutions to fulfill the needs of the multiple stakeholders in construction. To be able to set the correct requirements for 
the CLS, service modularization and differentiation through standardized service modules can simplify the CLS design. Additionally, paper 3 identifies typical logistics services offered to CLS customers as a starting point for service differentiation and modularization.

\subsubsection{Contribution to dissertation}

The contribution from paper 3 to the dissertation lies in the identification of service differentiation, service modularization, and standardization of service modules as a means for designing and implementing CLS's. The logistics services identified in paper 3 further contributes towards the dissertations aim of determining what CLS's can include in terms of CLS services.

Furthermore, paper 3 contributes to the dissertation through the identification of CLS's as a means to coordinate logistics between the construction project and the society in the vicinity of the site. This adds to the understanding of what CLS's can be used for, as well as highlighting the complexity of why construction logistics is needed in urban development projects.

\subsection{Paper 4: Effects of employing third-party logistics arrangements in construction projects}

\subsubsection{Background}

The interest in logistics management has gained momentum in the construction industry and with that, an increase in using CLS's and TPL arrangements has emerged. Employing CLS's however, often leads to logistics costs becoming visible, whereas the benefits are hard to quantify. CLS's and TPL arrangements in construction are thus still met with scepticism from different construction supply chain partners.

Using CLS's is still a new phenomenon for both clients and contractors, but also for the service providers whom have not traditionally been active in the construction industry. Hence, there is also a gap in researching this new phenomenon and how it can affect construction operations and project performance.

\subsubsection{Purpose}

The purpose of paper 4 is to investigate the effects that can be realized when employing TPL arrangements in large-scale construction projects, including possible benefits, concerns and effects on cost elements.

\subsubsection{Findings}

Paper 4 shows that adding a CLS can streamline the logistics process for urban construction projects. By adding a terminal-based setup, delivery traffic to the construction site can be reduced by consolidating smaller deliveries. Paper 4 also shows that by adding a terminal, the construction project has the opportunity to reduce materials stored at site, subsequently reducing the number of material related incidents and accidents. However, adding a new node in the delivery network also adds costs for warehousing, storage, handling, and 
administration. These costs have to be offset against efficiency gains on site. To achieve this, the initiator needs to show that the CLS creates benefits for the project.

Furthermore, paper 4 shows that the initiator must work to increase the logistics knowledge of the suppliers and subcontractors that are part of the construction project. Otherwise, there is a risk that the CLS only adds costs to the project without being able to harvest any benefits and thereby being able to reduce the total cost of the project.

\subsubsection{Contribution to dissertation}

The contribution from paper 4 to the dissertation lies in the identification of possible benefits and issues with introducing CLS's, as well as showing what costs are affected by the introduction of a CLS. Additionally, paper 4 shows that there seems to be an imbalance between the allocation of costs and reaping the benefits of CLS's between different construction stakeholders.

Furthermore, paper 4 contributes to the dissertation through the identification and discussion of the need for construction supply chain partners to be supply chain oriented and to possess logistics maturity for the CLS introduction to become a natural part of construction projects.

\subsection{Paper 5: Construction logistics in urban development projects - Learning from, or repeating, past mistakes of city logistics?}

\subsubsection{Background}

By utilizing a CLC, construction projects should be able to reduce the time spent on managing logistics on-site, thus increasing the projects' value-adding time. However, the benefits of implementing CLC's seems to primarily be reduced disturbances to the urban transport system as well as to residents and businesses nearby. At the same time, the cost of utilizing CLC services have been found to predominantly be allocated to the construction projects. Thus, there seems to be an imbalance between costs and benefits of utilizing CLC's. This imbalance seems to affect contractors' utilization of CLC's negatively. However, there have been no in-depth analysis of construction projects' utilization of CLC's. There is thus a need to go deeper into the perceived imbalance of the benefits and costs of utilizing CLC's.

To evaluate the utilization of a CLC from a construction point-of-view, an activity-based costing $(\mathrm{ABC})$ approach is adopted. This means that there is a possibility to analyse the contractors' cost of the CLC and contrast this against their actual utilization of the same. In construction the challenges of carrying out freight transports to site are similar as for city logistics and there should thus be an opportunity to learn from city logistics when introducing CLS's. To find areas where construction logistics operations can be improved, paper 5 thus utilizes knowledge from city logistics to identify challenges and drivers for utilizing CLC's. 


\subsubsection{Purpose}

The purpose of this study is to investigate CLC utilization in order to identify actual challenges and drivers for utilizing CLC's.

\subsubsection{Findings}

Paper 5 shows that the issue of low utilization of CLC's stems from two sides; 1) the lack of customer focus when developing the CLC and 2) the lack of understanding of how to utilise the CLC in a way that creates benefits from the contractors perspective. The contractors focus on costs, or a lack of logistics knowledge, prevents them from seeing that logistics operations on site are alleviated or simplified through the CLC. Simultaneously, paper 5 shows that the contractors that have utilized the CLC to a greater extent, have achieved benefits in terms of better on-site logistics by moving storage from site, and by controlling how much materials are delivered to site each time. Thus, paper 5 shows that utilizing a structured logistics setup such as a CLC, positively impacts construction projects by decreasing interruptions from logistics activities and providing an opportunity for the contractors to streamline their logistics within the projects. Subsequently, construction projects can save on cost, time and space on site.

Furthermore, paper 5 highlights that the main issue to achieving acceptance and utilization of a CLS is misaligned business models and not providing services that add value to the end-users. Paper 5 shows that there is a disconnect between the municipality's goal of reducing disturbances and emissions in the development area, and the construction management goal of ensuring efficient construction projects. The CLC primarily benefited residents and businesses within the vicinity of the construction area through lower emissions, decreased risk of accidents, and less congestion from fewer transports. Yet the cost of the CLC was carried by contractors.

Finally, paper 5 shows that when initializing CLC's, one must distinguish between the overall effect of the CLC for the urban development area and the sites. The consolidation effect of $60 \%$ experienced in the SRS area does not necessarily translate to the individual project's sites. On an overall level, the consolidation effect of SRS benefits residents and businesses within the vicinity of the construction area. On the individual project level, the question of CLC success is more complex. Some contractors prefer a reduction in deliveries whereas others want to utilize the opportunity to buffer materials for JIT deliveries to site from the CLC to better suit their production pace.

\subsubsection{Contribution to dissertation}

Paper 5 contributes to the dissertation by giving a good understanding of the mechanisms behind how a CLC is utilized by construction projects. By considering construction operations as well as urban transports, paper 5 contributes to the dissertation by highlighting the need to consider the end-users of the CLS when deciding on the service offerings of the CLS. 
Furthermore, paper 5 contributes to the dissertation by proposing the need to consider previous city logistics experiences when introducing CLS's. Finally, paper 5 discusses the issues that can face a CLS if a one-sided perspective is taken in setting the goal of the CLS.

\subsection{Paper 6: Construction logistics performance metrics: A Delphi study}

\subsubsection{Background}

Construction logistics can be used to streamline delivery processes to and from construction sites. However, the actual impact on logistics performance in construction projects is still largely an unknown entity. The cost of the solutions for the individual construction projects are made visible through the invoices sent by the logistics service and TPL providers, but the follow-up of construction logistics performance is still lagging behind.

A possible reason for this is that structured construction logistics is still fairly new, and traditionally, only performance of actual construction activities has been measured. There is thus a need for a focused study on construction logistics performance measuring.

\subsubsection{Purpose}

The purpose of paper 6 is to propose a set of logistics performance metrics (PM) for the follow-up of construction logistics activities of construction projects. The proposed PMs should be able to evaluate and monitor the performance of different types of CLS's, thus be flexible enough to include large-scale CLS's as well as small-scale initiatives.

\subsubsection{Findings}

Paper 6 found that the construction logistics PMs proposed for the delivery process followed those of more classical logistics management PMs. PMs proposed by the respondents for on-site logistics and logistics coordination, however, were initially focused more on construction, rather than logistics. Over the iterations, this changed to more accurately reflect the composite nature of construction logistics, i.e. to manage both the deliveries to and from site as well as managing the site. Paper 6 suggests that what is important to monitor and follow-up, will vary from different types of construction projects, and between projects depending on the context of the construction projects. Thus, there is a need for modularization of construction logistics PMs.

An initial hypothesis in paper 6 was that the stakeholder groups would rank PMs differently depending on their own core operations and perspectives. The Kruskal-Wallis test showed that these indications were true for three delivery activity PMs, two on-site logistics PMs, and for one logistics coordination PM. Paper 6 thus shows that stakeholders will value performance differently. However, what this also indicates is that a vast majority of the suggested PMs found in paper 6 are valuable for all respondent groups.

\subsubsection{Contribution to dissertation}

One of the contributions from paper 6 is the realization that construction logistics performance needs to be measured in three subprocesses; delivery process, on-site logistics, and coordination between deliveries and on-site logistics. Paper 6 further contributes to the 
dissertation by finding that there are some significant differences in how stakeholders rank the proposed PMs, albeit for the majority of the PMs this was found not to be true. This realization means that there should be a possibility to find a set of standardized construction logistics PMs. Paper 6 further contributes to the dissertation by proposing a set of performance metrics for construction logistics.

Finally, paper 6 suggests that the PMs used will vary from different types of construction projects, and between projects depending on the context of the construction projects. Thus, the standardized PMs should be modular to reflect the contextual considerations needed.

\subsection{Paper 7: Designing construction logistics setups in hospital projects}

\subsubsection{Background}

In hospital construction projects, construction activities and construction logistics can disturb on-going hospital operations and in worst case emergency response traffic. Often the developer place demands on the contractor to reduce or eliminate disturbances to hospital operations. For the construction logistics activities, this means introducing a CLS.

However, there is a lack of processes for deciding what type of CLS to choose and what services the CLS should utilize to decrease the disturbances, i.e. how to design the CLS. Furthermore, hospital construction projects are complicated by the many stakeholders involved in the project in terms of everything from designing the hospital to choosing medical equipment. The many actors involved in hospital construction projects also have different goals with a CLS, which complicates the CLS decision-making process. There is thus a need to categorize CLS's and CLS services in order to allow for modularized CLS design that can cope with the changing demands of hospital projects.

\subsubsection{Purpose}

The purpose of paper 7 is to explore how CLS design elements can be categorized and to develop a process for how to design CLS's based on the proposed categorization.

\subsubsection{Findings}

Building on city logistics design classification, paper 7 found that a lot can be learned from city logistics when it comes to categorizing design elements of CLS's. In city logistics, however, the design classification is primarily concerned with technical issues, e.g. infrastructure, land use management, etc., whereas for CLS's, it is equally important to take in contextual considerations such as goal of CLS, organizational complexity of the construction project, and structural complexity of site.

Based on a multiple case study, paper 7 found that logistics effects are rarely taken into consideration when designing a CLS. The focus is instead on reducing third-party disturbances. For the CLS to be successful, paper 7 suggests that as part of the design process, identifying the desired logistics effects and contextual considerations of the construction project has to be done before setting the goal of the CLS. 


\subsubsection{Contribution to dissertation}

Building on the classification efforts made in city logistics, paper 7 contributes to the dissertation by developing a classification for CLS design elements. Furthermore, paper 7 contributes to the dissertation through the identification of there being a risk that CLS's will interfere with, or be negatively impacted by, city logistics measures.

Finally, paper 7 contributes to the dissertation by proposing a five-step process for designing CLS's, consisting of identifying contextual factors of the project, identifying wanted logistics effects, designing business models, mapping logistics setup services, and establishing performance measuring (see Figure 4). Paper 7 also identifies that a CLS must be allowed to evolve over time to match the varying needs of construction projects.

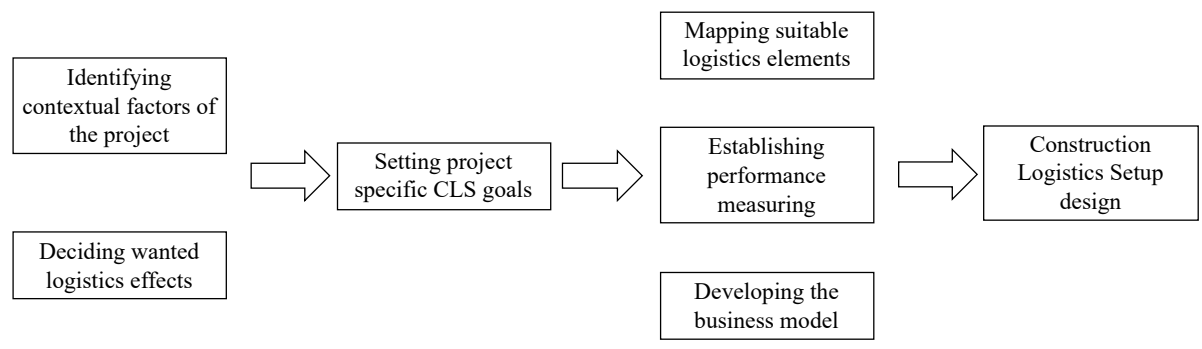

Figure 4 - Suggested CLS design process 


\section{Research findings}

This chapter analyses and synthesizes the research findings from the seven papers, answering the dissertations research questions. Figure 5 depicts how the papers are connected to the research questions.

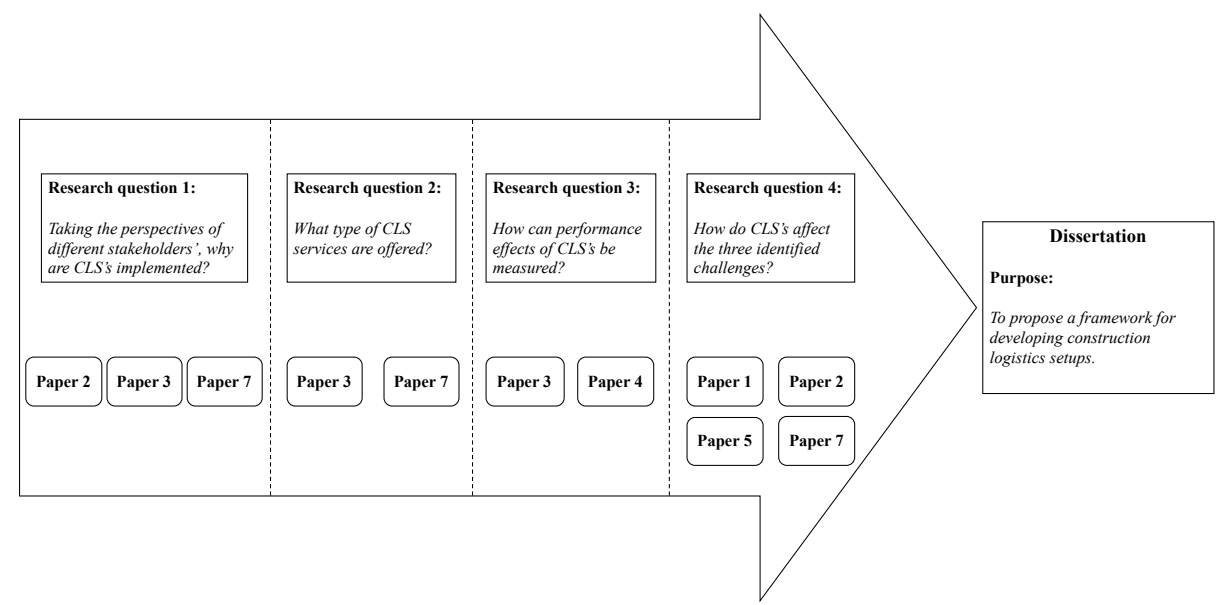

Figure 5 - The connection between papers and research questions

Figure 5 shows how the appended papers help answering the research questions, and how these help in meeting the purpose of the dissertation. Research questions 1,2 and 3 together lay the foundation for meeting research question 4. Exploring why CLS's are implemented from different stakeholder perspectives (RQ1), how to structure a CLS in terms of CLS services (RQ2), and how to follow up the CLS's performance (RQ3), allows for a deeper discussion on how the CLS affects the challenges identified in chapter 1 (RQ4).

\subsection{Exploring why CLS's are implemented}

Research question 1 focuses on understanding why CLS's are implemented from different stakeholder perspectives, i.e. finding the different stakeholders' drivers for implementing and operationalizing CLS's. Findings from papers 2, 3, and 7 help in addressing RQ1.

The logistics of city development affect many different stakeholders. Paper 2, paper 3, and paper 7 find that the main stakeholders are contractors, developers, municipalities, and TPL providers. Even though all four are to be considered main stakeholders of CLS's, their drivers for developing and/or initiating CLS's differ due to their individual contextual focus (paper 2, paper 3, paper 7). 
In papers 3 and 7, it was found that contractors' primary driver for initiating CLS's is to ensure that their projects are completed on time and budget by enhancing the control of their logistics activities within the project, e.g. both off and on site. This means that contractors initiate a CLS from a construction management perspective (paper 3, paper 7). Paper 7 found that a CLS, can reduce materials on site and free up space for construction activities, thus reducing the risk of material related accidents. Additionally, contractors initiate the use of CLS's in cases where economies-of-scale can be achieved by managing deliveries and logistics activities for multiple project, thus reducing costs (paper 3). When contractors initiate CLS's, the goal is thus to achieve good logistics support for construction projects to raise productivity and lower costs, either for one individual project or for multiple projects (paper 3, paper 7). Regardless if the CLS is initiated by a contractor or not, they are to be considered end-users in all types of CLS's (paper 2, paper 3, paper 7).

Developers were found in paper 3 and paper 7 to have a focus on the vicinity of the construction site. This focus can either be on a whole UDP if the developer owns the project, or to reduce disturbances on tenants and businesses in nearby houses owned by the developer (paper 3, paper 7). The primary goal for developers in initiating CLS's is to ensure that everyday operations are not impeded by construction activities and construction logistics activities, i.e. operations as usual (paper 7). Municipalities were found in paper 2 to have a similar focus as developers; to reduce disturbances on third parties. However, what concerns municipalities is the citizens of the urban area and that these citizens are not impacted by construction and construction logistics (paper 2, paper 7). A part of this municipal goal is to control the UTS, i.e. they have more of a city logistics perspective on construction logistics (paper 2). One of the strongest drivers for municipalities to introduce CLS's lies in reducing environmental impact from construction logistics operations (paper 2, paper 3).

TPL providers implement and/or operate CLS's primarily as a means to enter new markets through service differentiation (paper 3). This can either by through their own initiation of a CLS, or as a service provider employed by contractors, developers, or municipalities. Paper 2 highlights that a TPL provider can offer the construction industry new insights by providing logistics knowledge. At the same time, a TPL provider coming into the construction industry from the outside also has the opportunity to learn a new business context, thus increasing its service offerings (paper 3). However, the goal for the TPL provider can also be to just perform logistics operations to a paying customer (paper 3, paper 7). Table 7 summarizes the stakeholder drivers of developing and/or initiating CLS's. 
Table 7 - Stakeholders' drivers for implementing $C L S$ 's

\begin{tabular}{|c|c|c|c|}
\hline Stakeholder & Zone of interest & Role in CLS & Drivers for implementing/operating CLS's \\
\hline Contractor & Construction site & $\begin{array}{l}\text { Initiator } \\
\text { End-user (primary) }\end{array}$ & $\begin{array}{l}\text { Reduce cost overruns } \\
\text { Reduce time overruns } \\
\text { Better control of off-site logistics } \\
\text { Better control of on-site logistics } \\
\text { Economies-of-scale }\end{array}$ \\
\hline Developer & Area close to site & Initiator & $\begin{array}{l}\text { Reduced disturbances to ongoing operations } \\
\text { Construction project efficiency } \\
\text { Ensure tenants are not impacted by construction and } \\
\text { construction logistics }\end{array}$ \\
\hline Municipality & Surrounding city & Initiator & $\begin{array}{l}\text { Reduced disturbances to UTS } \\
\text { Reduced disturbances to third parties } \\
\text { Reduced impact to environment }\end{array}$ \\
\hline TPL provider & CLS & $\begin{array}{l}\text { Initiator } \\
\text { Service provider } \\
\text { (primary) }\end{array}$ & $\begin{array}{l}\text { Service differentiation } \\
\text { Entering new markets } \\
\text { Gain new capabilities } \\
\text { Financial gain }\end{array}$ \\
\hline
\end{tabular}

\subsection{Investigating what type of services are offered}

Depending on the why of the CLS, different combinations of services can be included in the CLS offering. Research question 2 thus focuses on understanding what CLS services are offered, as well as how to characterize the services. Findings from papers 3 and 7 are used to address RQ2. Table 8 summarizes and categorizes the possible CLS services found in the two papers.

Table 8 - Commonly offered CLS services as found in paper 3

\begin{tabular}{|l|l|l|}
\hline Asset-based services & Non-asset based services & Value-adding services \\
\hline Terminal with value-adding activities & Checkpoints with parking & Booking and planning systems \\
\hline Boundary-fencing & On-site materials handling & Logistics organization and coordination \\
\hline Site establishment & Traffic piloting & Site layout plans \\
\hline Machine resources & Road maintenance & Standardized labelling \\
\hline Waste management & VMI on site & Education \\
\hline & Surveillance and security & Follow-up of regulations \\
\hline
\end{tabular}

In paper 3, it is found that CLS services can be categorized into asset-based, non-asset based, or value-adding services. In construction logistics, asset-based services are primarily supplied through the utilization of terminal-based CLC's, providing services such as warehousing (e.g. inventory management, materials handling, repacking) and transports, including reverse logistics flows through utilizing own physical assets such as terminals, warehouses, lorries, etc. (paper 3, paper 7). Additionally, asset-based services include services such as site establishment and boundary fencing (paper 3, paper 7) to manage and control the actual construction site. Furthermore, paper 3 found that asset-based CLS's can also provide machine resources to reduce unnecessary machinery rentals, and joint waste management facilities to reduce the number of waste retrieval movements within an area. 
Non-asset based services on the other hand is found to rely on human expertise and information systems and offer management-oriented services, subcontracting physical distribution activities to asset-based companies (paper 3, paper 7). Non-asset based services focus on information-related activities (e.g. tracking and tracing, distribution planning), as well as the design and reengineering of the supply chain (paper 3). In construction logistics, this is catered to through JIT-based checkpoint setups where booking regulations are used to even delivery traffic out over the duration of the day (paper 3, paper 7). Additionally, dedicated material handlers can be utilized for the on-site materials handling (paper 3). Instead of working with logistics related activities, the craftsmen can thus focus on performing construction tasks (paper 3). Furthermore, services such as traffic piloting, road maintenance, surveillance and security, and organizing VMI on site falls under the nonasset based services (paper 3, paper 7).

Both asset-based and non-asset based CLS's can also offer value-adding services which stem from digitalization, focusing on the planning and coordination of logistics, both on and off site (paper 3, paper 7). The heart of the value-adding services thus lies in joint planning and booking systems that have been found to be essential for CLS's and the coordination of logistics activities amongst the different projects connected to the CLS (paper 3). In fact, paper 3 suggests that all CLS's serving multiple projects needs to have a planning and booking system in place. Additionally, value-adding services can take the form of dedicated logistics coordination within the site organization (paper 3, paper 7) and utilizing logistics-based site layout plans that specifies unloading zones and storage places on site (paper 3). These measures allow for a less cluttered construction site and better material traceability for the projects (paper 7).

It is found in paper 3 that construction TPL and CLS's are drivers for service differentiation as the construction industry context can call for more multifaceted solutions than other industry segments to fulfill the needs of the multiple construction stakeholders. Paper 3 suggests that one way for CLS providers to offer customer adaptations of the CLS services is to work with service modularization. By providing service modules based on standardized sets of services, the CLS customers can choose the service bundles that they benefit from. The combination of services will be dependent on whether the service provider is asset-based or non-asset based (paper 3).

\subsection{Measuring the performance effects of CLS's}

Research question 3 focuses on what construction logistics performance means and how this can be measured. What is important to monitor will vary from different types of construction projects, what phase the project is in, and even between projects depending on which context limits the construction projects (paper 6). Paper 6 also found that there were significant differences amongst how the different stakeholders valued different metrics. Their respective focus and operational contexts meant that, e.g. contractors, focused more on the metrics connected to progressing their construction projects, regardless of the subprocess in focus (paper 6). Paper 6 found that deciding on performance measuring early also allows CLS stakeholders more clarity regarding what is expected from them when 
utilizing the CLS. A conclusion is thus that performance metrics and monitoring need to be set up based on the stakeholder perspectives (paper 4, paper 6).

One of the main findings of paper 6 is that to a large extent, construction logistics needs to monitor the same type of performance metrics as other industries (paper 6). For example, classical delivery focused performance metrics such as on-time delivery and delivery performance are equally important in construction logistics as other industries (paper 4, paper 6). As highlighted in paper 6, construction logistics performance should be measured in three construction logistics subprocesses; the delivery process, on-site logistics, and logistics coordination. Within these three subprocesses, 47 performance metrics were identified in paper 6 (see Table 9).

\section{Table 9 - Construction logistics performance metrics as ranked in paper 6}

\begin{tabular}{|l|l|l|}
\hline Delivery activities & On-site logistics & Logistics coordination \\
\hline On-time delivery & Number of material movements & Regular planning meetings \\
\hline Correct place & $\begin{array}{l}\text { Number of deviations/ interruptions } \\
\text { due to logistics }\end{array}$ & Information availability \\
\hline Correct product & Material handling time craftsmen & Adherence to production plan \\
\hline In-full delivery & Time to find material & Adherence to delivery plan \\
\hline Delivery cost & Material handling cost & Delivery plan process \\
\hline Delivery error-free & Number of accidents/incidents & Established coordination process \\
\hline Delivery performance & Material damage and theft & Information accuracy \\
\hline Fill rate (kg, m3) & Material related delay & Construction logistics coordinator \\
\hline Emissions & Loading/unloading time & $\begin{array}{l}\text { Number of changes to the delivery } \\
\text { plan }\end{array}$ \\
\hline Consolidation rate & Accessibility on site & Integrated system support \\
\hline Correct packaging & Waste kg/m2 & $\begin{array}{l}\text { Percentage of orders/call-offs in the } \\
\text { correct system }\end{array}$ \\
\hline Delivery plan & Waste management time/m2 & Delivery documentation \\
\hline Waiting time, turnaround time & Utilization logistics resources & Order confirmation process \\
\hline Delivery notification & Storage cost & Order lead-time \\
\hline Delivery lead-time & Cost of defective material & Order administration time \\
\hline $\begin{array}{l}\text { Number of booked/un-booked } \\
\text { deliveries }\end{array}$ & Inventory turn-over rate & \\
\hline
\end{tabular}

Table 9 summarizes the metrics that the respondents of paper 6 highlighted as important to monitor and how they ranked them. These can be used to build the foundation of a monitoring system. However, from the perspective of the CLS, this dissertation suggests that a good starting point is to monitor how the CLS affects the delivery process in terms of on-time delivery, correct place, correct product, in-full delivery, and delivery cost. These were the five highest ranked metrics, and the first four gives a measure of how well deliveries are performed, and the final one gives the contractors a tangible cost (paper 4) for the delivery activities that can be used to budget for delivery activities in future projects with a CLS in place.

For on-site logistics, the results of paper 6 show that number of material movements, number of deviations/interruptions due to logistics, material handling time for craftsmen, time to find material, and material handling costs are the most important metrics to followup. These metrics are all aiming at highlighting the efficiency of the on-site logistics process but can also highlight inefficiencies in other parts of the material supply process. 
For instance, measuring the number material movements can shine a light on how well the purchasing planning works; it materials are moved a lot, they have been delivered before needed and thus probably ordered in an inefficient way.

For logistics coordination, the corresponding metrics are regular planning meetings, information availability, adherence to production plan, adherence to delivery plan, and delivery plan process. These metrics are all aimed at ensuring that information is shared amongst stakeholders and control for any issues that have arisen in the construction logistics process. Additionally, as found in paper 3, there is also a need to monitor adherence to regulations as part of the logistics coordination. This final metric can allow the CLS the opportunity to review whether or not the governance model set is feasible; if many CLS end-users are breaking the rules, there is thus a chance to revise the regulations to better comply with the construction projects' operations or to impose stricter follow-up of the regulations to ensure that the projects start adhering to the regulations.

\subsection{Exploring how CLS's affect the identified challenges}

Research question 4 focuses on how the implementation of CLS's affect the challenges of managing transports to and from construction projects, managing logistics at construction sites, and managing the interorganizational relationships amongst construction project stakeholders. RQ4 is addressed by the findings from papers 1, 2, 5, and 7.

\subsubsection{Managing transports to and from construction projects}

Depending on the type of CLS introduced, the transport flows are affected differently. Asset-based CLS's in terms of CLC's were found in papers 2 and 5 to reduce the overall transport volumes in an area. Subsequently, if a traffic reduction is achieved through consolidation, construction transports' environmental impact and disturbances to third parties can be lowered (paper 2, paper 5). However, what was also found in paper 5 is that the transport reduction does not necessarily lead to fewer deliveries arriving at site, depending on how the construction projects choose to utilize the CLC. If the terminal is used as a call-off point, the individual projects can in fact receive more deliveries than if the CLS was not in place (paper 5). Additionally, adding a new node in terms of a CLC means that additional logistics activities such as goods receiving, handling, picking, packing, and shipping are introduced into the delivery chain (paper 2, paper 5). Paper 2 finds that this new node thus adds time, cost, and risks for the goods into the delivery equation.

Non-asset based CLS's such as checkpoints on the other hand, evens out transport work over the course of the day through increased coordination of material flows to construction sites through time-slot bookings (paper 7). This means that the construction projects have a greater control of when deliveries arrive. This control of material flows allows for reductions of disturbances to third parties in terms of more even transport flows around the construction sites (paper 2, paper 5). However, paper 5 and paper 7 found that time-slot bookings also means that contractors and suppliers need to work more with planning and administration to ensure that deliveries arrive when needed. 


\subsubsection{Managing on-site logistics}

Asset-based CLS's can reduce material storage on site by supplying storage facilities offsite, delivering materials when needed (paper 2, paper 5). Furthermore, paper 5 found that utilizing an asset-based CLS means that construction projects can increase their control of when materials and resources are delivered to site. By using the CLS as an intermediate storage point, contractors can call-off materials and resources when needed, thus "converting" the delivery flow towards more of a JIT flow. Paper 5 found that having the materials off-site allows the contractors better control of the projects' materials through the warehouse management system of the CLS. The asset-based CLS can also reduce the time spent handling materials on site as materials handling to a large extent is transferred to the CLS (paper 5, paper 7).

Non-asset based CLS's in terms of on-site materials handling teams is found in paper 7 to increase control of where materials are located on site. However, a materials handling team also adds to the cost for on-site logistics (paper 7). The overall cost of materials handling in the project can however be reduced through more efficient on-site logistics operations through the on-site materials handling team (paper 7). Furthermore, the heart of the nonasset based CLS is that it is a planning based CLS which, as noted above, means that the construction projects' have a greater control of when deliveries arrive. For the on-site operations this means that it becomes easier to plan for when to receive deliveries. The onsite materials handling teams, or cases where craftsmen receive the goods the craftsmen, can thus be ready to receive goods when they arrive, and focus on value-adding activities during the rest of the day (paper 7).

\subsubsection{Managing interorganizational relationships amongst construction project stakeholders}

Introducing CLS's means that new interorganizational relationships will form as a new actor in terms of a CLS operator is introduced into the supply chain (paper 2, paper 5, paper 7). Paper 7 found that having many different stakeholders involved in construction projects adds to the organizational complexity of the project as more stakeholders influence the operations of the CLS and are influenced by the CLS operations. However, the introduction of a CLS helps coordinate stakeholders and material flows (paper 2, paper 5). The coordination has been found to be a positive effect for all stakeholders, and developers as well as contractors found the coordination effect of CLS's to be essential for working in UDP's (paper 2) and large-scale hospital projects (paper 7).

However, introducing a CLS is found to add to the administration that developers and contractors are not necessarily used to working with (paper 2). With the inclusion of a new stakeholder, the information chains get prolonged, leading to issues in information exchange (paper 2). These information exchange issues can lead to difficulties in diffusing the positive aspects and the potential that utilizing a CLS can bring (paper 2). This can in turn affect the acceptance of the CLS, primarily from the stakeholders who are most affected by the CLS operations, i.e. the contractors (paper 2, paper 5). 
Paper 1 highlights that the construction industry has not been fast to adopt new working practices, and paper 2 found that introducing new CLS approaches can cause friction between stakeholders due to different goals and focuses that are not always compatible. One reason for these goal conflicts is the structure of the construction industry with temporary organizations and supply chains where construction companies specialize to streamline their operations (paper 1). Introducing a CLS into this structure means introducing a new approach to carrying out logistics operations (paper 2). In order for the CLS to have a good coordination effect, it is found in paper 2 and paper 5 that it is essential for the TPL provider to have mandate to enforce regulations and to manage the construction logistics flows within the UDP. In cases where the TPL provider has this mandate, friction amongst stakeholders can be reduced (paper 5). 


\section{A framework for developing construction logistics setups}

This chapter seeks to fulfil the purpose of the dissertation, i.e. "to propose a framework for developing construction logistics setups". The chapters $6.1-6.3$ presents the contents of its different components. Chapter 6.4 presents the final framework followed by a discussion on the applicability and generalizability of the framework.

The suggested framework for developing CLS's consists of three main steps; 1. Setting the scope of the CLS, 2. Deciding the structure of the CLS, and 3. Understanding the interorganizational relationships of the CLS. Figure 6 shows the outline of the framework and the three steps.

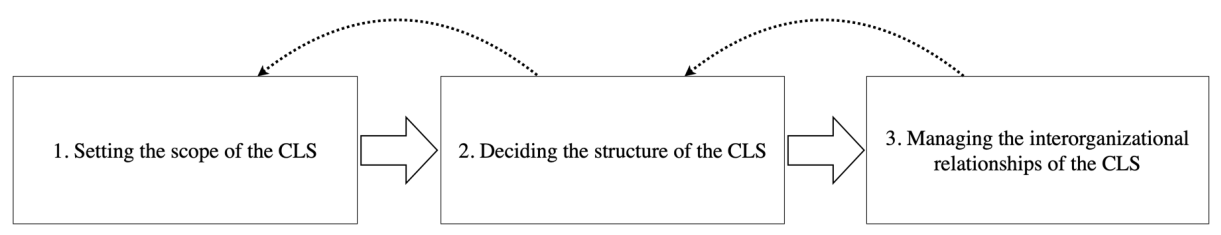

Figure 6 - The framework for developing construction logistics setups 


\subsection{Setting the scope of the CLS}

The first step in the framework is to set the scope of the CLS to be implemented. As highlighted in paper 7, setting the scope consists of two parts; identifying the contextual considerations (chapter 6.1.1) and setting project specific CLS goals (chapter 6.1.2).

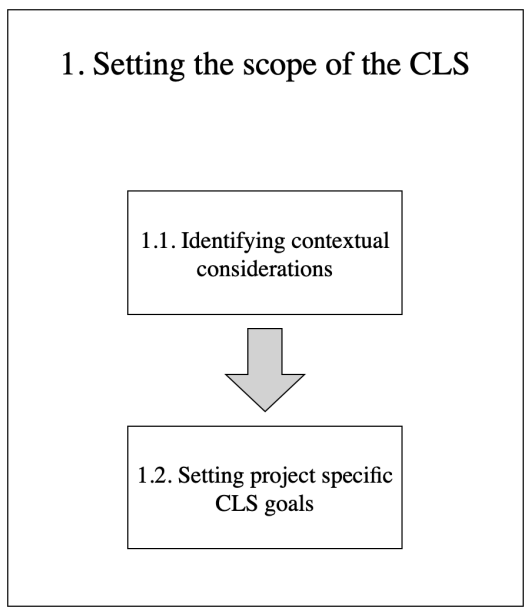

Figure 7 - Setting the scope of the CLS's is dependent on identifying the contextual considerations and setting project specific CLS goal

\subsubsection{Identifying contextual considerations of the project}

Different construction projects have different contextual considerations to make depending on the type of project (e.g. UDP, hospital, office building, infrastructure, etc.). These contextual considerations will impact the scope of the CLS as they set the conditions of what is possible to achieve in terms of CLS services on and off site. As such, identifying the contextual considerations of the CLS is an important first step in setting the scope of the CLS. As found in paper 7, this means mapping the structural context and the organizational complexity of the project that the CLS will serve.

\section{Structural context}

Creating an understanding of the structural context must be done as early as possible as this will affect what type of goal the CLS can fulfil. The initiator must thus look into a) what is being built, b) when design decisions are taken, c) the location of the project in relation to possible CLS location, d) what kind of challenges the surroundings impose on construction logistics, and e) what the conditions are on site in terms of available space.

Depending on what is being built, different structural aspects will come into play. As discussed in paper 7, hospital projects for instance set the final medical equipment design as late as possible in the project to allow for the latest medical advances to be installed in the hospital. Housing projects on the other hand, rarely wait as long into the actual project to set the final design. This means that the structural context can be investigated early on in the project, once construction drawings and models are in place. 
In paper 3 it is highlighted that understanding the location of the project and possible location of the CLS will affect what type of services are chosen to be offered through the CLS. Additionally, the surrounding area itself can set limitations on when deliveries are allowed, and even how they can be performed. In the SRS case reported on in paper 2 and paper 5 for instance, the municipality set limitations on third-party disturbances and environmental impact, meaning that the SRS area had to have a CLS that focused on reducing the amount of delivery traffic in the area. In this case, this meant introducing a CLC. In other cases, there can be limited space for vehicles waiting which can affect whether an asset-based or a non-asset based setup is proposed (paper 7). As found in paper 3 and paper 7, a solution to reduce the space needed in close proximity to the sites is the use on non-asset based checkpoint setups. However, there is a risk that the use of checkpoint setups pushes the space needed for wating vehicles to other areas, further away from the construction area. This must also be accounted for as part of the CLS's structural context.

\section{Organizational complexity}

To understand the organizational complexity of the project, the CLS initiator has to consider a) who are part of the overall project, b) where in the project management hierarchy the CLS should be situated, c) if additional CLS's are present in the project and how to relate to them, and d) what level of mandate the CLS operator should be given to ensure efficient CLS operations.

The many stakeholders involved in construction projects adds to the organizational complexity of the project and in the long run this organizational complexity will affect the operations of the CLS (paper 7). Knowing the organizational structure, how many contractors there will be in a project, where in the hierarchy the CLS will be placed, what type of operational expertise to include (e.g. medical expertise in hospital projects), etc. is thus a precondition for developing the CLS.

Furthermore, deciding on whether the CLS is part of the project management organization or not, is a decision that needs to be taken and communicated to different stakeholders early on. As described in paper 7, all six hospital projects had encountered challenges in getting their CLS's accepted and utilized due to unclear organizational structures and in some of the cases, multiple competing CLS's were in place. Additionally, four out of six CLS operators expressed that they had unclear or even low levels of mandate to set and enforce regulations (paper 7). Paper 2, paper 5 and paper 7 all show that the mandate of the CLS operator influences how well contractors adhere to the regulations, and as seen in paper 7, not having clear mandate is detrimental to the acceptance of the CLS.

Understanding the organizational context is thus dependent on understanding how the construction project is being built (i.e. the structural context) as this dictates the relationship of the different construction companies involved. Additionally, as was seen in paper 3 and paper 7, some larger contractors may have their own CLS's already in place, servicing their operations. It is thus important to understand how these CLS's can be incorporated as a part of the whole setup of a project. 


\subsubsection{Setting project specific goals}

When setting the project specific CLS goals, the initiator has to consider a) what their own goal is with the CLS, b) how this goal affects other CLS stakeholders, and c) how the CLS goal is communicated to stakeholders.

As discussed in chapter 5.1, stakeholders can have different goals from a CLS, and the project specific CLS goals will be strongly influenced by who the initiator is, and from what perspective the anticipated effects of the CLS are identified (paper 3, paper 7). When setting the project specific goals, it is thus important to consider how the CLS affects the different stakeholder perspectives in terms of e.g. construction efficiency or reduced impact on nearby businesses.

As seen in paper 2, paper 3, and paper 7, the different initiator perspectives means that setting the CLS goal is often a one-sided consideration from the initiator who will likely set a goal that is compliant with its own operations, i.e. a construction management goal, a developer goal, or a city logistics goal. The three possible goals are not mutually exclusive; as seen in paper 7 for instance, the CLS introduced in one of the hospital projects was at the demand of a main contractor who wanted to minimize the own impact on hospital operations. Another example is that of the office project in paper 4 where the CLS was developed by a construction management company with the goal of ensuring construction efficiency (construction management goal) as well as reduced disturbances to the surrounding areas (city logistics goal). However, what paper 4 also shows is that balancing these goals is difficult. In that case, it was a matter of not communicating the goals properly to all subcontractors and suppliers and their goals were thus not incorporated to the overall CLS goal (paper 4). Thus, finding the balance between the perspectives means taking goal conflicts as well as contextual considerations of the project into consideration.

Several of the cases reported on in this research can serve as examples of goal conflicts; the CLS's in paper 7 were developed strictly from the developers perspective of operations as usual and the SRS case in paper 2 and paper 5 had a CLS developed with the municipalities perspective of reducing emissions and third-party disturbances. In all these cases, the set goals of not disturbing third-parties took precedence over the contractors goals of efficient construction projects. However, when asked, contractors in the SRS case acknowledged that the CLS was crucial for working in UDP's such as SRS. Their main grievances were in fact a lack of communication from the initiator regarding the goal of the CLS (paper 2) and that the CLS had not been developed from a construction management perspective, thus reducing the possible benefits of the CLS for the construction projects (paper 5). To reduce the goal conflicts, the CLS initiator needs to clearly communicate the CLS goal to the other stakeholders early to increase the understanding for why the CLS is implemented and how it can be utilized to achieve different stakeholders' goals. 


\subsection{Deciding on the structure of the CLS}

After setting the scope of the CLS, the next step in the framework is to decide on how to manage construction logistics within this scope and what the CLS should entail, i.e. deciding on the structure of the CLS. This starts with mapping suitable logistics elements that help in achieving the goals set in the scope (chapter 6.2.1), followed by determining the adaptability of the CLS (chapter 6.2.2), and finally, establishing construction logistics performance measuring (chapter 6.2.3). As indicated in Figure 8 below, mapping suitable logistics services will inform the other activities in that the choice of services will affect the complexity of the service offering, as well as informing the performance measuring of the CLS (paper 2).

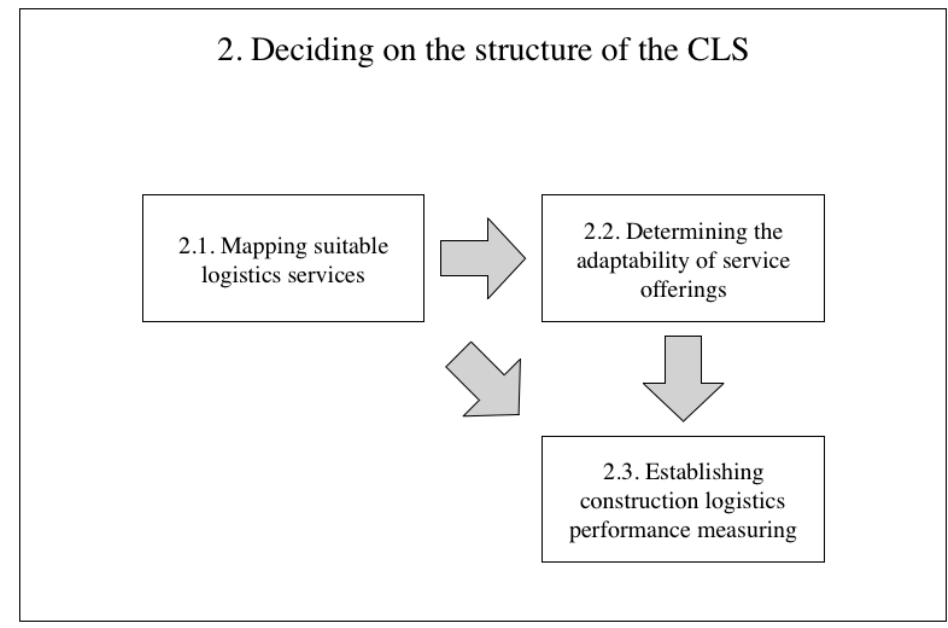

Figure 8 - Deciding on the structure the CLS means mapping suitable services based on the scope of the CLS, as well as investigating how to offer adaptability of CLS services, and how to monitor the provided services

\subsubsection{Mapping suitable logistics services}

When deciding on the CLS services to build the setup from, the initiator has to decide on a) how transports are to be controlled to best serve the scope of the CLS, b) what type of planning and booking system to use to facilitate the CLS can acting as systems coordinator, and c) what services to offer for the on-site scope of construction logistics to ensure efficient construction projects.

The foundation of the CLS structure lies in the services provided towards the end-users. As noted in chapter 6.1.1, and discussed in paper 3 however, the structural context of the project can delimit what type of services can be used. The first decision to make is whether to use an asset-based or non-asset based CLS, e.g. a CLC or a checkpoint, to control the construction traffic to, and around, the construction site. If the transport related goal of the CLS is to reduce the amount of construction traffic (i.e. a developer and/or city logistics goal) an asset-based CLC setup can achieve this through consolidation ( $c f$. paper 2, paper 3, paper 4, paper 5). If instead the transport goal is to regulate when and how deliveries can occur, the non-asset based checkpoint is more suitable (paper 3, paper 
7). The effect this type of setup has is instead that of ensuring that e.g. hospital operations can run as usual (i.e. a developer perspective). However, if a checkpoint setup is chosen, the consolidation effect cannot be achieved through the CLS. Instead, the consolidation has to occur outside of the CLS system, i.e. at suppliers' facilities.

Regardless the transport management setup chosen, a crucial value-adding service is the joint planning and booking system of the CLS. Paper 3 and paper 7 both found that without a joint planning system, the CLS cannot be efficiently operational. It is the planning system that allows the CLS operator to act as systems coordinator as discussed in paper 3, and it is in this role that the CLS operator can fully contribute to managing the construction logistics of the projects.

In paper 3 and paper 5 it was found that the decision between asset-based and non-asset based service providers also impacts what other types of services can be provided through the CLS. If the CLS is a terminal based CLC for instance, this provides opportunities to utilise the terminal as a storage point for calling off materials when needed (paper 5), e.g. creating a JIT flow. Depending on the project in question (i.e. the structural context) other asset-based services such as joint perimeter fencing to keep third-parties out of an entire UDP area or machine resources to reduce the amount of machinery on a site can be of interest to include in the CLS services. These two examples of asset-based services can also be found suitable to provide if the CLS is a non-asset based CLS. However, this means that the CLS operator has to orchestrate the supply chain to a greater extent and ensure that these services can be provided from other resource suppliers. Additionally, paper 3 found that non-asset based setups can open up for services such as on-site materials handlers that can receive and relocate goods for the contractors, thus reducing their material handling time. This place focus more on the execution of on-site logistics and further demands on the CLS operator to act as systems coordinator and service orchestrator. Table 8 in chapter 5.2 acts as a good starting point for deciding what type of services to include in the CLS.

\subsubsection{Adaptability of service offerings}

To determine the level of adaptability of the CLS, the CLS initiator has to collaborate with the CLS operator to a) determine how customizable the service offering should be to cater to the different end-users needs. Additionally, to meet the need of adaptability, the CLS operator has to b) determine the level of standardization of services offered to create the service modules that the end-users can utilize.

As seen in paper 3, the number of services that a CLS offers and the complexity of the service bundles offered will affect the structure of the CLS. Paper 2 and paper 5 found that the services offered in SRS were only utilized to the extent that was demanded of the contractors, i.e. the basic, mandatory services. The value-adding services provided were not used at all and were described by contractors as unnecessary from a construction perspective, i.e. the service offerings were too complex. One way to manage the complexity of the service bundles is deciding on the level of adaptability and customization the CLS should offer (paper 3). Paper 2 found that a certain level of 
adaptability from the CLS operator enhances acceptance from contractors, making them more prone to adhere to regulations and to utilize the CLS. However, the adaptability of the CLS must be determined to a level that does not conflict with the overarching scope of the CLS.

Just as in TPL arrangements, a major challenge for CLS operators will be balancing the ability to adapt to individual customers, while simultaneously organizing their operations to coordinate several customers (Hertz and Alfredsson, 2003). This holds especially true in city development, where the supply chains are typically convergent, meaning that all suppliers are delivering their goods to the same limited space. The way forward for the CLS operator is thus to standardize its service offering and creating service modules that can meet the goal of the CLS while also being aimed at increasing the efficiency of the construction projects.

\subsubsection{Establishing construction logistics performance monitoring}

To establish the CLS performance monitoring it is important to consider a) that performance needs to be monitored on strategic, financial, and operational levels from the different stakeholder perspectives. Furthermore, to monitor the CLS performance, b) performance metrics and measures needs to be decided on for both off-site and on-site logistics, as well as for the c) logistics coordination and d) the interorganizational relationships. Table 9 in chapter 5.3 acts as a good starting point for deciding what performance metrics to include in the monitoring of the CLS.

To get a comprehensive view of CLS performance, both the financial performance, the operational performance, and the service capabilities need to be measured. In line with Selviaridis and Spring (2007), it was suggested in paper 6 that the performance of the CLS services should be monitored on strategic, financial, and operational levels. This would allow for a greater understanding of the performance of the CLS on different levels; for instance, just because the CLS meets its strategic goals, it does not mean that it performs well on an operational level. Additionally, it was found in paper 6 that different stakeholders value performance metrics differently, depending on their own perspectives on construction logistics and what is important to control for. For instance, contractors were found to consider on-site efficiency regardless the subprocess under question (paper 6). Setting the scope of the performance monitoring thus need to include the four different perspectives of the contractor, the developer, the municipality, and the CLS operator.

The two more operative challenges of construction logistics, i.e. managing the transport flows to and from the construction projects and managing logistics at construction sites can be used as a starting point to decide what performance measurements to monitor in terms of logistics operations, and logistics coordination and adherence to regulations can be used as a starting point for monitoring the interorganizational relationships of the CLS and construction projects. Paper 6 and chapter 5.3 identified suitable performance metrics to utilize for monitoring CLS performance. These are presented in Table 9. 


\subsection{Managing the interorganizational relationships of the CLS}

For the purpose of developing a CLS that is acceptable for all four main stakeholders, there is a need for understanding the effects that the different stakeholders anticipate. This can be achieved by clearly stating logic and function of the CLS in the business model. Additionally, there is a corresponding need to clarify the regulations of the CLS and how these regulations are set in a governance model. The third step of the framework is thus creating the CLS's business and governance models.

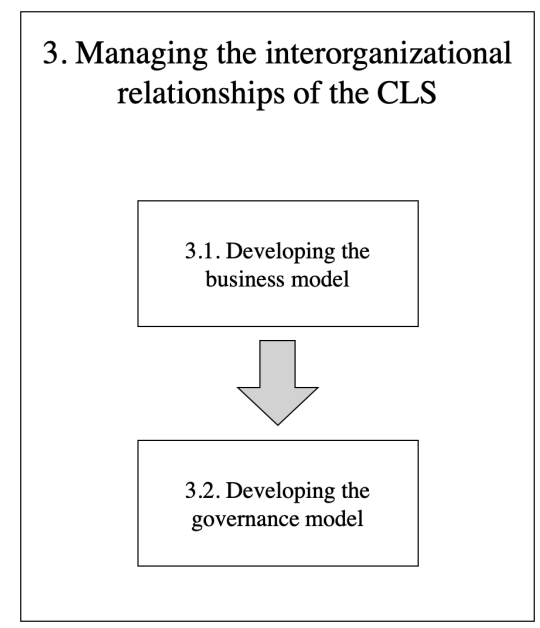

Figure 9 - Managing the interorganizational relationships of the CLS is intimately connected to the business model, as well as the governance model, of the CLS

\subsubsection{Developing the business model}

When setting the business model, the CLS initiator needs to a) acknowledge the end-user as the customer of the CLS. Furthermore, the business model needs to communicate b) the mandatory and additional services that are provided through the CLS and any bundling and modularization of services. Finally, the business model needs to address c) how communication is managed during the operational phase of the CLS.

This research has not focused on CLS business models. However, during the case studies it has been identified that a business model could help in increasing understanding and acceptance of the CLS (paper 5, paper 7). Paper 2 found that it is often unclear who the actual customer of the CLS is. This was also verified in papers 3 and paper 7. This dissertation thus suggests that the business model needs to be developed with end-users in mind, i.e. the contractors. Additionally, from chapters 6.1 and 6.2 it is suggested that the business model also needs to focus on communicating the services provided and how they should be utilized, and how the CLS facilitates communication amongst the different CLS stakeholders.

\subsubsection{Governance model}

The CLS initiator should build the CLS governance model a) from regulations of how to carry out logistics operations within the construction area served by the CLS. This 
includes setting regulations for how bookings are carried out, what is allowed in terms of closing of streets, etc. Furthermore, the governance model needs to include b) how to monitor the adherence to regulations. The performance metrics for adherence to regulations should be based on the performance metrics for logistics coordination presented in Table 9.

As is the case with CLS business models, this research has not focused on governance models, but rather it has identified the need to clearly establish the regulations of the CLS. The case studies of this research have shown that communicating the regulations of the CLS and what is expected from the end-users is an important step in increasing the acceptance and utilization of the CLS (paper 2, paper 3, paper 4, paper 5, paper 7). For this reason, it is suggested that the governance model needs to contain both the regulations themselves, as well as the performance measurement category adherence to regulations (paper 2, paper 3, paper 6). This will allow the CLS operator the ability to monitor whether end-users are adhering to the governance model as well as evaluating the governance model itself to see whether changes are needed (paper 2).

\subsection{The framework, its applicability, and generalizability}

The developed framework is presented in Figure 10 below and consists of the steps 1. Setting the scope of the CLS, 2. Deciding on the structure of the CLS, and 3. Managing the interorganizational relationships of the CLS.

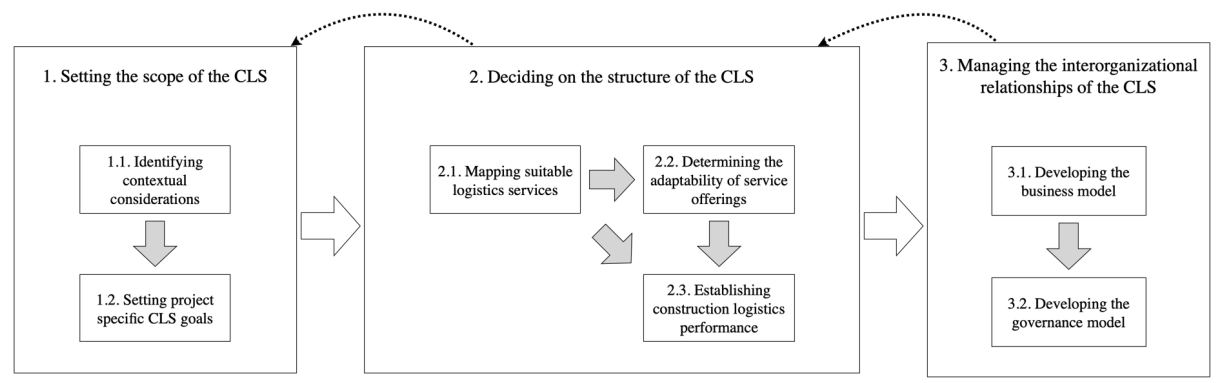

Figure 10 - The three steps in the framework are iteratively connected

The proposed framework for developing CLS's builds on research conducted in the Nordic countries, primarily Sweden. Additionally, the focus of the research has been on city development projects such as UDP's, offices, and hospitals in urban areas, thus a house-building context has been in focus. As such, it is important to address the question of generalizability, i.e. the ability to apply the research findings in other contexts.

This dissertation takes its departure from the three challenges of construction logistics; managing transports to and from construction projects, managing logistics at construction sites, and managing the interorganizational relationships amongst construction project stakeholders. The three challenges were identified from an international literature base and can thus be assumed to be present in an international context. However, the literature base is focused on developed countries working with densification and city development. 
As such, the framework is presumed to be applicable in other contexts than the Nordic one. Additionally, the key point of this framework is that the CLS initiator must consider the context in which the CLS is introduced. Thus, what the framework does is to allow for local adaptations of CLS's, further increasing the applicability of the framework beyond the Swedish and Nordic contexts.

The framework is developed from a house-building context and this differs greatly from infrastructure construction. However, the general nature of the framework and the focus on understanding the context that the CLS should operate in means that, at least in theory, the framework should be applicable to an infrastructure context as well. Similarly to the house-building context, infrastructure projects are also dependent on temporary organizations and supply chains. As such, the recommendations for how to manage interorganizational relationships are valid also in the infrastructure context. The biggest difference lies in the applicable transport management approaches. Infrastructure can to a greater extent be seen as dependent on removing materials from sites to be used again as input materials either in the same or other projects. This means that infrastructure projects will to a greater extent be dependent on being able to store large amounts of materials nearby to be used at a later stage of the project. However, through its contextual focus, the framework should help the CLS initiator to consider these changing conditions.

As the framework focuses on building the setup from a foundation of understanding the scope of the setup by acknowledging the context first, the framework should be adaptable to a city logistics context as well and could help in structuring the introduction of city logistics initiatives. Consumer goods markets and construction projects do differ a lot, but there are also similarities in that freight transports are undertaken in the urban transport system and there is a need to reduce the negative impact from both construction and consumer goods transports within this system. Additionally, as seen in previous research, these city logistics initiatives have faced similar issues as CLS's of noncompliance to regulations, low acceptance from end-users, and subsequently low utilization. Similar to previous CLS implementations, these issues stem from not taking end-users needs and operations into consideration when designing city logistics initiatives. By adapting the framework to a city logistics context, it should help in clarifying the scope of the city logistics initiative as well as in structuring the services provided by the initiative. 


\section{Conclusions}

This final chapter presents the conclusions and discusses the research questions and purpose of the dissertation. The chapter furthermore presents the dissertations theoretical contributions and managerial implications. The chapter is concluded with a discussion on the limitations of the dissertation and suggestions for further research.

\subsection{Answering the research questions}

The purpose of this dissertation was to propose a framework for developing construction logistics setups and the resulting framework is presented in chapter 6 . The four research questions put forth to help fulfil the purpose were:

RQ1: Taking the perspectives of different stakeholders', why are CLS's implemented?

RQ2: What type of CLS services are offered?

RQ3: How can performance effects of CLS's be measured?

RQ4: How do CLS's affect the identified challenges of managing transports to and from construction projects, managing logistics at construction sites, and managing the interorganizational relationships amongst construction project stakeholders?

RQ1 was answered through the findings of papers 2,3 , and 7. It was found that depending on the stakeholder in question, different goals are of interest. Contractors have a focus on construction management goals such as increased on- and/or off-site logistics efficiency, whereas developers wish to reduce disturbances to their tenants and their everyday operations, i.e. ensuring operations as usual. Municipalities on the other hand were found to have a focus on reducing third-party disturbances from construction logistics, i.e. they have a city logistics goal of CLS's. Even though TPL providers can initiate CLS's, it was found that they more often enter the CLS market as operators in search of new markets to gain new capabilities, or to gain market shares through service differentiation. Table 7 in chapter 5.1 further details the stakeholders' drivers for implementing and/or operating a CLS.

RQ2 was answered through the findings of papers 3 and 7. It was found that CLS services can be divided into asset-based, non-asset based, and value-adding services, where the first two types will determine how transports to and from sites are managed. If the foundation of the CLS is asset-based, e.g. a terminal, the transport goal will be to reduce traffic through consolidation. If the foundation of the CLS is non-asset based, e.g. a JIT based checkpoint, the transport goal will instead be to even out transport work over the 
duration of the day. Value-adding services can be offered either as part of an asset-based or a non-asset based CLS. Paper 3 found that the common denominator of all CLS's is that they utilize the value-adding service of a joint planning and booking system to coordinate all activities and stakeholders connected to the CLS. Additional suggestions for what services to include in a CLS is presented in Table 8 in chapter 5.2.

RQ3 was answered through the findings of papers 4 and 6. It was suggested that performance monitoring should be applied to three construction logistics processes; delivery process, on-site logistics, and logistics coordination. Within these processes, it was found that different stakeholders (again) have different focus. However, it was also found that performance monitoring should be based on the logistics operations carried out as part of the CLS offering. Furthermore, Table 9 proposes a set of performance metrics for the three logistics processes.

RQ4 was answered through the findings of papers 1, 2, 5, and 7. It was found that the scope of the CLS will impact what type of CLS (asset-based or non-asset based) is introduced. This choice will in turn affect whether the transports are reduced through consolidation or evened out over time through JIT based checkpoints. Thus, CLS's can positively impact the first challenge. Furthermore, it was found in paper 2, paper 5, and paper 7 that by utilizing different CLS services such as warehousing or materials handling teams, construction sites can be less cluttered, and craftsmen can focus more on valueadding activities (e.g. construction). Thus, CLS's can have a positive impact on the second challenge. Finally, it was found through papers 1, 2, and 7 that CLS's "force" stakeholders to address coordination issues within large-scale projects. As such, CLS's can positively impact the third challenge.

\subsection{Theoretical contribution}

The theoretical contributions of this dissertation are to the research areas of logistics management, city logistics, and construction management.

Firstly, this dissertation identifies CLS's as part of the TPL realm, thus the dissertation in its entirety along with the appended papers makes a contribution to logistics management in general and TPL research in particular through the identification of why CLS's are introduced. In traditional TPL arrangements, the initiation comes either from a cost reasoning in terms of reducing logistics costs, increasing the value-adding time, and focus on core competencies at the focal company, or as a knowledge seeking endeavour in that the logistics capabilities are missing within the focal company (Bolumole, 2001). Both the cost reasoning and knowledge seeking are valid also for the introduction of CLS's (Ekeskär and Rudberg, 2016). However, as this research has shown, these drivers are mostly from a contractor perspective (paper 3). However, out of the seventeen CLS's studied, thirteen are initiated by municipalities or developers. Their drivers are much more related to city logistics in that they seek to reduce disturbances to urban areas or the vicinity of the site (paper 2, paper 3, paper 4, paper 7). This research thus suggests that CLS's at least need to consider the end-users' need of efficient construction logistics 
when setting the CLS goals. The CLS can thus reduce disturbances while supporting the construction projects in terms of logistics and construction efficiency.

The second contribution of this dissertation is enhancing the understanding of how to manage service complexity in construction logistics. Halldórsson and Vural (2019) highlight that TPL is composed of simple or complex service bundles. Furthermore, TPL service offerings can be distinguished between logistics operations where the TPL provider has tangible assets, and logistics capabilities where the TPL provider offers knowledge-based services (Liu and Lyons, 2011, Stefansson, 2006). Deciding on the service offerings that can meet the scope of the CLS is at the heart of the matter as CLS's are first and foremost meant to manage construction logistics. However, as was found in paper 2, paper 3 and paper 5, the complexity of the service offerings can be a hindrance for the acceptance and utilization of CLS's. As discussed in paper 3 and chapter 6.3, the decision between asset-based and non-asset based services is not solely dependent on what the CLS operator can offer, but what is feasible for the construction project in focus. In essence this means that, unlike traditional TPL ( $c f$. Berglund et al., 1999), in CLS's you first need to decide on the management dimensions of the CLS before setting the structural dimensions of the setup (paper 3, paper 7). As an example, one of the first things to decide in the development of CLS's is how transports are managed for the construction project, depending on what the scope and structural context of the project is (paper 7). If the scope is concerned with reducing the number of transports in the construction area of a UDP, this implies that an asset-based CLS is developed. If instead the goal is to facilitate even transport flows throughout the day to reduce disturbances to on-going operations, a non-asset based CLS should be used. The former alternative resembles that of a classic logistics outsourcing or TPL setup in that physical assets are provided by the CLS operator, whereas the latter alternative was found in paper 3 to more resemble that of fourth-party logistics in that the services provided are more of an orchestration of construction logistics ( $c f$. Saglietto, 2013). The decision between asset-based and nonasset based CLS's will also dictate what types of services can be offered to ensure on-site efficiency. As suggested by Halldórsson and Vural (2019), to control for the service complexity, and subsequently be able to offer more user-adaptable service offerings, paper 3 suggested that CLS's should move towards standardized and modular sets of services as modularizing the service offerings can be an efficient way to provide adaptability to customer needs while simultaneously being able to provide standardized CLS services, something that has been seen as largely missing today.

Thirdly, as amongst others Dablanc (2007) highlight, the goal for city logistics is to reduce impact on the urban environment and emissions from freight transports in urban areas, whereas construction logistics is found in paper 2, paper 3, paper 4, paper 5, and paper 7 to be more connected to ensuring efficient goods movements between suppliers and construction projects. However, city logistics research focuses more on consumer goods freight flows, i.e. last mile deliveries ( $c f$. Dablanc et al., 2013). As such, the industrial flows are somewhat forgotten in the city logistics research strand, which also impacts the regulations imposed on the urban transport system. This finding highlights 
something important; construction projects are in essence temporary factories (Spillane et al., 2013), and in city development, these factories are located within the urban area. Yet, the focus of CLS's has primarily been to reduce disturbances to the UTS and not to ensure efficient construction projects, i.e. CLS's has been treated as city logistics initiatives (paper 2, paper 3, paper 7). Thus, this dissertation contributes to city logistics research by re-introducing a more industrial focus to urban freight transports and enhancing the understanding of different goods flows in the UTS and that these cannot be managed and controlled in the same way.

The fourth contribution of this dissertation is to construction management by enhancing the understanding of how interorganizational relationships are affected when CLS's become part of the construction supply chain. As discussed in paper 1, the construction industry in general is fragmented and consists of many different supply chain actors. When a CLS is introduced into this supply chain, in essence, a new stakeholder enters the supply chain, further complicating the relationships amongst the supply chain stakeholders (paper 1, paper 2). Amongst others Marasco (2008) and Hertz and Alfredsson (2003) highlight that TPL is the outsourcing of a company's logistics function to an external logistics service provider that acts as an intermediary between two supply chain companies. What this means is that one party initiates and utilizes the services of a TPL provider, and as highlighted by amongst others Selviaridis and Spring (2007), this is a long-term business arrangement. In construction logistics and CLS's, this is not the norm. In only four of the seventeen CLS's studied as part of this research, the relationship between initiator and CLS operator resembles that of the traditional TPL one-to-one relationship (paper 3, paper 7). These were the CLS's initiated by contractors whom acts as both initiator and customer. These relationships were also contracted over a longer time-period. However, in thirteen of the CLS's, the initiator cannot be seen as the customer in terms of being the one utilizing the CLS services. Instead, it was found in paper 2, paper 3, paper 4, and paper 7 that the relationships in these seventeen CLS's were at best a one-to-one-to-one relationship where e.g. a developer initiates the CLS and the contractor pays for the services and the utilization of the CLS. At its worst, these relationships were far more complex in that a municipality initiated the CLS, developers paid for parts of the CLS operations, and the contractors paid for parts of the CLS while also being the ones to utilize its services (paper 2). In order to manage these many relationships, paper 3 and paper 7 suggests that there is a need to establish the CLS provider with mandate to set and control regulations for how the CLS is utilized. This differs from traditional construction management paradigms where the project management organization holds the mandate of the construction project.

\subsection{Managerial implications of using the framework}

The foundation of the developed framework is applied research, i.e. research that has been conducted in close collaboration with practice. First and foremost, the framework is thus developed with practice in mind which also means that there are managerial implications of using the framework. These are presented in the following paragraphs. 
Traditionally, setting the CLS goal has been the starting point for developing CLS's. However, paper 2, paper 3, paper 4, and paper 7 shows that this often leads to a one-sided CLS goal and subsequently the CLS itself may not cater to the needs of all stakeholders. To set a more comprehensive goal, the CLS initiator has to consider the wider scope that the CLS impacts, i.e. the construction project, the surrounding area, and the city. To set the scope of the CLS, the CLS initiator should thus start by mapping the structural context of the project, i.e. the projects physical properties and its site, the surrounding transport system, any technical solutions that will enter the project, etc. This will give the CLS initiator an understanding for how the transports to the construction area has to be managed. This means that the CLS initiator develops a CLS that is adapted to the construction project or area that it is to serve, rather than mimicking previous CLS implementations without considering differences between projects. As such, the CLS should work well for the context that it is situated in which should lead to better construction logistics management off site. The CLS can thus reduce disturbances to the urban transport system nearby and to third-parties in the surrounding areas.

Additionally, as the construction area and its conditions are known through the mapping of the structural context, the CLS operator will have a good basis for deciding what services to provide that helps in increasing the construction projects on-site efficiency. This means that the CLS operator can start early to define its service modules and offerings. This does, however, mean that the operator will have to consider what they can provide themselves and whether they need to acquire new competencies and capabilities to be able to provide the services needed. Here it is important that the CLS operator considers not only what they can provide, but also investigate what services are needed from a construction management perspective. As seen in paper 2, paper 4, and paper 5, if the service offerings do not add value to construction projects, they will not be utilized. Similar notions from city logistics ( $c f$. Gammelgaard et al., 2016) suggest that services should be co-created with end-users to provide value for the end-users (paper 5). This can be difficult to achieve for the CLS operator but can also be worth the risk if it means that the services are procured and utilized by contractors. Combining the CLS operators capabilities with knowledge of end-user needs will allow the CLS operator to modularize its service offerings which can also be an efficient way to provide adaptability to customer needs (paper 3). As a base for what services to offer, CLS operators can find inspiration in Table 8 (chapter 5.2), presenting the service offerings found throughout this research.

Measuring logistics performance is important for understanding how well the CLS performs, but performance monitoring is even more essential for identifying improvement areas. Additionally, future CLS developments can learn from previous CLS monitoring's what operations work well, and what operations may need to be developed further in a coming CLS introduction. In paper 6 it was suggested that construction logistics performance needs to be monitored in three logistics processes; delivery process, on-site logistics, and logistics coordination. As a starting point, Table 9 in chapter 5.3 presents 47 performance metrics that can be used for setting up the performance monitoring of a CLS. The measurements suggested offer a possibility for the CLS 
stakeholders to understand what they themselves need to improve in their logistics operations and how to adapt their operations to the CLS. Thus, a well-designed performance monitoring system can increase the logistics capabilities of construction companies connected to a CLS. As seen in paper 5, increased knowledge of, or understanding for, logistics implies that CLS's are utilized to a greater extent than if there is a low level of understanding for CLS's. In the long run, monitoring construction logistics can thus increase the demand for CLS's on a wider scale.

Adding a CLS into the construction supply chain means adding a new stakeholder and new interorganizational relationships into the supply chain as well. As seen in this research, introducing a CLS operator into the supply chain can lead to coordination effects amongst stakeholders ( $c f$. paper 1, paper 2, paper 3, paper 7). By introducing a neutral party to coordinate construction logistics activities this actor (the CLS operator) acts an intermediary between the CLS initiator and the end-users in the cases where the initiators and end-users are different entities. However, as seen in papers 3 and papers 7, this intermediary effect is dependent on the CLS operator having the right mandate to change and enforce services and regulations connected to the CLS. If the CLS operator does not have that mandate, it will be powerless compared to the initiators and end-users. In these cases, it will be difficult to align the stakeholders often conflicting perceptions of what the CLS is there for, i.e. the conflicting goals of contractors and municipalities and/or developers. As seen in paper 2, this can lead to low acceptance of the CLS with subsequently low utilization of the CLS services. This thus suboptimizes the CLS to some extent as contractors only utilize a bare minimum of services (paper 2, paper 5). If, instead, the CLS operator is given the mandate to adapt the CLS to current needs, the overall scope of the CLS can be easier to achieve as this "forces" the contractors to address how they can contribute to the overall goal of the CLS. However, this mandate needs to be decided early on in the CLS development, and more importantly, it has to be communicated to all stakeholders connected to the CLS. This should be done through business and governance models. Clearly defined business and governance models allows all CLS stakeholders access to the same information, thus reducing the risk of conflicting interpretations of what is expected and how. This clarity will lead to greater acceptance and utilization of the CLS.

There are also risks associated with blindly following the framework to the letter. If the CLS is too adapted to an individual construction project, the pendulum can go from the ad hoc one size fits all approach commonly used to develop CLS's today, towards an overfitting of CLS's for individual projects. In the long run, this could lead to an increase in the temporary nature of the construction industry at large as CLS's and CLS operators will be procured for each individual project. Thus, CLS initiators and CLS operators has to consider how to balance the contextual adaptations and the longevity of CLS's. In certain sectors, such as hospital projects, it can be fine to have a CLS up and running for only one project. However, if the focus of the CLS is to serve multiple projects around the same city, the contextual focus has to be widened to include more of a portfolio view of the projects the CLS should serve. This means that both the CLS initiator and the CLS 
operator has to consider what can happen further in the future in terms of new projects. This implies that the CLS as such needs to be developed from a modularization perspective, i.e. from asking the question of how the CLS can serve current and future projects without having to adapt every time. This can be a challenge for the initiator, but one that is worth addressing to achieve longevity of the CLS and economies-of-scale by supporting multiple projects.

\subsection{Limitations and further research}

This dissertation is the final part of a doctoral research project focusing on construction logistics setups and their role in governing and coordinating materials and resource flows in city development. This dissertation does not offer an all-encompassing view of CLS's. It does, however, provide insights into how CLS's can affect the urban transport system and the material and resource flows to construction sites, and it proposes a development framework for CLS's. It is thus important to acknowledge that the framework has some limitations. These limitations are elaborated below, alongside suggestions for further research directions.

- Firstly, the framework is a proposition for how to approach CLS development. Even though it builds on insights from multiple empirical studies, it is a conceptual framework. Parts of the framework has been validated as part of a workshop with respondents representing developers and municipalities. However, further testing is needed in different project contexts to further enhance the validity of the framework. Future research studies should thus aim to test and validate this framework in several cases with different contexts (e.g. UDP's, infrastructure projects, hospital projects, etc.) to investigate the applicability of the framework. Are the needs for CLS's and the considerations to be made the same? This research should be undertaken in close collaboration with industry and municipal development offices to add more empirical evidence to the framework.

- Secondly, as described by Halldórsson and Vural (2019), service offerings are shifting from complex sets of services to a standardized and modular sets of services. This dissertation suggests that modularizing and standardizing CLS service offerings can be an efficient way to meet the increased demands for CLS's. However, the proposed framework is of a general nature and addresses CLS's in terms of asset-based, nonasset based, and value-adding CLS services. Future research should thus focus on whether it is possible to standardize and modularize CLS services and how modularization can affect the viability of CLS's for different construction contexts. This research stream should add more insights into construction logistics and how to increase the utilization of construction logistics services. In the long run this should help the construction industry to add understanding for how to manage construction logistics in their projects.

- Thirdly, in chapter 5.1, three initiators and their goals were identified and elaborated on; the contractor with a construction management goal, the developer with an 
operations as usual goal, and the municipality with a city logistics goal. Each of these stakeholders can initiate CLS's from their own goal perceptions. However, an issue that this dissertation does not elaborate on, is who amongst the possible initiators should initiate CLS's, i.e. who has the most to benefit from a CLS? Further research should thus elaborate on driving forces and barriers for implementing CLS's from different stakeholder perspectives.

- Fourthly, this dissertation has taken the perspectives of the direct CLS stakeholders (e.g. contractors, developers, municipalities, and TPL providers). However, due to the transient nature of city development, construction logistics affects many more stakeholders. Even though these four perspectives are ultimately the ones who can affect the implementation and operationalization of a CLS, future research should also widen the scope to investigate how the use of CLS's affect the wider system of the city, thus considering indirect stakeholders such as citizens, transporters, business owners, etc. This research can help in increasing the understanding of construction logistics and CLS's as part urban freight transports and in the long run increase construction logistics as an area of interest for municipal traffic management.

- Fifth, as discussed in chapter 6.3, this research has identified the need for developing business models and governance models for CLS's. These are however two directions that have not been researched within the limits of this research project. Throughout the research project, it has become evident that many CLS's have not developed their business models from the perspective of how to best serve construction projects as end-users of the CLS services. Partly this has been found to stem from a misalignment of goals (discussed in chapter 5.1). Similarly, it has also been identified that set CLS regulations have not been fully adhered to due to regulations not taking construction operations into account. Future research should thus focus on how business models and governance models for CLS's can be developed and how to address the issue of compliance to set CLS regulations. 


\section{References}

Aastrup, J., Gammelgaard, B. \& Prockl, G. 2012. 3PL Services in City Logistics: A User's Perspective. 24th Annual NOFOMA Conference. Naantali, Finland.

Aditjandra, P. \& Zunder, T. 2018. Developing a Multi-Dimensional Poly-Parametric Typology for City Logistics. In: Taniguchi, E. \& Thompson, R. G. (eds.) City Logistics 2: Modelling and Planning Initiatives. Wiley-ISTE.

Agapiou, A., Clausen, L. E., Flanagan, R., Norman, G. \& Notman, D. 1998a. The role of logistics in the materials flow control process. Construction Management and Economics, 16, 131-137.

Agapiou, A., Flanagan, R., Norman, G. \& Notman, D. 1998b. The changing role of builders merchants in the construction supply chain. Construction Management and Economics, 16, 351361.

Akintoye, A. 1995. Just-in-Time application and implementation for building material management. Construction Management and Economics, 13, 105-113.

Allen, J., Browne, M., Woodburn, A. \& Leonardi, J. 2014. A review of urban consolidation centres in the supply chain based on a case study approach. Supply Chain Forum, 15, 100-112.

Anderson, S., Allen, J. \& Browne, M. 2005. Urban logistics - How can it meet policy makers' sustainability objectives? Journal of Transport Geography, 13, 71-81.

Arbnor, I. \& Bjerke, B. 2009. Methodology for Creating Business Knowledge, London, Sage Publications.

Axelsson, K. \& Granath, M. 2018. Stakeholders' stake and relation to smartness in smart city development: Insights from a Swedish city planning project. Government Information Quarterly, $35,693-702$.

Bakhshi, J., Ireland, V. \& Gorod, A. 2016. Clarifying the project complexity construct: Past, present and future. International Journal of Project Management, 34, 1199-1213.

Ballantyne, E. E. F., Lindholm, M. \& Whiteing, A. 2013. A comparative study of urban freight transport planning: addressing stakeholder needs. Journal of Transport Geography, 32, 93-101.

Balm, S., Macharis, C., Milan, L. \& Quak, H. 2016. A City Distribution Impact Assessment Framework. In: Blanquart, C., Clausen, U. \& Jacob, B. (eds.) Towards Innovative Freight and Logistics. Wiley.

Bankvall, L., Bygballe, L. E., Dubois, A. \& Jahre, M. 2010. Interdependence in supply chains and projects in construction. Supply Chain Management: An International Journal, 15, 385-393.

Benjelloun, A., Crainic, T. G. \& Bigras, Y. 2010. Towards a taxonomy of City Logistics projects. Procedia - Social and Behavioral Sciences, 2, 6217-6228. 
Benson, J. K. 1975. The Interorganizational Network as a Political Economy. Administrative Science Quarterly, 20, 229-249.

Berglund, M., van Laarhoven, P., Sharman, G. \& Wandel, S. 1999. Third-Party Logistics: Is There a Future? The International Journal of Logistics Management, 10, 59-70.

Bertrand, J. W. M. \& Fransoo, J. C. 2002. Operations management research methodologies using quantitative modeling. International Journal of Operations \& Production Management, 22, 241264.

Biernacki, P. \& Waldorf, D. 1981. Snowball Sampling: Problems and Techniques of Chain Referral Sampling. Sociological Methods \& Research, 10, 141-163.

Boissinot, A. \& Paché, G. 2011. Opportunism control in exchange relationships: Lessons from the French logistics industry. Problems and Perspectives in Management, 9, 71-77.

Bolumole, Y. A. 2001. The Supply Chain Role of Third-Party Logistics Providers. The International Journal of Logistics Management, 12, 87-102.

Bornstein, L. 2010. Mega-projects, city-building and community benefits. City, Culture and Society, 1, 199-206.

Browne, M. 2015. The challenge of construction logistics. In: Lundesjö, G. (ed.) Supply Chain Management and Logistics in Construction: Delivering Tomorrow's Built Environment. 1st ed. London, Great Britain: Kogan Page.

Bryman, A., Bell, E. \& Harley, B. 2019. Business research methods.

Bygballe, L. E., Håkansson, H. \& Jahre, M. 2013. A critical discussion of models for conceptualizing the economic logic of construction. Construction Management and Economics, 31, 104-118.

Caldwell, N. D., Roehrich, J. K. \& Davies, A. C. 2009. Procuring complex performance in construction: London Heathrow Terminal 5 and a Private Finance Initiative hospital. Journal of Purchasing and Supply Management, 15, 178-186.

Carlsson, C.-M. \& Janné, M. 2012. Sustainable Urban Distribution in the Øresund Region. In: Carlsson, C.-M., Emtairah, T., Gammelgaard, B., Vestergaard Jensen, A. \& Thidell, Å. (eds.) Rethinking Transport in the Øresund Region: Policies, Strategies and Behaviours. Lund: Lund University.

Christopher, M. 2011. Logistics \& Supply Chain Management, Dorchester, United Kingdom, Pearson Education Limited.

Cook, K. S. \& Emerson, R. M. 1978. Power, Equity and Commitment in Exchange Networks. American Sociological Review, 43, 721-739.

Crainic, T. G., Ricciardi, N. \& Storchi, G. 2009. Models for Evaluating and Planning City Logistics Systems. Transportation Science, 43, 432-454.

Dablanc, L. 2007. Goods transport in large European cities: Difficult to organize, difficult to modernize. Transportation Research Part A: Policy and Practice, 41, 280-285.

Dablanc, L. 2008. Urban Goods Movement and Air Quality Policy and Regulation Issues in European Cities. Journal of Environmental Law, 20, 245-266. 
Dablanc, L., Giuliano, G., Holliday, K. \& O'Brien, T. 2013. Best Practices in Urban Freight Management. Transportation Research Record: Journal of the Transportation Research Board, 2379, 29-38.

Department for Transport 2017. Freight Carbon Review. In: Transport, D. f. (ed.). London, United Kingdom: Department for Transport (DfT).

Domingues, M. L., Reis, V. \& Macário, R. 2015. A Comprehensive Framework for Measuring Performance in a Third-party Logistics Provider. Transportation Research Procedia, 10, 662672.

Donato, M., Ahsan, K. \& Shee, H. 2015. Resource dependency and collaboration in construction supply chain: Literature review and development of a conceptual framework. International Journal of Procurement Management, 8, 344-364.

Dubois, A. \& Gadde, L.-E. 2000. Supply strategy and network effects - Purchasing behaviour in the construction industry. European Journal of Purchasing and Supply Management, 6, 207-215.

Dubois, A. \& Gadde, L.-E. 2002a. The construction industry as a loosely coupled system: implications for productivity and innovation. Construction Management and Economics, 20, 621631.

Dubois, A. \& Gadde, L.-E. 2002b. Systematic combining: an abductive approach to case research. Journal of Business Research, 55, 553-560.

Dubois, A., Hulthén, K. \& Sundquist, V. 2019. Organising logistics and transport activities in construction. The International Journal of Logistics Management, 30, 620-640.

Durach, C. F., Kembro, J. \& Wieland, A. 2017. A New Paradigm for Systematic Literature Reviews in Supply Chain Management. Journal of Supply Chain Management, 53, 67-85.

Dyer, J. H. \& Singh, H. 1998. The Relational View: Cooperative Strategy and Sources of Interorganizational Competitive Advantage. The Academy of Management Review, 23, 660-679.

Egan, J. 1998. Rethinking construction. London, United Kingdom: Department of Trade and Industry.

Eisenhardt, K. M. 1989. Building Theories from Case Study Research. The Academy of Management Review, 14, 532-550.

Ekeskär, A. 2016. Exploring Third-Party Logistics and Partnering in Construction: A Supply Chain Management Perspective. Licentiate of Engineering Licentiate thesis, Linköping University.

Ekeskär, A. 2019. Exploring the Introduction of a New Actor Role in a Construction Project Setting. The 35th IMP Conference, August 28-30, 20192019 Paris, France. The IMP Group (Industrial Marketing And Purchasing Group).

Ekeskär, A., Ingemansson Havenvid, M. \& Karrbom Gustavsson, T. 2019. Horizontal InterOrganizational Collaboration: The Case of Third-Party Logistics. 35th Annual ARCOM Conference, 2-4 September 20192019 Leeds, UK. Leeds, UK.

Ekeskär, A. \& Rudberg, M. 2016. Third-party logistics in construction: the case of a large hospital project. Construction Management and Economics, 34, 174-191. 
Ellinger, A. E., Daugherty, P. J. \& Gustin, C. M. 1997. The relationship between integrated logistics and customer service. Transportation Research Part E: Logistics and Transportation Review, 33, 129-138.

Emerson, R. M. 1962. Power-Dependence Relations. American Sociological Review, 27, 31-41.

Engblom, J., Solakivi, T., Töyli, J. \& Ojala, L. 2012. Multiple-method analysis of logistics costs. International Journal of Production Economics, 137, 29-35.

European Environment Agency 2015. Urban sustainability issues - What is a resource-efficient city? Luxembourg: European Environment Agency.

Evangelista, P. \& Durst, S. 2015. Knowledge management in environmental sustainability practices of third-party logistics service providers. VINE, 45, 509-529.

Everaert, P., Bruggeman, W., Sarens, G., Anderson, S. R. \& Levant, Y. 2008. Cost modeling in logistics using time-driven ABC: Experiences from a wholesaler. International Journal of Physical Distribution \& Logistics Management, 38, 172-191.

Fang, Y. \& Ng, S. T. 2011. Applying activity-based costing approach for construction logistics cost analysis. Construction Innovation, 11, 259-281.

Fawcett, S. E. \& Cooper, M. B. 1998. Logistics performance measurement and customer success. Industrial Marketing Management, 27, 341-357.

Fernie, S., Leiringer, R. \& Thorpe, T. 2006. Change in construction: A critical perspective. Building Research and Information, 34, 91-103.

Fernie, S. \& Tennant, S. 2013. The non-adoption of supply chain management. Construction Management and Economics, 31, 1038-1058.

Fernie, S. \& Thorpe, A. 2007. Exploring change in construction: supply chain management. Engineering, Construction and Architectural Management, 14, 319-333.

Flyvbjerg, B. 2006. Five Misunderstandings About Case-Study Research. Qualitative Inquiry, 12, 219-245.

Flyvbjerg, B. 2014. What You Should Know About Megaprojects and Why: An Overview. Project Management Journal, 45, 6-19.

Fossheim, K. \& Andersen, J. 2017. Plan for sustainable urban logistics - comparing between Scandinavian and UK practices. European Transport Research Review, 9.

Fredriksson, A., Janné, M. \& Rudberg, M. 2020. Characterizing Third-Party Logistics Setups in the Context of Construction. International Journal of Physical Distribution \& Logistics Management, UNDER REVIEW.

Fulford, R. \& Standing, C. 2014. Construction industry productivity and the potential for collaborative practice. International Journal of Project Management, 32, 315-326.

Gammelgaard, B. 2004. Schools in logistics research?: A methodolical framework for analysis of the discipline. International Journal of Physical Distribution \& Logistics Management, 34, 479491.

Gammelgaard, B. 2015. The emergence of city logistics: the case of Copenhagen's Citylogistikkbh. International Journal of Physical Distribution \& Logistics Management, 45, 333-351. 
Gammelgaard, B., Andersen, C. B. G. \& Aastrup, J. 2016. Value Co-creation in the Interface between City Logistics Provider and In-store Processes. Transportation Research Procedia, 12, 787-799.

Gauthier, T. D. \& Hawley, M. E. 2015. Statistical Methods. Introduction to Environmental Forensics. 3rd ed. San Diego, CA, USA: Academic Press/Elsevier Ltd.

Ghanem, M., Hamzeh, F., Seppänen, O. \& Zankoul, E. 2018. A New Perspective of Construction Logistics and Production Control: An Exploratory Study. In: González, V. A. (ed.) 26th Annual Conference of the International Group for Lean Construction. Chennai, India: International Group for Lean Construction.

Gibbert, M., Ruigrok, W. \& Wicki, B. 2008. What passes as a rigorous case study? Strategic Management Journal, 29, 1465-1474.

Gosling, J., Towill, D. R., Naim, M. M. \& Dainty, A. R. J. 2015. Principles for the design and operation of engineer-to-order supply chains in the construction sector. Production Planning and Control, 26, 203-218.

Granovetter, M. 1985. Economic Action and Social Structure: The Problem of Embeddedness. American Journal of Sociology, 91, 481-510.

Green, S. D., Fernie, S. \& Weller, S. 2005. Making sense of supply chain management: a comparative study of aerospace and construction. Construction Management and Economics, 23, 579-593.

Gríful-Miquela, C. 2001. Activity-based costing methodology for third-party logistics companies. International Advances in Economic Research, 7, 133-146.

Gualini, E. \& Majoor, S. 2007. Innovative Practices in Large Urban Development Projects: Conflicting Frames in the Quest for "New Urbanity". Planning Theory \& Practice, 8, 297-318.

Guerlain, C., Renault, S. \& Ferrero, F. 2019. Understanding Construction Logistics in Urban Areas and Lowering Its Environmental Impact: A Focus on Construction Consolidation Centres. Sustainability, 11.

Hadaya, P. \& Pellerin, R. 2010. Determinants of construction companies' use of web-based interorganizational information systems. Supply Chain Management, 15, 371-384.

Halldórsson, Á., Hsuan, J. \& Kotzab, H. 2015. Complementary theories to supply chain management revisited - from borrowing theories to theorizing. Supply Chain Management: An International Journal, 20, 574-586.

Halldórsson, Á., Kotzab, H., Mikkola, J. H. \& Skjøtt-Larsen, T. 2007. Complementary theories to supply chain management. Supply Chain Management: An International Journal, 12, 284-296.

Halldórsson, Á. \& Vural, C. A. 2019. Servitization and logistics: Building a service-based typology. The 26th annual EurOMA conference: Operations adding value to society. Helsinki, Finland.

Hallowell, M. R. \& Gambatese, J. A. 2010. Qualitative Research: Application of the Delphi Method to CEM Research. Journal of Construction Engineering and Management, 136, 99-107.

Harrison, A. \& van Hoek, R. 2011. Logistics Management \& Strategy: Competing Through the Supply Chain, Harlow, England, Pearson Education Limited. 
Hasson, F. \& Keeney, S. 2011. Enhancing rigour in the Delphi technique research. Technological Forecasting and Social Change, 78, 1695-1704.

Hedborg Bengtsson, S., Karrbom Gustavsson, T. \& Eriksson, P. E. 2018. Users' influence on inter-organizational innovation: mapping the receptive context. Construction Innovation, 18, 488504.

Hertz, S. \& Alfredsson, M. 2003. Strategic development of third party logistics providers. Industrial Marketing Management, 32, 139-149.

Heskett, J. L., Glaskowsky, N. A. \& Ivie, R. M. 1973. Business logistics; physical distribution and materials management, Ronald Press Co.

Holguín-Veras, J., Ozbay, K., Kornhauser, A., Brom, M. A., Iyer, S., Yushimito, W. F., Ukkusuri, S., Allen, B. \& Silas, M. A. 2011. Overall Impacts of Off-Hour Delivery Programs in New York City Metropolitan Area. Transportation Research Record, 2238, 68-76.

Homans, G. C. 1958. Social Behavior as Exchange. American Journal of Sociology, 63, 597-606.

Hufty, M. 2011. Investigating Policy Processes: The Governance Analytical Framework (GAF). In: Wiesmann, U. \& Hurni, H. (eds.) Research for Sustainable Development: Foundations, Experiences, and Perspectices. Bern, Switzerland: University of Bern.

Jang, H., Russell, J. S. \& Yi, J. S. 2003. A project manager's level of satisfaction in construction logistics. Canadian Journal of Civil Engineering, 30, 1133-1142.

Janné, M. \& Fredriksson, A. 2019. Construction logistics governing guidelines in urban development projects. Construction Innovation, 19, 89-109.

Jereb, B. 2017. Mastering logistics investment management. Transformations in Business and Economics, 16, 100-120.

Jesson, J. K., Matheson, L. \& Lacey, F. M. 2011. Doing you literature review: Traditional and systematic techniques, London, United Kingdom, SAGE Publications Ltd.

Josephson, P.-E. \& Saukkoriipi, L. 2007. Waste in Construction Projects: Call for a New Approach. Gothenburg, Sweden: The Centre for Management of the Built Environment, Chalmers University of Technology.

Karlsson, C. 2009. Researching Operations Management. In: Karlsson, C. (ed.) Researching Operations Management. New York: Routledge.

Karrbom Gustavsson, T. \& Hallin, A. 2015. Goal seeking and goal oriented projects - trajectories of the temporary organisation. International Journal of Managing Projects in Business, 8, 368378.

Keynes, J. M. 1933. National Self-Sufficiency. Studies: An Irish Quarterly Review, 22, 177-193.

Khalfan, M. A., Kashyap, M., Li, X. \& Abbott, C. 2010. Knowledge management in construction supply chain integration. International Journal of Networking and Virtual Organisations, 7, 207221.

Kin, B., Verlinde, S., Mommens, K. \& Macharis, C. 2017. A stakeholder-based methodology to enhance the success of urban freight transport measures in a multi-level governance context. Research in Transportation Economics, 65, 10-23. 
Klakegg, O. J. 2009. Challenging the Interface between Governance and Management in Construction Projects. 5th Nordic Conference on Construction Economics and Organisation. Reykjavik, Iceland.

Klein, B., Crawford, R. G. \& Alchian, A. A. 1978. Vertical Integration, Appropriable Rents, and the Competitive Contracting Process. The Journal of Law \& Economics, 21, 297-326.

Kluge, S. 2000. Empirically Grounded Construction of Types and Typologies in Qualitative Social Research. Forum: Qualitative Social Research, 1, 1-11.

Kovács, G., van Hoek, R. \& Spens, K. M. 2005. Abductive reasoning in logistics research. International Journal of Physical Distribution \& Logistics Management, 35, 132-144.

Kristiansen, K., Emmitt, S. \& Bonke, S. 2005. Changes in the Danish construction sector: the need for a new focus. Engineering, Construction and Architectural Management, 12, 502-511.

Kurien, G. P. \& Qureshi, M. N. 2011. Study of performance measurement practices in supply chain management. International Journal of Business, Management and Social Sciences, 2, 1934.

Kyrö, R., Peltokorpi, A. \& Luoma-Halkola, L. 2019. Connecting adaptability strategies to building system lifecycles in hospital retrofits. Engineering, Construction and Architectural Management, 26, 633-647.

LaLonde, B. J. \& Pohlen, T. L. 1996. Issues in Supply Chain Costing. The International Journal of Logistics Management, 7, 1-12.

Langley, C. J. 2015. 2016 Third-Party Logistics Study: The State of Logistics Outsourcing, the Annual Study on the State of Logistics Outsourcing. In: Langley, C. J. \& Capgemini Consulting (eds.). USA: Capgemini Consulting.

Latham, S. M. 1994. Constructing the team, London, United Kingdom, HM Stationery Office London.

Lavikka, R., Kyrö, R., Peltokorpi, A. \& Särkilahti, A. 2019. Revealing Change Dynamics in Hospital Construction Projects. Engineering, Construction and Architectural Management, 26, 1946-1961.

Lehtinen, J., Peltokorpi, A. \& Artto, K. 2019. Megaprojects as organizational platforms and technology platforms for value creation. International Journal of Project Management, 37, 4358 .

Lin, B., Collins, J. \& Su, R. K. 2001. Supply chain costing: an activity-based perspective. International Journal of Physical Distribution \& Logistics Management, 31, 702-713.

Lindén, S. \& Josephson, P. E. 2013. In-housing or out-sourcing on-site materials handling in housing? Journal of Engineering, Design and Technology, 11, 90-106.

Lindholm, M. 2012a. Enabling sustainable development of urban freight from a local authority perspective. Ph.D., Chalmers University of Technology.

Lindholm, M. 2012b. How Local Authority Decision Makers Address Freight Transport in the Urban Area. Procedia - Social and Behavioral Sciences, 39, 134-145. 
Lindholm, M. 2014. Successes and Failings of an Urban Freight Quality Partnership - The Story of the Gothenburg Local Freight Network. Procedia - Social and Behavioral Sciences, 125, 125 135.

Liu, C.-L. \& Lyons, A. C. 2011. An analysis of third-party logistics performance and service provision. Transportation Research Part E: Logistics and Transportation Review, 47, 547-570.

Liu, Q., Xu, J. \& Zhang, Z. 2015. Construction supply chain-based dynamic optimisation for the purchasing and inventory in a large scale construction project. European Journal of Industrial Engineering, 9, 839-865.

Loo, R. 2002. The Delphi method: a powerful tool for strategic management. Policing: An International Journal of Police Strategies \& Management, 25, 762-769.

Lu, C. S. \& Yang, C. C. 2010. Logistics service capabilities and firm performance of international distribution center operators. Service Industries Journal, 30, 281-298.

Lundesjö, G. 2015. Consolidation centres in construction logistics. In: Lundesjö, G. (ed.) Supply Chain Management and Logistics in Construction: Delivering Tomorrow's Built Environment. 1st ed. London, United Kingdom: Kogan Page.

Löfgren, P. 2010. Effektiva Byggtransporter. Stockholm, Sweden: Sveriges Byggindustrier.

Magretta, J. 2002. Why business models matter. Harvard business review, 80, 86.

Majoor, S. J. H. 2018. Coping with ambiguity: An urban megaproject ethnography. Progress in Planning, 120, 1-28.

Malhene, N., Trentini, A., Marques, G. \& Burlat, P. 2012. Freight consolidation centers for urban logistics solutions: The key role of interoperability. IEEE International Conference on Digital Ecosystems and Technologies.

Marasco, A. 2008. Third-party logistics: A literature review. International Journal of Production Economics, 113, 127-147.

MDS Transmodal 2012. DG MOVE European Commission: Study on Urban Freight Transport. Brussels, Belgium.

Meredith, J. 1993. Theory Building through Conceptual Methods. International Journal of Operations \& Production Management, 13, 3-11.

Meredith, J. 1998. Building operations management theory through case and field research. Journal of Operations Management, 16, 441-454.

Meredith, J. 2001. Reconsidering the Philosophical Basis of OR/MS. Operations Research, 49, 325-333.

Morgan, R. M. \& Hunt, S. D. 1994. The Commitment-Trust Theory of Relationship Marketing. Journal of Marketing, 58, 20-38.

Murry, J. W. \& Hammons, J. O. 1995. Delphi: A Versatile Methodology for Conducting Qualitative Research. The Review of Higher Education, 18, 423-436.

Norrman, A. \& Henkow, O. 2014. Logistics principles vs. legal principles: frictions and challenges. International Journal of Physical Distribution \& Logistics Management, 44, 744-767. 
OECD 2003. Delivering the Goods: 21st Century Challenges to Urban Goods Transport. Organisation for Economic Co-operation and Development (OECD).

Okoli, C. \& Pawlowski, S. D. 2004. The Delphi method as a research tool: an example, design considerations and applications. Information \& Management, 42, 15-29.

Penrose, E. T. 1959. The theory of the growth of the firm, Oxford, B. Blackwell.

Perttula, P., Korhonen, P., Lehtelä, J., Rasa, P. L., Kitinoja, J. P., Mäkimattila, S. \& Leskinen, T. 2006. Improving the safety and efficiency of materials transfer at a construction site by using an elevator. Journal of Construction Engineering and Management, 132, 836-843.

Pfeffer, J. \& Nowak, P. 1976. Joint Ventures and Interorganizational Interdependence. Administrative Science Quarterly, 21, 398-418.

Pfeffer, J. \& Salancik, G. R. 1978. The external control of organizations: a resource dependence perspective, Harper \& Row.

Riordan, M. H. \& Williamson, O. E. 1985. Asset specificity and economic organization. International Journal of Industrial Organization, 3, 365-378.

Rodrigue, J.-P. \& Notteboom, T. 2017. Transportation, economy and society. In: Rodrigue, J.-P., Comtois, C. \& Slack, B. (eds.) The geography of transport systems. 4th ed. Oxon, UK: Routledge.

Rousseau, D. M., Manning, J. \& Denyer, D. 2008. Evidence in Management and Organizational Science: Assembling the Field's Full Weight of Scientific Knowledge Through Syntheses. The Academy of Management Annals, 2, 475-515.

Rowe, G., Wright, G. \& Bolger, F. 1991. Delphi: A reevaluation of research and theory. Technological Forecasting and Social Change, 39, 235-251.

Saad, M., Jones, M. \& James, P. 2002. A review of the progress towards the adoption of supply chain management (SCM) relationships in construction. European Journal of Purchasing and Supply Management, 8, 173-183.

Saglietto, L. 2013. Towards a classification of Fourth Party Logistics (4PL). Universal Journal of Industrial and Business Management, 1, 104-116.

Sandberg, E., Kihlén, T. \& Abrahamsson, M. 2011. Characteristics of a Logistics-Based Business Model. Journal of Marketing Channels, 18, 123-145.

Scarsi, R. \& Spinelli, R. 2017. An analysis of strategic groups in the Third-Party Logistics industry. $27,1$.

Schmidt, G. \& Wilhelm, W. E. 2000. Strategic, tactical and operational decisions in multi-national logistics networks: A review and discussion of modelling issues. International Journal of Production Research, 38, 1501-1523.

Segerstedt, A. \& Olofsson, T. 2010. Supply chains in the construction industry. Supply Chain Management: An International Journal, 15, 347-353.

Selviaridis, K. \& Norrman, A. 2014. Performance-based contracting in service supply chains: a service provider risk perspective. Supply Chain Management: An International Journal, 19, 153172. 
Selviaridis, K. \& Spring, M. 2007. Third party logistics: a literature review and research agenda. The International Journal of Logistics Management, 18, 125-150.

Seuring, S. \& Gold, S. 2012. Conducting content-analysis based literature reviews in supply chain management. Supply Chain Management: An International Journal, 17, 544-555.

Seuring, S. \& Müller, M. 2008. From a literature review to a conceptual framework for sustainable supply chain management. Journal of Cleaner Production, 16, 1699-1710.

Shaharudin, M. R., Zailani, S. \& Ismail, M. 2014. Third party logistics orchestrator role in reverse logistics and closed-loop supply chains. International Journal of Logistics Systems and Management, 18, 200-215.

Shakantu, W., Tookey, J. E. \& Bowen, P. A. 2003. The Hidden Cost of Transportation of Construction Materials: An Overview. Journal of Engineering, Design and Technology, 1, 103118.

Skjøtt-Larsen, T., Halldórsson, Á., Andersson, D., Dreyer, H., Virum, H. \& Ojala, L. 2006. Third party logistics - a Nordic approach. International Journal of Value Chain Management, 1, 190204.

Slack, B., Notteboom, T. \& Rodrigue, J.-P. 2017. Transportation planning and policy. In: Rodrigue, J.-P., Comtois, C. \& Slack, B. (eds.) The geography of transport systems. 4th ed. Oxon, UK: Routledge.

Sourani, A. \& Sohail, M. 2015. The Delphi Method: Review and Use in Construction Management Research. International Journal of Construction Education and Research, 11, 5476.

Spillane, J. \& Oyedele, L. O. 2013. Strategies for effective management of health and safety in confined site construction. Construction Economics and Building, 13, 50-64.

Spillane, J. P., Cahill, G., Oyedele, L. O., Von Meding, J. \& Konanahalli, A. 2013. Supply Chain Management in Confined Site Construction: Strategies to Reduce Delay in the Delivery of Materials to Site. RICS COBRA 2013 Research Conference.

Spillane, J. P. \& Oyedele, L. O. 2017. Effective material logistics in urban construction sites: a structural equation model. Construction Innovation, 17, 406-428.

Stank, T. P., Pellathy, D. A., In, J., Mollenkopf, D. A. \& Bell, J. E. 2017. New Frontiers in Logistics Research: Theorizing at the Middle Range. Journal of Business Logistics, 38, 6-17.

Stefansson, G. 2006. Collaborative logistics management and the role of third-party service providers. International Journal of Physical Distribution \& Logistics Management, 36, 76-92.

Stock, J. R. \& Lambert, D. M. 2001. Strategic Logistics Management, McGraw-Hill/Irwin.

Strale, M. 2019. Sustainable urban logistics: What are we talking about? Transportation Research Part A: Policy and Practice, 130, 745-751.

Strale, M., Lebeau, P., Wayens, B., Hubert, M. \& Macharis, C. 2015. Le transport de marchandises et la logistique à Bruxelles : état des lieux et perspectives. In: Thiry, C. (ed.) Cahiers de l'Observatoire de la mobilité de la Région de Bruxelles-Capitale. Brussels, Belgium: Bruxelles Mobilité. 
Strategic Forum 2002. Accelerating Change. In: Construction, S. F. f. (ed.). London, Great Britain: Strategic Forum for Construction.

Sundquist, V., Gadde, L.-E. \& Hulthén, K. 2018. Reorganizing construction logistics for improved performance. Construction Management and Economics, 36, 49-65.

Swyngedouw, E., Moulaert, F. \& Rodriguez, A. 2002. Neoliberal Urbanization in Europe: LargeScale Urban Development Projects and the New Urban Policy. Antipode, 34, 542-577.

Tanskanen, K., Holmström, J. \& Öhman, M. 2015. Generative Mechanisms of the Adoption of Logistics Innovation: The Case of On-site Shops in Construction Supply Chains. Journal of Business Logistics, 36, 139-159.

Teece, D. J. 2007. Explicating dynamic capabilities: the nature and microfoundations of (sustainable) enterprise performance. Strategic Management Journal, 28, 1319-1350.

Teece, D. J. 2018. Business models and dynamic capabilities. Long Range Planning, 51, 40-49.

Teisman, G. \& Klijn, E. H. 2004. PPPs: torn between two lovers. EBF Debate, 18, 27-29.

Thunberg, M. \& Fredriksson, A. 2018. Bringing planning back into the picture - How can supply chain planning aid in dealing with supply chain-related problems in construction? Construction Management and Economics, 1-18.

Thunberg, M. \& Persson, F. 2014. Using the SCOR models performance measurements to improve construction logistics. Production Planning and Control, 25, 1065-1078.

Thunberg, M., Rudberg, M. \& Karrbom Gustavsson, T. 2017. Categorising on-site problems: A supply chain management perspective on construction projects. Construction Innovation, 17, 90111.

Toor, S.-u.-R. \& Ogunlana, S. O. 2010. Beyond the 'iron triangle': Stakeholder perception of key performance indicators (KPIs) for large-scale public sector development projects. International Journal of Project Management, 28, 228-236.

Transport for London 2013. Construction Logistics Plan Guidance for Developers. Windsor House, London, United Kingdom: Transport for London.

United Nations 2015. World Urbanization Prospects: The 2014 Revision. New York.

van Heeswijk, W., Larsen, R. \& Larsen, A. 2019. An urban consolidation center in the city of Copenhagen: A simulation study. International Journal of Sustainable Transportation, 13, 675691.

van Laarhoven, P., Berglund, M. \& Peters, M. 2000. Third-party logistics in Europe - five years later. International Journal of Physical Distribution \& Logistics Management, 30, 425-442.

van Wee, B., Anne Annema, J. \& Banister, D. 2013. The transport system and transport policy: an introduction.

Vasiliauskas, A. V. \& Jakubauskas, G. 2007. Principle and benefits of third party logistics approach when managing logistics supply chain. Transport, 22, 68-72.

Vivek, S. D., Richey, R. G. \& Dalela, V. 2009. A longitudinal examination of partnership governance in offshoring: A moving target. Journal of World Business, 44, 16-30. 
Voss, C. 2009. Case Research in Operations Management. In: Karlsson, C. (ed.) Researching Operations Management. New York, New York, USA: Routledge.

Voss, C., Tsikriktsis, N. \& Frohlich, M. 2002. Case research in operations management. International Journal of Operations \& Production Management, 22, 195-219.

Vrijhoef, R. \& Koskela, L. 2000. The four roles of supply chain management in construction. European Journal of Purchasing \& Supply Management, 6, 169-178.

Wacker, J. G. 1998. A definition of theory: research guidelines for different theory-building research methods in operations management. Journal of Operations Management, 16, 361-385.

Wegelius-Lehtonen, T. 2001. Performance measurement in construction logistics. International Journal of Production Economics, 69, 107-116.

Wilkins, A. L. \& Ouchi, W. G. 1983. Efficient Cultures: Exploring the Relationship Between Culture and Organizational Performance. Administrative Science Quarterly, 28, 468-481.

Williamson, O. E. 1979. Transaction-Cost Economics: The Governance of Contractual Relations. The Journal of Law and Economics, 22, 233-261.

Williamson, O. E. 1985. The economic intstitutions of capitalism, Simon and Schuster.

Williamson, O. E. 1991. Comparative Economic Organization: The Analysis of Discrete Structural Alternatives. Administrative Science Quarterly, 36, 269-296.

Williamson, O. E. 1999. Strategy research: governance and competence perspectives. Strategic Management Journal, 20, 1087-1108.

Williamson, O. E. 2008. Outsourcing: Transaction Cost Economics and Supply Chain Management. Journal of Supply Chain Management, 44, 5-16.

Winch, G. M. 2001. Governing the project process: a conceptual framework. Construction Management and Economics, 19, 799-808.

Woudenberg, F. 1991. An evaluation of Delphi. Technological Forecasting and Social Change, $40,131-150$.

Yin, R. K. 2014. Case Study Research: Design and Methods, Thousand Oaks, California, USA, SAGE Publications, Inc.

Yin, Y., Rader Olsson, A. \& Håkansson, M. 2016. The role of local governance and environmental policy integration in Swedish and Chinese eco-city development. Journal of Cleaner Production, 134, 78-86.

Ying, F., Tookey, J. \& Seadon, J. 2018. Measuring the invisible: A key performance indicator for managing construction logistics performance. Benchmarking: An International Journal, 25, 1921-1934.

Yuchtman, E. \& Seashore, S. E. 1967. A System Resource Approach to Organizational Effectiveness. American Sociological Review, 32, 891-903.

Zajac, E. J. \& Olsen, C. P. 1993. From Transaction Cost to Transactional Value Analysis: Implications for the Study of Interorganizational Strategies. Journal of Management Studies, 30, 131-145. 
Zeng, A. Z. \& Rossetti, C. 2003. Developing a framework for evaluating the logistics costs in global sourcing processes. International Journal of Physical Distribution \& Logistics Management, 33, 785-803.

Åsvoll, H. 2013. Abduction, deduction and induction: can these concepts be used for an understanding of methodological processes in interpretative case studies? International Journal of Qualitative Studies in Education, 27, 289-307.

Österle, I., Aditjandra, P. T., Vaghi, C., Grea, G. \& Zunder, T. H. 2015. The role of a structured stakeholder consultation process within the establishment of a sustainable urban supply chain. Supply Chain Management, 20, 284-299. 
Construction logistics in a city development setting

[This page is intentionally left blank.] 


\section{Papers}

The papers associated with this thesis have been removed for copyright reasons. For more details about these see:

http://urn.kb.se/resolve?urn=urn:nbn:se:liu:diva-170231 


\section{FACULTY OF SCIENCE AND ENGINEERING}

Linköping Studies in Science and Technology, Dissertation No. 2091, 2020 Department of Science and Technology

Linköping University

SE-601 74 Norrköping, Sweden

www.liu.se

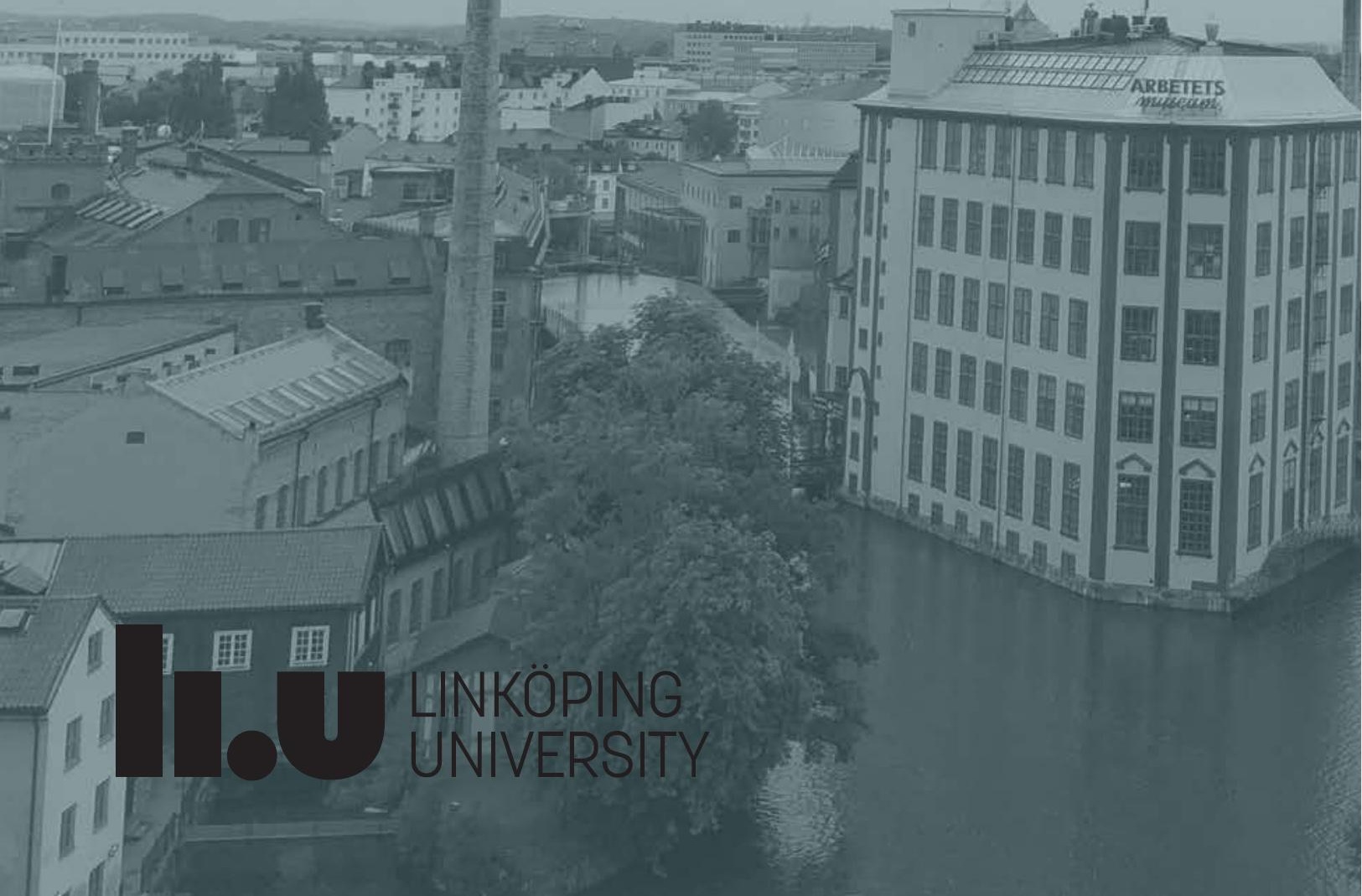

